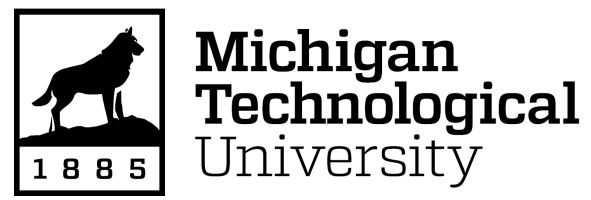

Michigan Technological University Digital Commons @ Michigan Tech

Dissertations, Master's Theses and Master's Reports

2015

Investigating the role of polyploidy in the response of Chamerion angustifolium to increased soil nitrogen availability and insect herbivory

Alex Bales

Michigan Technological University, albales@mtu.edu

Copyright 2015 Alex Bales

Recommended Citation

Bales, Alex, "Investigating the role of polyploidy in the response of Chamerion angustifolium to increased soil nitrogen availability and insect herbivory", Open Access Master's Thesis, Michigan Technological University, 2015.

https://doi.org/10.37099/mtu.dc.etdr/5

Follow this and additional works at: https://digitalcommons.mtu.edu/etdr

Part of the Ecology and Evolutionary Biology Commons 


\title{
INVESTIGATING THE ROLE OF POLYPLOIDY IN THE RESPONSE OF CHAMERION ANGUSTIFOLIUM TO INCREASED SOIL NITROGEN AVAILABILITY AND INSECT HERBIVORY
}

\author{
By \\ Alex L. Bales \\ A THESIS \\ Submitted in partial fulfillment of the requirements for the degree of \\ MASTER OF SCIENCE \\ In Biological Sciences
}

MICHIGAN TECHNOLOGICAL UNIVERSITY

2015

(C) 2015 Alex L. Bales 
This thesis has been approved in partial fulfillment of the requirements for the Degree of MASTER OF SCIENCE in Biological Sciences.

Department of Biological Sciences

Thesis Advisor: $\quad$ Dr. Erika Hersch-Green

Committee Member: Dr. Amy Marcarelli

Committee Member: $\quad$ Dr. Christopher Webster

Department Chair: $\quad$ Dr. Chandrashekhar P. Joshi 


\section{Table of Contents}

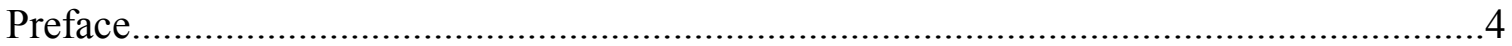



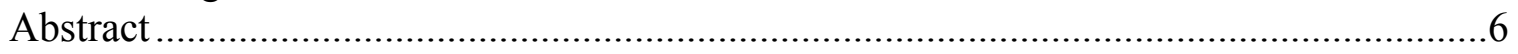

Chapter 1: Polyploidy influences the ecological tolerance of plants to different abiotic

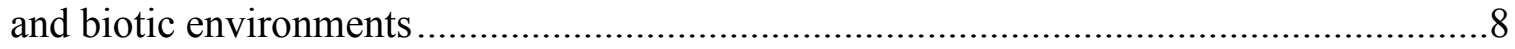



Chapter 2: Effects of polyploidy and soil nitrogen availability on the growth, reproduction, and resource allocation strategies of Chamerion angustifolium..................18

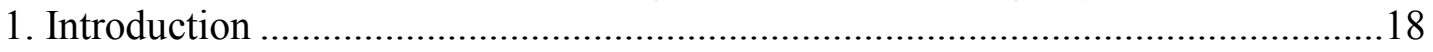

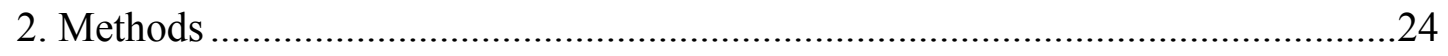



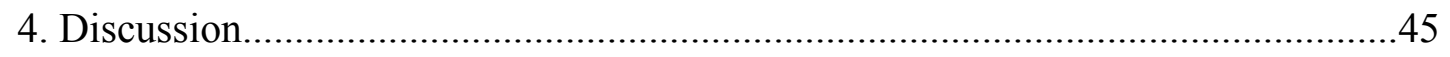

5. Appendix 1 - Fireweed sampling in Alaska......................................................52



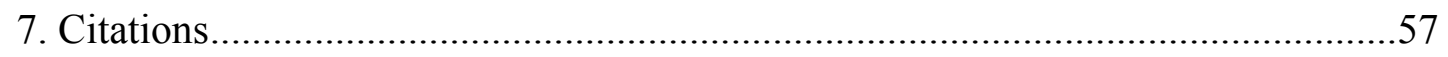

Chapter 3: Effects of polyploidy and soil nitrogen availability on the resistance and tolerance of Chamerion angustifolium to insect herbivory...........................................61

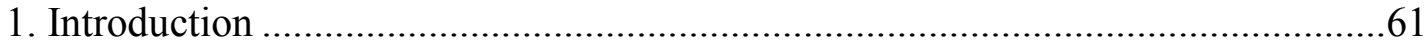

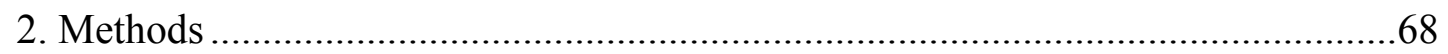

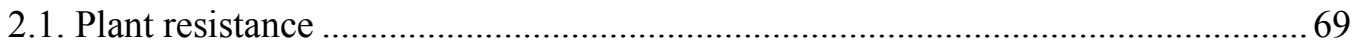

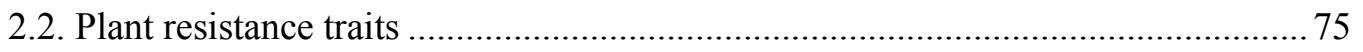

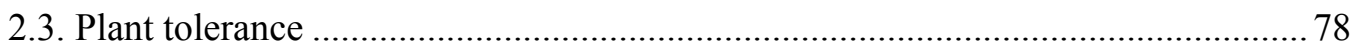

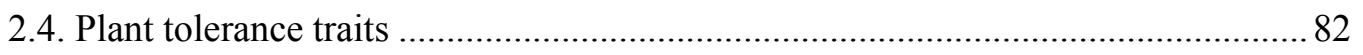

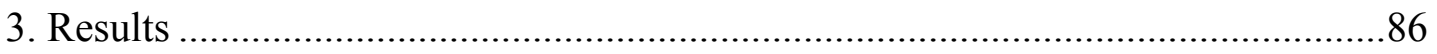

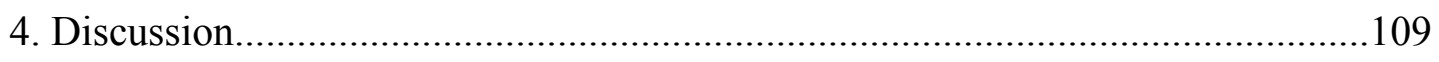

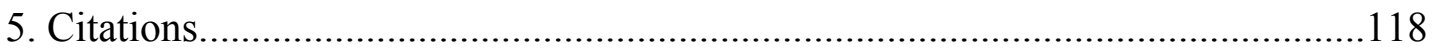




\section{Preface}

Chapters 1, 2, and 3 of this thesis were completed collaboratively with Dr. Erika HerschGreen of Michigan Technological University. I collected and analyzed data and wrote the three chapters. Dr. Hersch-Green assisted with designing experiments, data collection, data analysis, and editing the three chapters. Chapter 2 is in preparation to be submitted to the journal Plant Ecology, and chapter 3 is in preparation to be submitted to the journal Ecology. 


\section{Acknowledgements}

Research in Chapters 2 and 3 was funded by Dr. Hersch-Green's lab, the Department of Biological Sciences at Michigan Technological University, and the Ecosystem Science Center at Michigan Technological University.

Thank you to Erika Hersch-Green for her guidance throughout the duration of this research. Thank you to my committee members for their thoughtful discussions and helpful advice. I would also like to thank Jeannie Van Viannen and Tashi Zandstra for their assistance with greenhouse studies and data collection. Thank you to Kevyn Juneau for his insightful discussions about science and other worldly advice. Thank you to Emily Geiger for working hard to keep pests away from the greenhouse.

Big thanks to my fellow graduate students in the Biology and Forestry Departments for their thoughtful and often humorous discussions of science, research, and statistics, many times over beers. Many thanks to Brian Danhoff, Angela Yu, Tony Matthys, Emily Matthys, Jamie Olson, Adam Coble, and Shawn O’Neil.

I would also like to thank my family for always supporting me throughout my education.

Most importantly, thank you to Rose Schwartz for her tremendous love and support during the completion of this degree. 


\begin{abstract}
Human activities have more than doubled the input rate of nitrogen to terrestrial ecosystems. Increased soil nitrogen availability is associated with increased plant productivity, changes in plant resource allocation strategies, and changes in interactions between plants and their associated insect herbivores. For example, nitrogen-rich conditions can alter the physiological and chemical properties of plants in ways that increase their ability to deter herbivore attack (resistance) and maintain fitness following herbivore attack (tolerance). The ecological tolerance of plants to such abiotic and biotic environments is thought to be influenced by autopolyploidy, a commonly occurring phenomenon in plants in which individuals have twice as many pairs of homologous chromosomes as other members from the same species. We examined the role of polyploidy in plants' response to changes in soil nitrogen availability and insect herbivory. In two greenhouse experiments, we cultivated field collected genetic lines of diploid and autotetraploid Chamerion angustifolium (fireweed) under different soil nitrogen conditions and used a variety of insect-feeding experiments to examine whether polyploidy and soil nitrogen interact to influence (1) the growth, reproduction, and resource allocation of fireweed, and (2) the resistance and/or tolerance of fireweed to insect herbivory. Our results suggest that polyploidy influences reproductive output (e.g. flower and seed production) and resource allocation strategies (e.g. shoot:root ratio, C:N ratio) of fireweed, and that these differences can be dependent on soil nitrogen availability. The influence of polyploidy on patterns of resistance and tolerance of
\end{abstract}


fireweed to herbivory were complex. Tetraploids were more resistant to herbivory in some instances but less resistant in others, and these contrasting results were influenced by genotype, the type of insect herbivory, and the phenological age of plants. Despite ploidal differences in traits associated with plant tolerance (e.g. maximum photosynthetic capacity, shoot:root ratio), neither polyploidy nor soil nitrogen availability appeared to influence the tolerance of fireweed to herbivory. These experiments demonstrate the importance of polyploidy in regulating the relative success of plants responding to increased soil nitrogen availability and pressures from insect herbivores. 


\section{Chapter 1: Polyploidy influences the ecological tolerance of plants to different abiotic and biotic environments}

Polyploidy resulting from whole genome duplication has long been recognized as an important force promoting plant diversification and evolution (Levin 2002). Polyploidy occurs commonly in plants either through interspecific hybridization (allopolyploidy) or through intraspecific genome duplication (autopolyploidy), and both have been shown to affect the rate and direction of plant adaptation by introducing novel physiological or ecological traits such as increased cell size (Molin et al. 1982, Warner and Edwards 1989), increased tolerance to water stress (Maherali et al. 2009), or altered resistance to insect herbivory (Thompson et al. 1997, Arvanitis et al. 2010). Studies that have examined the ecological and/or evolutionary consequences of genome duplication have primarily focused on allopolyploids. However, studies that focus on autopolyploids are also important because they allow us to examine the effects of genome doubling, per se, while removing the confounding effects of interspecific genome combinations found in allopolyploids.

Autopolyploid plants often inhabit ecological niches that are distinct from their diploid progenitors. For example, the percentage of autopolyploid species generally increases with latitude (Löve and Löve 1957). Autopolyploids often have broader ranges than their diploid progenitors (Ehrendorfer et al. 1965, Mosquin and Small 1971, Van Dijk and Bakx-Schotman 1997), perhaps suggesting that autopolyploids are more tolerant of different abiotic and biotic environmental stressors than related diploids. This has, in 
fact, been found in some instances. For example, Ramsey (2011) examined hexaploid Achillea borealis occupying more xeric dune habitats and tetraploids occupying mesic grasslands. Similarly, Maherali et al. (2009) showed tetraploid Chamerion angustifolium to be more tolerant of water stress (and possibly less tolerant to freezing temperatures) than related diploids, likely due to tetraploids' larger xylem cells. Physiological differences are thought to contribute to cytotypes' distinct geographic distributions and relative success in different abiotic conditions (Thompson et al. 2014).

A central focus of my thesis research was to examine whether physiological differences between diploid and tetraploid C. angustifolium (fireweed) contribute to their relative performance under different levels of soil nitrogen availability (Chapter 2) and insect damage (Chapter 3). Surprisingly few studies have examined the role of soil nutrient availability in regulating the relative success of polyploid and closely related diploid plants (Cacco et al. 1976, Karn et al. 2003, Šmarda et al. 2013). Theory suggests that polyploids may be at a disadvantage under nutrient-poor soils because of their greater demand for nutrients (specifically nitrogen and phosphorous) required to synthesize their larger genomes (Lewis Jr 1985, Leitch and Bennett 2004, Cavalier-Smith 2005). However, some studies have found polyploid species to occupy nutrient-poor soils that their diploid counterparts cannot (Rohweder 1937, Noguti et al. 1940), and so the relationship between polyploid occurrence and nutrient availability is not straightforward. We hypothesized that differences in the ability of diploid and tetraploid fireweed to grow and reproduce in soils with differing amounts of available nitrogen might be contributing to cytotypes' distinct geographic ranges - diploids are known to occupy high northern 
latitudes, where nitrogen is often cited as the most important resource limiting plant productivity (Shaver et al. 1986, Chapin 1991, Bret-Harte et al. 2002), and tetraploids occupy more southern latitudes, where soil nitrogen is generally less limiting (Tamm 1991).

In the greenhouse study designed to look at the influence of soil $\mathrm{N}$ availability on growth and reproduction (Chapter 2), we found that tetraploid fireweed exhibit more plastic responses to increased soil nitrogen availability in terms of their resource allocation strategies. Tetraploids also appeared to have lower reproductive output relative to diploids under low levels of soil nitrogen availability, but greater reproductive output relative to diploid under higher levels of soil nitrogen availability. Cytotypes also differed in their relative concentrations of nitrogen in shoot and root tissues; tetraploids had a higher ratio of carbon to nitrogen compared to diploids. Plant carbon to nitrogen ratio is an indicator of the nutritive quality of plants and has been positively associated with higher levels of carbon-based secondary compounds used in defense against herbivory. The results of this study suggest that diploid and tetraploid fireweed may differ in their susceptibility to insect herbivory.

The second focus of my thesis research was to examine whether physiological and/or chemical differences between tetraploid and diploid fireweed contribute to differences in their relative response to insect herbivory, and whether soil nitrogen availability influences these differences. The response of plants to insect herbivory is traditionally characterized by two adaptive traits - resistance and tolerance. Plants can deter herbivore damage through mechanisms of resistance, and plants can withstand and 
maintain fitness following herbivore damage through mechanisms of tolerance (Strauss and Agrawal 1999). Previous studies have suggested that morphological, physiological, and chemical differences between polyploid and related diploid plants may influence their resistance and tolerance to insect herbivory (Dhawan and Lavania 1996, Thompson et al. 1997, Janz and Thompson 2002, Levin 2002, Ramsey and Schemske 2002, Arvanitis et al. 2007, Halverson et al. 2008, Arvanitis et al. 2010, Münzbergová et al. 2015). Polyploids often have greater concentrations of secondary metabolites (reviewed in Dhawan and Lavania 1996), which may provide polyploids with greater resistance to herbivory relative to diploid progenitors. In contrast, polyploids often have lower growth rates relative to related diploids (Noguti et al. 1940, Von Well and Fossey 1998, Otto and Whitton 2000), which could make polyploids less tolerant of damage, as lower growth rates have been associated with a reduced ability to regrow following herbivore damage (Detling et al. 1979, Oba et al. 2000). Soil nutrient availability has also been shown to influence plant traits that are associated with resistance and tolerance to herbivory. For example, plants that are grown under nitrogen-poor conditions often have high carbon:nitrogen ratios (Chapin 1980), a trait that is positively associated with carbonbased secondary defense compounds and plant resistance (Bryant et al. 1987, Ibrahim et al. 2011). Alternatively, plants grown in nutrient-poor conditions may have inadequate resources for re-growing and maintaining fitness following herbivore attack, and thus may have lower tolerance to herbivory relative to plants grown in nutrient-rich conditions (Maschinski and Whitham 1989). Because polyploids are thought to require a greater amount of soil nutrients in order to synthesize their larger genomes (Lewis 1985, Leitch 
and Bennett 2004, Cavalier-Smith 2005), polyploids may be less tolerant of herbivore damage in nutrient-poor soils relative to diploids. Studies on closely related diploid and polyploid plants, however, show that polyploids can be more, less, and equally susceptible to damage (Thompson et al. 1997, Halverson et al. 2008) and that they also show a range of tolerance responses to damage (Boalt et al. 2010, König et al. 2014b).

In chapter three, we used a variety of insect feeding experiments in the lab and greenhouse to better understand the influence of polyploidy in plant-insect interactions and how this influence may be altered by soil nitrogen availability. Our results suggest that diploid and tetraploid fireweed differ in their relative resistance to insect damage, and that these differences are complex. Tetraploids appeared to be more resistant in some feeding trials but less resistant in others, and our results suggest that these differences were related to genotype, plant phenological age, and the type of insect inflicting damage. The tolerance of fireweed to herbivory did not appear to be dependent on ploidy, and soil nitrogen availability did not influence the relative tolerance of diploid and tetraploids or the tolerance of fireweed plants overall.

This thesis highlights some important factors contributing to physiological and ecological differences between diploid and polyploid fireweed, which could have important implications for the relative distribution and success of fireweed cytotypes in changing environments. Soil nitrogen availability is increasing globally as a result of anthropogenic inputs and is thought to be impacting terrestrial and aquatic plant communities (Matson et al. 2002, Rabalais 2002, Vitousek et al. 2002). Temperatures (Houghton et al. 2001) and growing season length (Walther et al. 2002) are projected to 
increase dramatically throughout high northern latitudes as a result of global warming, which could accelerate future interactions between plants and their associated herbivores (Bryant et al. 1987, Bale et al. 2002, Walther et al. 2002, DeLucia et al. 2012). Because polyploidy is extremely common in plants (Soltis et al. 2007), its role in allowing plants to respond to such changes should be considered an important component of shifts in plant distribution, relative plant fitness, and plant evolution in changing environments. 


\section{Citations}

Arvanitis, L., C. Wiklund, and J. Ehrlén. 2007. Butterfly seed predation: effects of landscape characteristics, plant ploidy level and population structure. Oecologia 152:275-285.

Arvanitis, L., C. Wiklund, Z. Munzbergova, J. P. Dahlgren, and J. Ehrlén. 2010. Novel antagonistic interactions associated with plant polyploidization influence trait selection and habitat preference. Ecology Letters 13:330-337.

Bale, J. S., G. J. Masters, I. D. Hodkinson, C. Awmack, T. M. Bezemer, V. K. Brown, J. Butterfield, A. Buse, J. C. Coulson, and J. Farrar. 2002. Herbivory in global climate change research: Direct effects of rising temperature on insect herbivores. Global Change Biology 8:1-16.

Boalt, E., L. Arvanitis, K. Lehtilä, and J. Ehrlén. 2010. The association among herbivory tolerance, ploidy level, and herbivory pressure in Cardamine pratensis. Evolutionary Ecology 24:1101-1113.

Bret-Harte, M. S., G. R. Shaver, and F. S. Chapin. 2002. Primary and secondary stem growth in arctic shrubs: implications for community response to environmental change. Journal of Ecology 90:251-267.

Bryant, J., T. Clausen, P. Reichardt, M. McCarthy, and R. Werner. 1987. Effect of nitrogen fertilization upon the secondary chemistry and nutritional value of quaking aspen (Populus tremuloides michx.) leaves for the large aspen tortrix (Choristoneura conflictana walker). Oecologia 73:513-517.

Cacco, G., G. Ferrari, and G. Lucci. 1976. Uptake efficiency of roots in plants at different ploidy levels. The Journal of Agricultural Science 87:585-589.

Cavalier-Smith, T. 2005. Economy, speed and size matter: evolutionary forces driving nuclear genome miniaturization and expansion. Annals of Botany 95:147-175.

Chapin, F. S. 1980. The mineral nutrition of wild plants. Annual Review of Ecology and Systematics 11:233-260.

Chapin, F. S., III. 1991. Integrated Responses of Plants to Stress. BioScience 41:29-36.

DeLucia, E. H., P. D. Nabity, J. A. Zavala, and M. R. Berenbaum. 2012. Climate change: resetting plant-insect interactions. Plant Physiology 160:1677-1685.

Detling, J., M. Dyer, and D. Winn. 1979. Net photosynthesis, root respiration, and regrowth of Bouteloua gracilis following simulated grazing. Oecologia 41:127134.

Dhawan, O. P., and U. C. Lavania. 1996. Enhancing the productivity of secondary metabolites via induced polyploidy: A review. Euphytica 87:81-89.

Ehrendorfer, F., H. Baker, and G. Stebbins. 1965. Dispersal mechanisms, genetic systems, and colonizing abilities in some flowering plant families. The genetics of colonizing species. ed. H. G. Baker, G. L. Stebbins. New York: Academic 331$351 \mathrm{pp}$.

Halverson, K., S. B. Heard, J. D. Nason, and J. O. Stireman III. 2008. Differential attack on diploid, tetraploid, and hexaploid Solidago altissima L. by five insect gallmakers. Oecologia 154:755-761. 
Houghton, J.T., Ding, Y., Griggs, D.J., Noguer, M., van der Linden, P.J., Dai, X., Maskell, K. \& Johnson, C.A. (eds.) 2001. Climate change 2001: The scientific basis. Contribution of Working Group I to the Third Assessment Report of the Intergovernmental Panel on Climate Change. Cambridge University Press, Cambridge, UK.

Ibrahim, M. H., H. Z. E. Jaafar, A. Rahmat, and Z. A. Rahman. 2011. Effects of nitrogen fertilization on synthesis of primary and secondary metabolites in three varieties of Kacip fatimah (labisia pumila blume). International Journal of Molecular Sciences 12:5238-5254.

Janz, N., and J. Thompson. 2002. Plant polyploidy and host expansion in an insect herbivore. Oecologia 130:570-575.

Karn, J. F., A. B. Frank, J. D. Berdahl, and W. W. Poland. 2003. Water, nitrogen and ploidy effects on russian wildrye mineral concentrations. Journal of Range Management 56:534-541.

König, M. E., C. Wiklund, and J. Ehrlén. 2014. Context-dependent resistance against butterfly herbivory in a polyploid herb. Oecologia 174:1265-1272.

Leitch, I., and M. Bennett. 2004. Genome downsizing in polyploid plants. Biological Journal of the Linnean Society 82:651-663.

Levin, D. A. 2002. The role of chromosomal change in plant evolution. Oxford University Press.

Lewis Jr, W. M. 1985. Nutrient scarcity as an evolutionary cause of haploidy. American Naturalist 125:692-701.

Löve Á, Löve D. 1957. Arctic polyploidy. Proceedings of the Genetics Society of Canada 2:23-27.

Maherali, H., E. W. Alison, and B. C. Husband. 2009. Genome duplication and the evolution of physiological responses to water stress. New Phytologist 184:721731.

Maschinski, J., and T. G. Whitham. 1989. The continuum of plant responses to herbivory: the influence of plant association, nutrient availability, and timing. American Naturalist 134:1-19.

Matson, P., K. A. Lohse, and S. J. Hall. 2002. The globalization of nitrogen deposition: consequences for terrestrial ecosystems. AMBIO: A Journal of the Human Environment 31:113-119.

Molin, W. T., S. P. Meyers, G. R. Baer, and L. E. Schrader. 1982. Ploidy effects in isogenic populations of alfalfa. II. Photosynthesis, chloroplast number, ribulose1,5-bisphosphate carboxylase, chlorophyll, and DNA in protoplasts. Plant Physiology 70:1710-1714.

Mosquin, T., and E. Small. 1971. An example of parallel evolution in Epilobium (Onagraceae). Evolution 24(4):678-682.

Münzbergová, Z., J. Skuhrovec, and P. Maršík. 2015. Large differences in the composition of herbivore communities and seed damage in diploid and autotetraploid plant species 115(2):270-287. Biological Journal of the Linnean Society: 
Noguti, Y., H. Oka, and T. Ôtuka. 1940. Studies on the polyploidy in Nicotiana induced by the treatment with colchicine. II. Growth rate and chemical analysis of diploid and its autotetraploid in Nicotiana rustica and N. Tabacum. Japanese Journal of Botany 10:343-364.

Oba, G., Z. Mengistu, and N. C. Stenseth. 2000. Compensatory growth of the African dwarf shrub Indigofera spinosa following simulated herbivory. Ecological Applications 10:1133-1146.

Otto, S. P., and J. Whitton. 2000. Polyploid incidence and evolution. Annual review of genetics 34:401-437.

Rabalais, N. N. 2002. Nitrogen in aquatic ecosystems. AMBIO: A Journal of the Human Environment 31:102-112.

Ramsey, J. 2011. Polyploidy and ecological adaptation in wild yarrow. Proceedings of the National Academy of Sciences 108:7096-7101.

Ramsey, J., and D. W. Schemske. 2002. Neopolyploidy in flowering plants. Annual Review of Ecology and Systematics 33:589-639.

Rohweder, H. 1937. Versuch zur Erfassung der mengenmässigen bedeckung des dars $\backslash$ und zingst mit polyploiden pflanzen. Planta 27:500-549.

Shaver, G. R., F. C. Iii, and B. L. Gartner. 1986. Factors limiting seasonal growth and peak biomass accumulation in Eriophorum vaginatum in Alaskan tussock tundra. Journal of Ecology 74:257-278.

Šmarda, P., M. Hejcman, A. Březinová, L. Horová, H. Steigerová, F. Zedek, P. Bureš, P. Hejcmanová, and J. Schellberg. 2013. Effect of phosphorus availability on the selection of species with different ploidy levels and genome sizes in a long-term grassland fertilization experiment. New Phytologist 200:911-921.

Soltis, D. E., P. S. Soltis, D. W. Schemske, J. F. Hancock, J. N. Thompson, B. C. Husband, and W. S. Judd. 2007. Autopolyploidy in angiosperms: have we grossly underestimated the number of species? Taxon 56(1):13-30.

Strauss, S. Y., and A. A. Agrawal. 1999. The ecology and evolution of plant tolerance to herbivory. Trends in Ecology \& Evolution 14:179-185.

Tamm, C. O. 1991. Nitrogen-limited and nitrogen-depleted terrestrial ccosystems: Ecological characteristics. Pages 34-49 Nitrogen in Terrestrial Ecosystems. Springer.

Thompson, J. N., K. A. Segraves, B. M. Cunningham, D. M. Althoff, and D. Wagner. 1997. Plant polyploidy and insect/plant interactions. The American Naturalist 150:730-743.

Thompson, K. A., B. C. Husband, and H. Maherali. 2014. Climatic niche differences between diploid and tetraploid cytotypes of Chamerion angustifolium (Onagraceae). Am J Bot 101:1868-1875.

Van Dijk, P., and T. Bakx-Schotman. 1997. Chloroplast DNA phylogeography and cytotype geography in autopolyploid Plantago media. Molecular Ecology 6:345352.

Vitousek, P. M., S. Hättenschwiler, L. Olander, and S. Allison. 2002. Nitrogen and nature. AMBIO: A Journal of the Human Environment 31:97-101. 
Von Well, E., and A. Fossey. 1998. A comparative investigation of seed germination, metabolism and seedling growth between two polyploid Triticum species. Euphytica 101:83-89.

Walther, G.-R., E. Post, P. Convey, A. Menzel, C. Parmesan, T. J. Beebee, J.-M. Fromentin, O. Hoegh-Guldberg, and F. Bairlein. 2002. Ecological responses to recent climate change. Nature 416:389-395.

Warner, D. A., and G. E. Edwards. 1989. Effects of polyploidy on photosynthetic rates, photosynthetic enzymes, contents of DNA, chlorophyll, and sizes and numbers of photosynthetic cells in the $\mathrm{C}_{4}$ dicot Atriplex confertifolia. Plant Physiology 91:1143-1151. 


\section{Chapter 2: Effects of polyploidy and soil nitrogen availability on} the growth, reproduction, and resource allocation strategies of Chamerion angustifolium ${ }^{1}$

\section{Introduction}

Human activities have more than doubled the input rate of nitrogen to ecosystems (Vitousek et al. 1997), impacting both terrestrial and aquatic plant communities (Matson et al. 2002, Rabalais 2002, Vitousek et al. 2002). Increased soil nitrogen availability is most often associated with an increase in plant primary productivity (Shaver et al. 1986, Chapin 1991, Shaver et al. 1992, Bret-Harte et al. 2002), although plant species do differ in their ability to capture and use nitrogen for growth and reproduction (Chapin 1980, Tilman 1982). Such differences are thought to play a major role in species distributions (Tilman 1986a, Tamm 1991) and in shaping community composition (Tilman 1987, Huenneke et al. 1990, Suding et al. 2005). For example, very low levels of plantavailable nitrogen typically characterize soils in arctic and boreal regions, and many plant species in these communities have adapted to nitrogen-poor environments (Shaver et al. 1986, Chapin 1991, Bret-Harte et al. 2002). Interestingly, increasing soil nitrogen availability in artic and boreal areas has been shown to alter community composition (richness and diversity), typically favoring species that are better at utilizing nitrogen additions (Shaver and Chapin 1980, Bret-Harte et al. 2002).

\footnotetext{
${ }^{1}$ The material in this chapter is planned for submission
} 
The relative success of plants in different soil nutrient conditions might be partially explained by differences in plants' resource allocation strategies (i.e. the relative proportion of resources allocated to root, shoot, and/or reproductive tissues) and their ability to adjust such strategies in response to changing nutrient availability (Hickman 1975, Abrahamson and Caswell 1982, Tilman and Cowan 1989). For example, plant species adapted to nutrient-poor habitats often allocate a high percentage of biomass to root growth at the expense of shoot growth (i.e. low shoot:root; Dennis and Johnson 1970) and a higher percentage of aboveground biomass to reproductive tissues relative to those in higher N-soils (i.e. high seed:shoot; Tilman and Cowan 1989). However, species from nutrient-poor habitats often have low phenotypic plasticity in resource allocation strategies relative to species from nutrient-rich habitats (Christie and Moorby 1975, Grime and Curtis 1976) and therefore may compete poorly on nutrient-rich sites. Differences in the effects of nutrient availability on resource allocation strategies among species could have significant impacts on species distributions (Abrahamson and Caswell 1982, Tilman 1988).

For plant species exhibiting polyploidy, or whole genome duplication, the relative geographic distribution and abundance of ploidal races (cytotypes) can similarly be influenced by their ecophysiological properties, resource allocation strategies, and/or abilities to tolerate different abiotic (Lumaret et al. 1987, Ramsey 2011, Hao et al. 2013, Šmarda et al. 2013, Thompson et al. 2014). Polyploidy commonly occurs in plants through interspecific hybridization (allopolyploidy) and less commonly through intraspecific genome duplication (autopolyploidy); both mechanisms are considered to be 
major factors promoting plant diversification (reviewed in Levin 2002). While empirical research has primarily focused on allopolyploids, studies focusing on autopolyploids have a major advantage in that they allow us to examine the effects of genome doubling while removing the confounding effects of interspecific genome combinations seen in allopolyploids. Autopolyploids often occupy geographic ranges that are distinct from their diploid counterparts (reviewed in Levin 2002). Reasons for differences in spatial distributions among polyploids and their related diploids are not entirely clear but could, in part, be due to differences in ecological tolerances. In fact, some polyploid species are more tolerant of water stress (Maherali et al. 2009, Thompson et al. 2014), salt stress (Wang et al. 2013), cold temperatures (Liu et al. 2011), and shade (Fukuda 1967) than related diploids. There have been very few studies that have examined whether polyploidy influences plants' nutrient use (Cacco et al. 1976, Karn et al. 2003, Huang et al. 2007, Šmarda et al. 2013), although theory predicts polyploids should be at a competitive disadvantage relative to related diploids when nutrients are limiting because polyploids require more nutrients (nitrogen and phosphorous) to synthesize the additional DNA nucleotides necessary for their larger genomes (Lewis Jr 1985, Leitch and Bennett 2004, Cavalier-Smith 2005). Congruent with this idea, Šmarda et al. (2013) found that polyploid species are more competitive with increasing soil phosphorous availability. Nevertheless, the role of nutrient availability in regulating the relative success of cytotypes and in shaping geographic distribution patterns of related cytotypes is not well understood. 
Here, we examined the influence that soil nitrogen availability plays in the relative growth, fitness, and resource allocation patterns of polyploid and diploid plants. To do this, we grew field collected Chamerion angustifolium (fireweed) seeds in a greenhouse setting. Fireweed is an herbaceous perennial plant species that is widely distributed throughout much of the northern hemisphere. Fireweed exists as diploid $(2 n=$ $2 \mathrm{x}=36$ chromosomes per diploid cell) and autotetraploid $(2 \mathrm{n}=4 \mathrm{x}=72$ chromosomes per diploid cell) cytotypes and is a model system for studying the ecological consequences of autopolyploidy. Previous studies have suggested that tetraploids exhibit greater tolerance to water stress but lower tolerance to freezing temperatures than diploid progenitors (Maherali et al. 2009), and these ploidal differences in ecophysiological traits are thought to be important factors contributing to divergent geographic ranges of fireweed cytotypes across its range in North America (Thompson et al. 2014). For instance, historical census data shows that diploids occupy colder, more extreme northern latitudes, while tetraploids occupy warmer/drier more southern latitudes, and a broad band of mixed-ploidy populations occurs between these distributions with diploids, triploids, and tetraploids in varying proportions (Fig. 2.1 redrawn from Mosquin and Small 1971). Interestingly, however, we surveyed fireweed populations throughout southern and interior Alaska in 2013 and 2014, an area in which historical data showed was dominated by diploids, and found that tetraploids were the most common cytotype in these regions (Fig. 2.1, Appendix 1 for details). Whether such findings indicate a replacement of diploids by tetraploids in these regions, historical contingencies (i.e., patterns from glaciation), or whether such replacement is due to changes in abiotic and/or 
biotic factors (e.g. soil nutrient availability, temperature, competition) is unclear. To begin to understand whether polyploidy influences the physiological and potentially adaptive responses of plants to changes in soil nitrogen availability, we specifically tested whether ploidy and soil nitrogen availability interact to influence fireweed's nitrogen and carbon status (total plant nitrogen, percent nitrogen, and percent carbon), reproductive output (flower, seed, pollen, and biomass production), and/or fireweed's resource allocation strategies (shoot biomass to root biomass ratio, total shoot-nitrogen to total root-N ratio, shoot carbon to nitrogen ratio, and reproductive output to total shoot-N ratio). 


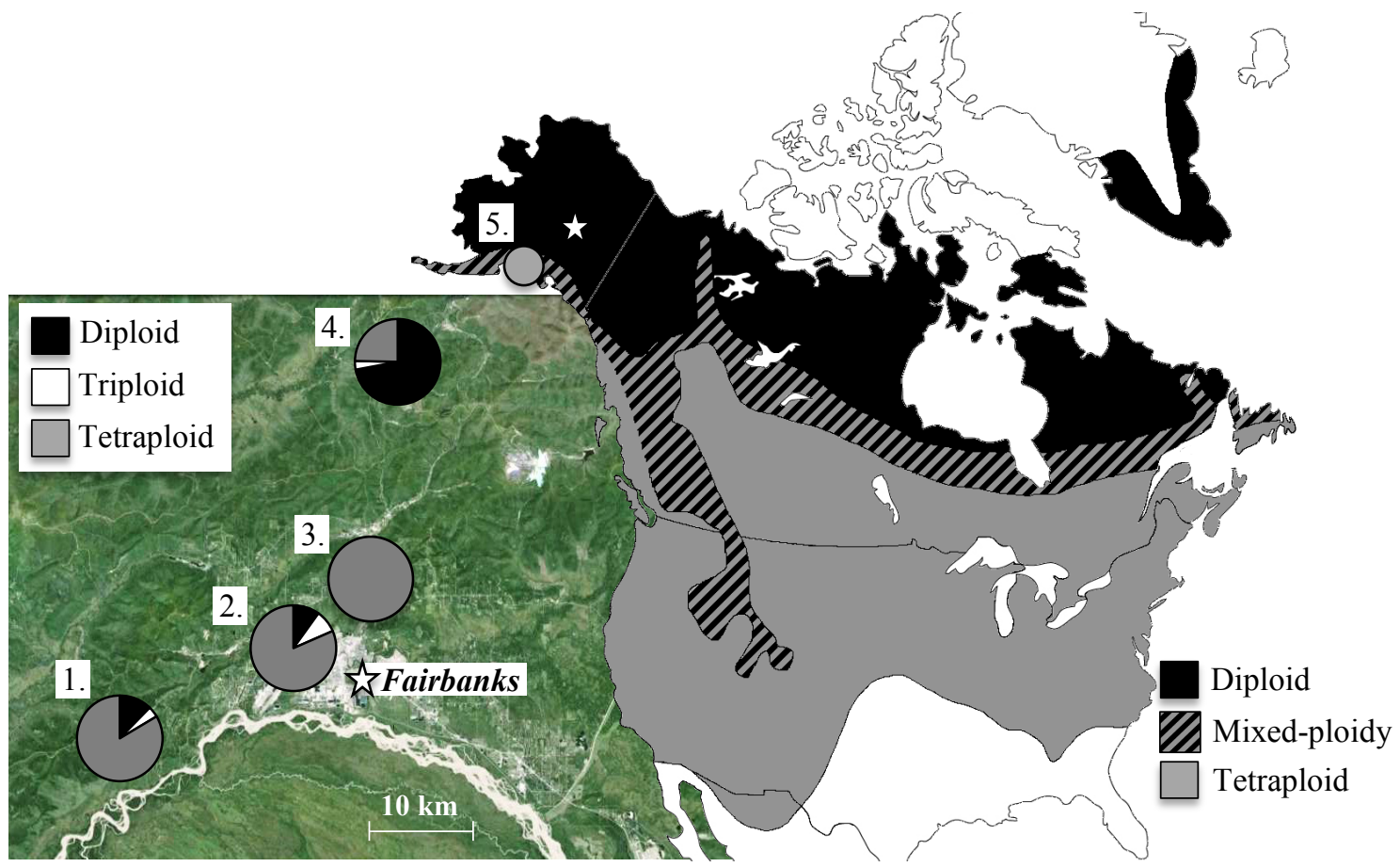

Fig. 2.1: Putative distribution of diploid and tetraploid fireweed throughout North America (right; redrawn from Mosquin and Small 1971). The star is Fairbanks, Alaska and serves as a reference point to the location of fireweed sampling locations (left). Pie charts represent the relative proportion of 684 plants sampled in August 2013 and 2014 (196 diploid, 26 triploid and 462 tetraploid plants). Plants were collected from five general areas: (1) Bonanza Creek Long-term Ecological Research Site, (2) the University of Alaska Fairbanks trail system, (3) Dog Mushers Association Park, (4) the Caribou-Poker Creek Research Watershed, and (5) Southern Alaska, an area spanning Anchorage to Seward AK (see Appendix 1 for location and sampling details). Seeds collected from sites 1, 2, and 4 were used to generate plants used in greenhouse experiments. Map data (C2015 Google. 


\section{Methods}

Plant material. - We used fireweed seeds that we collected in the summer 2013 from three mixed ploidy sites in interior Alaska (Fig. 2.1, Appendix 1) to generate diploid and tetraploid seed families for our greenhouse study. We first grew plants from different maternal families (seeds collected from different individuals) in the greenhouse at Michigan Technological University (MTU; Dept. of Biological Sciences, Houghton, MI) until they produced four or more true leaves. Next, we determined the ploidy level of plants by excising one leaf from each plant to estimate plant nuclear 2C DNA content using flow cytometry (see methods in Baldwin and Husband 2013 and Appendix 1 for details); in fireweed, DNA content is positively correlated with the number of chromosomes and ploidy level (Husband and Schemske 1998). Briefly, we chopped fireweed leaf tissue with an internal standard (Solanum lycospersicum - 2C DNA content $=1.96$, Doležel et al. 2007) in a modified DeLaat's nuclei isolation buffer with $50 \mu \mathrm{g} \mathrm{ml}{ }^{-1}$ RNase, stained cells with propidium iodide, and analyzed samples on an Accuri C6 flow cytometer with CFlow Plus Analysis software (Accuri Inc., Ann Arbor, MI, USA). Once we determined the ploidy level (diploid $=2 \mathrm{x}$ or tetraploid $=4 \mathrm{x}$ ) of each plant, we allowed plants to reach maturity and cross-pollinated them within each cytotype to generate genetic lines for subsequent experimentation. In this way we were able to document parentage and grow all parental plants under the same environmental conditions before experimentation, thus minimizing any potential maternal effects from field collected seeds that could impact our results. Because spontaneous whole genome duplications can 
occur, we also used flow cytometry to confirm the ploidy level of each individual plant used in subsequent experiments.

Greenhouse experiment. - We germinated 18 seeds from each of seven diploid and tetraploid genetic lines (a total of 252 plants $)$ in pots $(14 \times 14 \times 13 \mathrm{~cm})$ containing a 1:1 mixture of vermiculite to Sunshine soil mix \#4 (Sun Grow Horticulture Ltd., Vancouver, British Columbia) in a growth chamber at $24^{\circ} \mathrm{C}$. After three weeks, we randomly arranged plants in the greenhouse, grew them under a 16:8 hour light:dark cycle, and rotated plants weekly to minimize nonrandom environmental effects imposed by variable greenhouse conditions.

Nitrogen treatments. - Three weeks after germination, we assigned plants to one of three $\mathrm{N}$ treatments and began fertilizing plants once per week for three weeks with a prepared nitrogen-phosphorous-potassium solution. Nitrogen was supplied as ammonium nitrate to obtain a total soil concentration of 12,120 , or $1200 \mathrm{ppm}\left(\mu \mathrm{g} \mathrm{N} \cdot \mathrm{g}^{-1}\right.$ soil per pot; low, medium, high treatments, respectively). Treatment concentrations were calculated on a dry soil basis, wherein we used an average dry-weight mass of soil from ten unseeded pots to determine the appropriate amount of $\mathrm{N}$ that would provide each ppm value ( $\mu \mathrm{g} \mathrm{N} \cdot \mathrm{g}^{-1}$ soil per pot). Phosphorous and potassium were supplied as potassium monophosphate and potassium sulfate in equal amounts for all pots $(\mathrm{P}=15 \mathrm{ppm}, \mathrm{K}=250$ ppm). During the sixth week of growth, we supplied each plant with micronutrients as a 
single treatment of $0.615 \mathrm{~mL}$ Fertilome Chelated Liquid Iron and Other Micronutrients (Voluntary Purchasing Groups, Inc., Bonham, TX).

We chose our $\mathrm{N}$ concentrations based, in part, upon a literature search of previous measurements of inorganic soil $\mathrm{N}$ availability near our seed collection sites, which showed that the range of inorganic soil $\mathrm{N}$ concentrations $\left(\mathrm{NH}_{4}-\mathrm{N}+\mathrm{NO}_{3}-\mathrm{N}\right)$ was between 5 and $220 \mathrm{ppm}\left(\mu \mathrm{g} \mathrm{N} \cdot \mathrm{g}^{-1}\right.$ soil) throughout interior AK sites (Van Cleve et al. 1981, Gordon et al. 1987, Van Cleve et al. 1990, Clein and Schimel 1995, Kielland et al. 2007). We also measured inorganic soil $\mathrm{N}$ levels at our seed collection sites in summer 2014 and found that soil $\mathrm{NH}_{4}-\mathrm{N}+\mathrm{NO}_{3}-\mathrm{N}$ concentrations were around $3.30 \pm 0.51 \mathrm{ppm}$ (Appendix 2). Such low values at our sites likely reflect a heavy leaching of $\mathrm{N}$ from soils due to record summer rainfall throughout the region immediately prior to our soil sampling. Both our low and medium treatment levels were selected to be within the range of field concentrations commonly observed at these sites (12 and $120 \mathrm{ppm}$; Van Cleve et al. 1981, Gordon et al. 1987, Van Cleve et al. 1990, Clein and Schimel 1995, Kielland et al. 2007), while the high treatment was set an order of magnitude higher (1200 ppm).

Plant nitrogen and carbon status. - We estimated the percentage of nitrogen and carbon in fireweed shoots and roots and the total nitrogen in shoots and roots. Mature plants were harvested, separated into above and belowground portions, and dried to a constant weight. Plants that showed no signs of flowering were harvested at approximately 16 weeks of growth, and plants that did flower were harvested 
immediately following completion of fruit maturation (see plant reproductive output below). To measure percent $\mathrm{N}$ and $\mathrm{C}$ in shoots and roots, we separately homogenized each entire dried shoot and root biomass portion to a fine powder with a ball mill and used an elemental analyzer (ECS 4010, Costech Analytical Technologies Inc., Valencia, CA) to measure carbon and nitrogen content at MTU (School of Forest Resources and Environmental Science, Houghton, MI). We used biomass and percent N measurements to estimate the total nitrogen in shoot biomass (total shoot-N; shoot dry weight $\times$ percent $\mathrm{N}$ in shoots) and root biomass (total root-N; root dry weight $\times$ percent $\mathrm{N}$ in roots). Shoot biomass was also used as a proxy for fitness (see plant reproductive output below) and carbon/nitrogen content was used to calculate plant $\mathrm{C}: \mathrm{N}$ ratio (see resource allocation strategies below). To examine whether percent $\mathrm{N}$, percent $\mathrm{C}$, total shoot-N, and/or total root-N were influenced by ploidy, soil $\mathrm{N}$ treatment, an interaction between ploidy and soil $\mathrm{N}$ treatment, and/or genetic line (a fixed effect nested within ploidy), we used ANOVA models. We used Tukey's HSD tests to make multiple comparisons among means when an interaction among factors was significant.

Plant reproductive output. - In order to evaluate how soil $\mathrm{N}$ availability and polyploidy influence fireweed's reproductive output, we examined four components of plant reproductive success: shoot biomass, seed production (a proxy for female fitness; Strauss et al. 1996), flower production, and pollen production (two measures that are often used as proxies for male fitness; Sutherland and Delph 1984). Shoot biomass was measured as described above. To measure seed production, we used controlled crosses 
designed to mimic the self- and cross-pollinations normally facilitated by bees and other insects in natural populations (Schemske 2000, Kennedy et al. 2006, personal observation). On each plant we selected four flowers, two of which we self-pollinated and two of which we cross-pollinated. All hand-pollinations were performed by applying two anther's worth of pollen evenly across receptive stigmas; cross-pollinated flowers received pollen from plants within the same ploidy and soil $\mathrm{N}$ treatment, whereas selfpollinated plants received pollen from a different flower but on the same plant. After pollinations, we removed any remaining stigmas on plants to prevent pollination of additional flowers. Approximately three weeks after pollinations, we collected fruits as they began to dehisce, and counted the total number of seeds in pods from self and outcross treatments using a Pfueffer Contador 2 seed counter (Pfueffer GmbH, Kitzingen, Bavaria, Germany). To measure flower production, we counted the total number of flowers per plant. To estimate pollen production, we collected one anther near dehiscence from two flowers on each plant, allowed anthers to dehisce, and suspended them in 500 $\mu 1$ of $95 \%$ ethanol. Pollen production was determined as the average number of pollen grains from two $10 \mu 1$ subsamples (Kearns and Inouye 1993, page 95).

We used several methods to determine whether cytotypes differed in their relative fitness and whether soil $\mathrm{N}$ availability influenced these differences. We examined whether ploidy, soil $\mathrm{N}$ treatment, an interaction between ploidy and soil $\mathrm{N}$ treatment, and/or genetic line (fixed effect nested in ploidy) influenced shoot biomass, the number of selfed seeds produced per seed pod, the number of outcrossed seeds produced per seed pod, and the number of pollen grains per $10 \mu 1$ sample of pollen homogenate using 
ANOVA models. Because many plants did not flower, we examined flower production by first testing whether ploidy, soil $\mathrm{N}$ treatment, an interaction between ploidy and soil $\mathrm{N}$ treatment, and/or genetic line (fixed effect nested in ploidy) influenced the odds flowering. Given that a plant flowered, we then used ANOVA models to test whether ploidy, soil $\mathrm{N}$ treatment, their interaction, and/or genetic line (fixed effect nested in ploidy) influenced the number of flowers produced. When an interaction among factors was found to be significant we used Tukey's HSD tests to compare means.

Resource allocation strategies. - Soil $\mathrm{N}$ availability can play a role in regulating the proportion of resources that plants allocate to different plant tissues (e.g. shoots, roots, flowers, seeds; Chapin 1980) and these differences might be dependent upon the soil $\mathrm{N}$ environment that plants are adapted to (e.g. low soil N, high soil N; Hickman 1975, Tilman and Cowan 1989). We tested whether variation in ploidy, soil N treatment, and/or genetic line (nested within ploidy) influenced four resource allocation strategies in fireweed: (1) the ratio of shoot biomass to root biomass ( $\left(\right.$ hhoot $_{\text {mass }}:$ root $\left._{\text {mass }}\right),(2)$ the ratio of total shoot-N to total root-N ( shoot $\left._{\mathrm{N}}: \operatorname{root}_{\mathrm{N}}\right)$, (3) the ratio of carbon to nitrogen in shoots $(\mathrm{C}: \mathrm{N})$, and (4) the ratio of reproductive output to total shoot-N (RO:shoot $\mathrm{N})$. Here, we created a metric to be used in estimating the maximum reproductive output per plant (RO $=$ seeds per pod $\times$ flowers per plant). RO:shoot ${ }_{\mathrm{N}}$ values were calculated for both selfed and outcrossed pollinations $\left(\mathrm{RO}_{\text {self: }}\right.$ :shoot $\mathrm{N}, \mathrm{RO}_{\text {outcross }}:$ shoot $_{\mathrm{N}}$, respectively) and allowed us to compare whether diploids or tetraploids were able to allocate a higher percentage of aboveground resources to reproduction at different levels of soil $\mathrm{N}$ availability. 
We tested whether ploidy, soil $\mathrm{N}$ treatment, their interaction, and/or genetic line (fixed effect nested within ploidy) influenced fireweed's shoot ${ }_{\text {mass }}: \operatorname{root}_{\text {mass }}(\log$ transformed), shoot $_{\mathrm{N}}: \operatorname{root}_{\mathrm{N}}$ (log transformed), selfed and outcrossed RO: shoot $_{\mathrm{N}}$, and/or shoot C:N ratio with ANOVA models. We used Tukey's HSD tests to compare means when a factor and/or an interaction among factors was significant $(\mathrm{P}<0.05)$. We conducted all analyses in JMP version 11.2.0 (SAS Institute Inc. 2013) and transformations were made to meet model assumptions of normality and homogeneity of variances where required. 


\section{Results}

Plant nitrogen and carbon status. - The percentage of $\mathrm{N}$ in fireweed shoots was significantly affected by soil $\mathrm{N}$ treatment $\left(\mathrm{F}_{2,222}=291.75, P<0.0001\right)$, ploidy $\left(\mathrm{F}_{1,222}=\right.$ 23.80, $P<0.0001)$, and genetic line $\left(\mathrm{F}_{12,222}=5.33, P<0.0001\right)$. Shoots in the low $\mathrm{N}$ treatment contained significantly less $\% \mathrm{~N}(1.31 \% \pm 0.04 \mathrm{SE})$ than plants in the medium $(1.49 \% \pm 0.04 \mathrm{SE})$ and high $(2.45 \% \pm 0.04 \mathrm{SE})$ soil $\mathrm{N}$ treatments (Fig. 2.2A). Diploid shoots contained a higher $\% \mathrm{~N}(1.85 \% \pm 0.03 \mathrm{SE})$ than tetraploid shoots $(1.66 \% \pm 0.03$ SE; Fig. 2.2A). Ploidy and soil $\mathrm{N}$ treatment did not interact to influence $\% \mathrm{~N}$ in shoots $\left(\mathrm{F}_{2}\right.$, $222=0.26, P=0.770)$. The percentage of $\mathrm{C}$ in fireweed shoots was affected by soil $\mathrm{N}$ treatment $\left(\mathrm{F}_{2,222}=6.25, P=0.002\right)$ and genetic line $\left(\mathrm{F}_{12,222}=1.91, P=0.034\right)$. Shoots in the low $\mathrm{N}$ treatment contained higher $\% \mathrm{C}(41.54 \% \pm 0.11 \mathrm{SE})$ than shoots in the medium $(41.46 \% \pm 0.11 \mathrm{SE})$ and high $(41.02 \% \pm 0.11 \mathrm{SE})$ soil $\mathrm{N}$ treatments. Neither ploidy $\left(\mathrm{F}_{1}\right.$, $222=1.40, P=0.238)$ nor an interaction between ploidy and soil $\mathrm{N}$ treatment $\left(\mathrm{F}_{2,222}=\right.$ $0.02, P=0.976)$ influenced the $\% \mathrm{C}$ in shoots.

There was a significant ploidy $\times$ soil $\mathrm{N}$ treatment interaction on the $\% \mathrm{~N}$ in fireweed roots $\left(\mathrm{F}_{2,114}=4.048, P=0.020\right.$; Fig. 2.2B $)$. Tukey's HSD results showed that diploid roots had significantly higher $\% \mathrm{~N}$ than tetraploids at the low and high soil $\mathrm{N}$ treatments $(\mathrm{P}<0.05)$, but not the medium $\mathrm{N}$ treatment $(\mathrm{P}>0.05)$. Genetic line also influenced the $\% \mathrm{~N}$ in fireweed roots $\left(\mathrm{F}_{12,114}=2.49, P=0.006\right)$. The $\% \mathrm{C}$ in fireweed roots was affected by soil $\mathrm{N}$ treatment $\left(\mathrm{F}_{2,114}=6.86, P=0.002\right)$ and genetic line $\left(\mathrm{F}_{12,114}\right.$ $=2.36, P=0.010)$. Roots in the low $\mathrm{N}$ treatment contained higher $\% \mathrm{C}(43.53 \% \pm 0.16$ $\mathrm{SE})$ than roots in the medium $(43.33 \% \pm 0.16 \mathrm{SE})$ and high $(42.79 \% \pm 0.16 \mathrm{SE})$ soil $\mathrm{N}$ 
treatments. Neither ploidy $\left(\mathrm{F}_{1,114}=0.01, P=0.912\right)$ nor an interaction between ploidy and soil $\mathrm{N}$ treatment $\left(\mathrm{F}_{2,114}=0.003, P=0.997\right)$ influenced the $\% \mathrm{C}$ in roots.

Total shoot-N was significantly affected by soil $\mathrm{N}$ treatment $\left(\mathrm{F}_{2,221}=181.16, P<\right.$ $0.0001)$ with plants in the low $\mathrm{N}$ treatment containing significantly less shoot- $\mathrm{N}$ (30.43 $\mathrm{mg} \pm 1.18 \mathrm{SE})$ than plants in the medium $(35.53 \mathrm{mg} \pm 1.18 \mathrm{SE})$ and high $(60.17 \mathrm{mg} \pm$ 1.19 SE) soil $\mathrm{N}$ treatments (Fig. 2.3A). Total shoot-N was not influenced by ploidy ( $\mathrm{F}_{1}$, $\left.{ }_{221}=0.004, P=0.950\right)$, genetic line $\left(\mathrm{F}_{12,221}=1.66, P=0.077\right)$, or a ploidy $\times$ soil $\mathrm{N}$ treatment interaction $\left(\mathrm{F}_{2,221}=0.17, P=0.846\right)$. In contrast, total root- $\mathrm{N}$ was influenced by a ploidy $\times$ soil $\mathrm{N}$ treatment interaction $\left(\mathrm{F}_{2,113}=3.13, P=0.047\right.$; Fig. 2.3B $)$. Tukey's HSD results showed that diploids had higher total root-N at the high $\mathrm{N}$ treatment $(P<$ 0.05), but no significant ploidal differences in total root-N were found at low and medium soil $\mathrm{N}$ treatments $(\mathrm{P}>0.05)$. Total root- $\mathrm{N}$ was not influenced by genetic line $\left(\mathrm{F}_{12,113}=\right.$ $0.88, P=0.570)$.

Plant reproductive output. - Fireweed shoot biomass was significantly affected by ploidy $\left(\mathrm{F}_{1,222}=20.46, P<0.0001 ; \mathrm{Fig} .2 .4 \mathrm{~A}\right)$ and genetic line $\left(\mathrm{F}_{12,222}=5.17, P<\right.$ $0.0001)$. On average, tetraploid shoots were 1.13 times heavier than diploids. Neither soil $\mathrm{N}$ treatment nor an interaction between ploidy and soil $\mathrm{N}$ treatment significantly affected shoot biomass (Table 2.1). 
Tetraploids were significantly more likely to flower than diploids (odds ratio $=$ $\left.2.42,95 \% \mathrm{CI}=1.20-5.06 ; \chi_{(1, \mathrm{~N}=240)}^{2}=5.89, P=0.015\right)$. The likelihood of a plant flowering was also influenced by genetic line $\left(\chi_{(12, \mathrm{~N}=240)}^{2}=59.36, P<0.0001\right)$. Neither soil $\mathrm{N}$ treatment $\left(\chi_{(2, \mathrm{~N}=240)}^{2}=1.94, P=0.379\right)$ nor an interaction between ploidy and soil $\mathrm{N}$ treatment $\left(\chi_{(2, \mathrm{~N}=240)}^{2}=0.87, P=0.649\right)$ affected the likelihood of a plant flowering. For plants that did flower, the total number of flowers produced was not influenced by ploidy, soil $\mathrm{N}$ treatment, a ploidy $\times$ soil $\mathrm{N}$ treatment interaction, or genetic line (Table 2.1).

Ploidy and soil $\mathrm{N}$ treatment both affected seed production, and this varied between self and outcross pollinations. For instance, in self-crosses, tetraploids produced an average of $87 \pm 7.52$ (mean $\pm 1 \mathrm{SE}$ ) seeds per pod, whereas diploids only produced an average of $24 \pm 10.07$ (mean $\pm 1 \mathrm{SE})$ seeds per pod $\left(\mathrm{F}_{2,68}=16.10, P=0.0002\right.$; Fig. 2.4B). The number of seeds per pod from self-pollinations was also influenced by genetic line $\left(\mathrm{F}_{12,68}=2.17, P=0.023\right)$. We found no significant effects of soil $\mathrm{N}$ treatment or any significant interaction between ploidy and soil $\mathrm{N}$ treatment to influence the number of seeds produced per pod from self-crosses (Table 2.1). In outcrosses, the number of seeds produced per pod was influenced by a significant ploidy $\times$ soil $\mathrm{N}$ treatment interaction $\left(\mathrm{F}_{2,75}=3.13, P=0.049\right)$. Tetraploids in the medium and high $\mathrm{N}$ treatments produced more outcrossed seeds per pod than diploids in the medium and high $\mathrm{N}$ treatments. In contrast, tetraploids in the low soil $\mathrm{N}$ treatment produced fewer outcrossed seeds per pod than diploids in the low soil $\mathrm{N}$ treatment (Fig. 2.4C). The number of seeds per pod from outcross pollinations was not influenced by genetic line (Table 2.1). 
In contrast to flower and seed production trends, diploids produced significantly more pollen than tetraploids $\left(\mathrm{F}_{1,54}=5.06, P=0.029\right.$; Fig. $\left.2.4 \mathrm{D}\right)$, and no effects of soil N treatment, ploidy $\times$ soil $\mathrm{N}$ treatment interaction, or genetic line were observed (Table 2.1). Our estimates of diploid and tetraploid pollen production translates to a mean of $21,350.80( \pm 1 \mathrm{SE}=1722.58)$ and $16,928.53( \pm 1 \mathrm{SE}=945.74)$ pollen grains per diploid and tetraploid flower, respectively. 

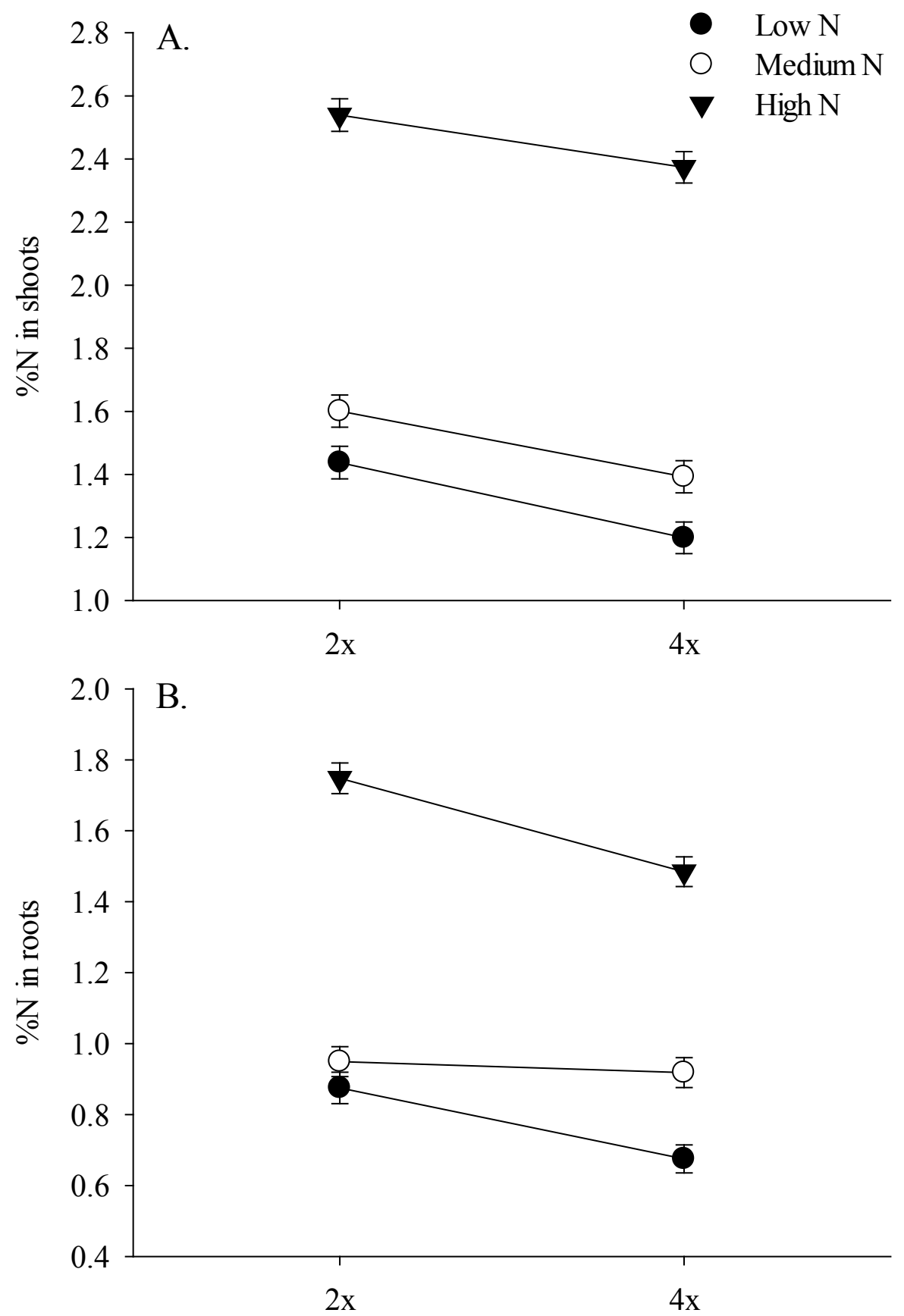

Fig. 2.2: ANOVA results showing the effects of ploidy and soil $\mathrm{N}$ treatment on the $\% \mathrm{~N}$ in shoots $(\mathrm{A})$ and roots $(\mathrm{B})$. Ploidy $\left(\mathrm{F}_{1,222}=23.80, P<0.0001\right)$ and soil $\mathrm{N}\left(\mathrm{F}_{2,222}=\right.$ $291.75, P<0.0001)$ affected $\% \mathrm{~N}$ in shoots, whereas ploidy and soil $\mathrm{N}$ interacted to influence $\% \mathrm{~N}$ in roots $\left(\mathrm{F}_{2,114}=4.048, P=0.020\right)$; no other factors significantly affected total shoot or total root N. Error bars represent $\pm 1 \mathrm{SE}$. 


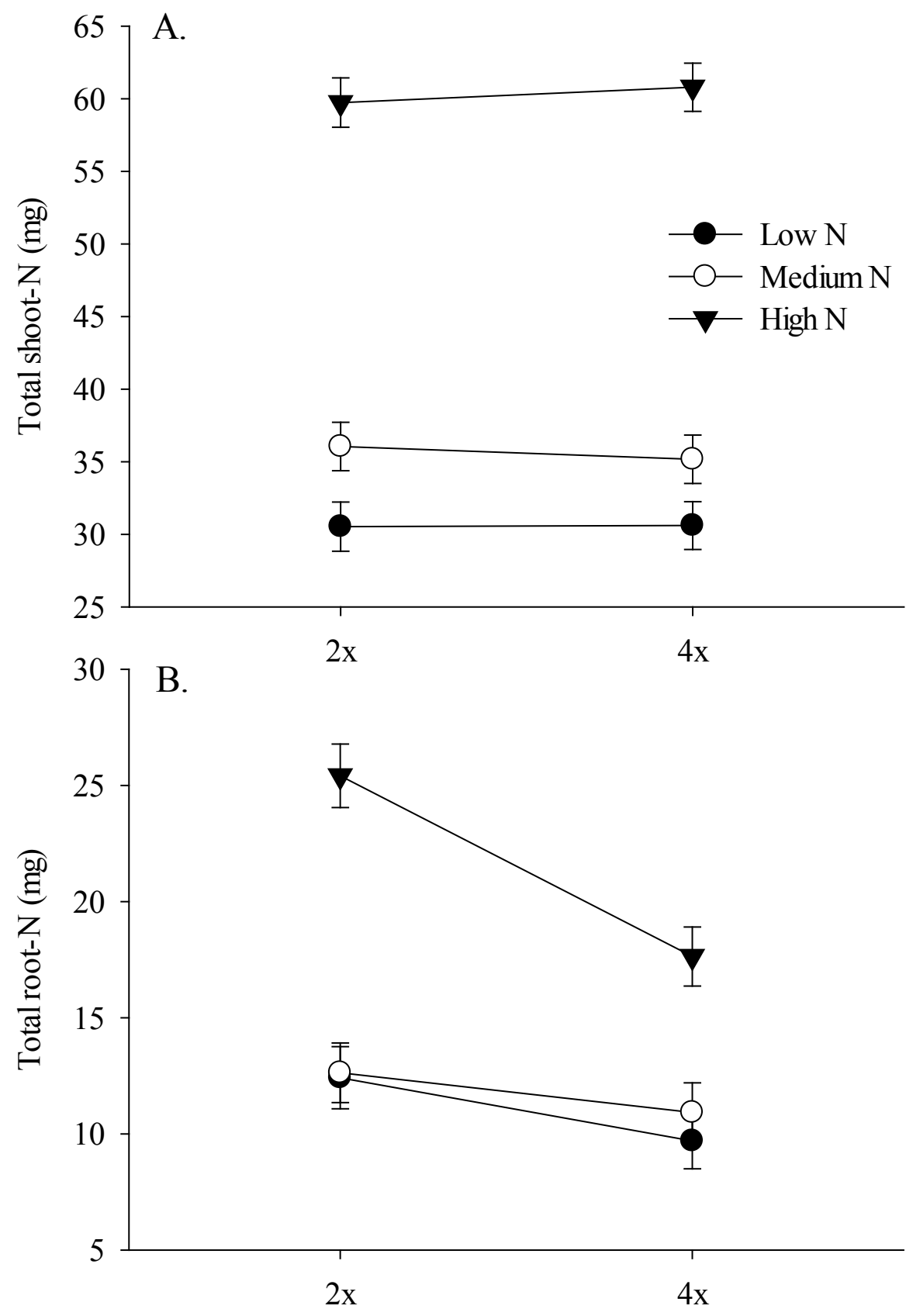

Fig. 2.3: ANOVA results showing the effects of ploidy and soil $\mathrm{N}$ on the total shoot-N (A) and total root-N (B). Only soil $\mathrm{N}$ affected total shoot-N $\left(\mathrm{F}_{2,221}=181.16, P<0.0001\right)$, whereas ploidy and soil $\mathrm{N}$ interacted to influence total root-N $\left(\mathrm{F}_{2,113}=3.13, P=0.047\right)$. Error bars represent $\pm 1 \mathrm{SE}$. 

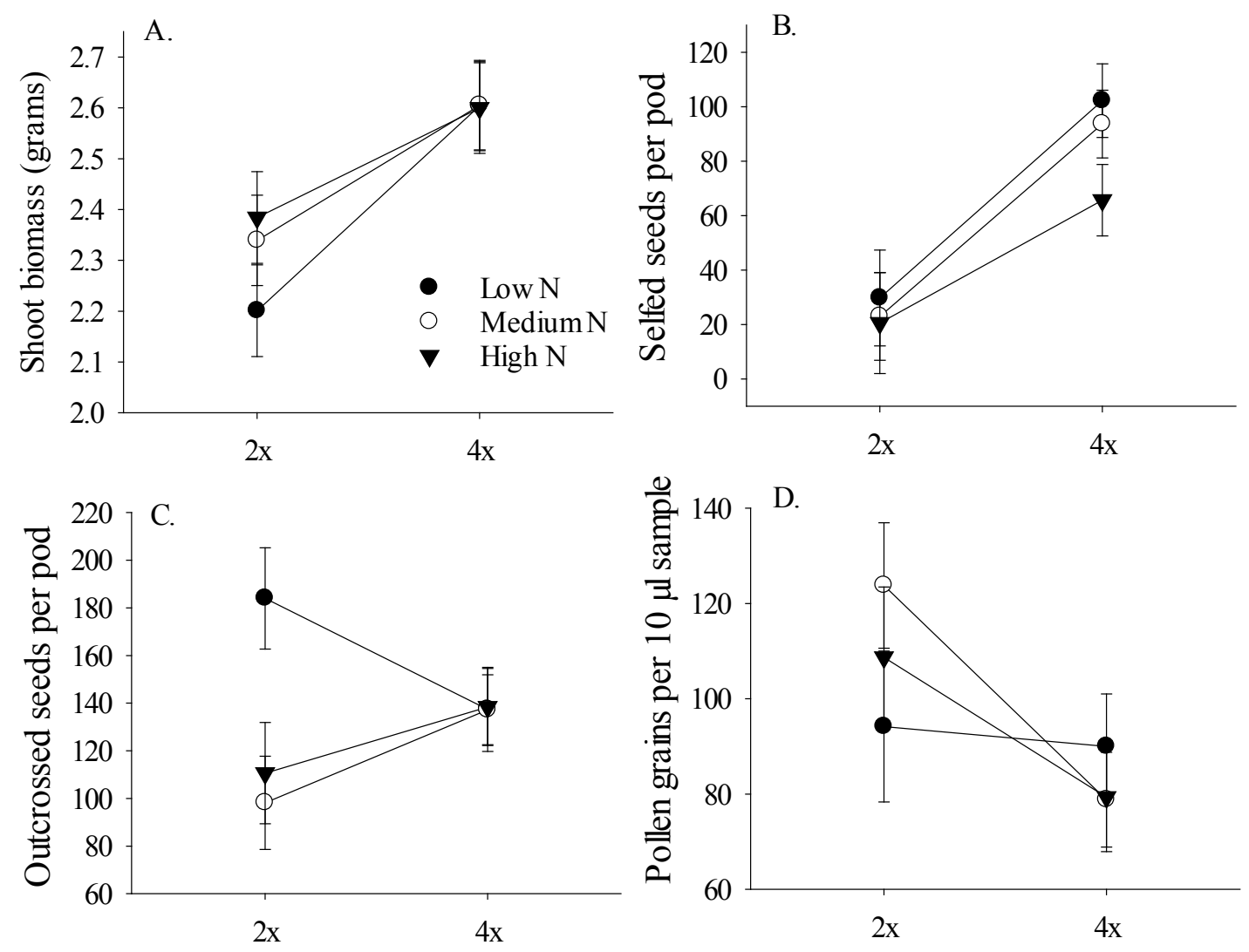

Fig. 2.4: ANOVA results showing the effects of ploidy and soil $\mathrm{N}$ availability on four fitness components: Shoot biomass (A), the number of seeds per pod produced from selfpollinations (B), the number of seeds per pod produced from outcross-pollinations (C), and the estimated number of pollen grains produced per stamen (D). Ploidy significantly affected shoot biomass $\left(\mathrm{F}_{1,222}=20.46, P<0.0001 ; \mathrm{A}\right)$ and the number of selfed seeds produced per pod $\left(\mathrm{F}_{2,68}=16.10, P=0.0002 ; \mathrm{B}\right)$. Ploidy and soil $\mathrm{N}$ interacted to influence the number of outcrossed seeds produced per pod $\left(\mathrm{F}_{2,75}=3.13, P=0.049\right.$; $\left.\mathrm{C}\right)$. Ploidy affected the number of pollen grains in $10 \mu \mathrm{l}$ of pollen homogenate $\left(\mathrm{F}_{1,54}=5.06, P=\right.$ 0.029 ; D). No other factors were significant. Error bars represent $\pm 1 \mathrm{SE}$. 
TABLE 2.1: ANOVA results for ploidy and soil $\mathrm{N}$ treatment effects on components of fireweed reproductive output. $\mathrm{P} \times \mathrm{N}$ is a ploidy by soil N interaction. Genetic line is a fixed effect nested within ploidy.

\begin{tabular}{lllr}
\hline \hline Factor & Source & \multicolumn{1}{c}{$F_{d f}$} & \multicolumn{1}{c}{$P$} \\
\hline Shoot biomass & Ploidy & $20.46_{(1,222)}$ & $<0.001$ \\
& Soil N & $0.65_{(2,222)}$ & 0.521 \\
& P $\times$ N & $0.78_{(2,222)}$ & 0.461 \\
& Genetic line & $5.17_{(12,22)}$ & $<0.001$ \\
Flower production & Ploidy & $0.57_{(1,82)}$ & 0.452 \\
& Soil N & $1.66_{(2,82)}$ & 0.197 \\
& P $\times$ N & $2.79_{(2,82)}$ & 0.067 \\
& Genetic line & $1.13_{(12,82)}$ & 0.348 \\
Selfed seeds per pod & & & \\
& Ploidy & $16^{1} .10_{(1,68)}$ & $<0.001$ \\
& Soil N & $1.20_{(2,68)}$ & 0.309 \\
& P $\times$ N & $0.36_{(2,68)}$ & 0.702 \\
Outcrossed seeds per pod & Genetic line & $2.17_{(12,68)}$ & 0.023 \\
& Ploidy & $0.17_{(1,75)}$ & 0.682 \\
& Soil N & $2.70_{(2,75)}$ & 0.073 \\
& P $\times$ N & $3.13_{(2,75)}$ & 0.049 \\
Pollen per stamen & Genetic line & $0.44_{(12,75)}$ & 0.944 \\
& Ploidy & $5.07_{(1,54)}$ & 0.029 \\
& Soil N & $0.37_{(2,54)}$ & 0.693 \\
& P $\times$ N & $1.48_{(2,54)}$ & 0.238 \\
& Genetic line & $1.71_{(12,54)}$ & 0.090 \\
\hline
\end{tabular}


Resource allocation strategies. - We found that diploids and tetraploids differed significantly in their resource allocation strategies, and such differences can be influenced by soil nitrogen availability. In general, plants invested significantly more into shoot biomass relative to root biomass with increasing soil $\mathrm{N}$ availability $\left(\mathrm{F}_{2,221}=3.73, P=\right.$ 0.026, Fig. 2.5A). Tetraploids invested more biomass into shoots than roots compared to diploids $\left(\mathrm{F}_{1,221}=19.10, P<0.0001 ;\right.$ Fig. $\left.2.5 \mathrm{~A}\right)$; tetraploids' mean shoot ${ }_{\text {mass }}$ : root $_{\text {mass }}$ ratio was 1.23 times greater than that of diploids. Shoot mass: $_{\text {root }}$ mass ratio was also influenced by plant genetic line $\left(\mathrm{F}_{12,221}=2.05, P=0.022\right)$, and no significant ploidy $\times$ soil $\mathrm{N}$ treatment interaction was found $\left(\mathrm{F}_{2,221}=2.80, P=0.063\right)$. Interestingly, only ploidy significantly affected the total amount of $\mathrm{N}$ that was invested into shoots versus roots (shoot ${ }_{\mathrm{N}}:$ root $_{\mathrm{N}}$ ); tetraploids invested 1.29 times more $\mathrm{N}$ into shoots versus roots than diploids $\left(\mathrm{F}_{(1,113)}=18.47, P<0.0001 ;\right.$ Fig. $\left.2.5 \mathrm{~B}\right)$. No other factors or interactions among factors had significant effects on shoot $_{\mathrm{N}}:$ root $_{\mathrm{N}}$ ratio (Table 2.2).

There was a significant ploidy $\times$ soil $\mathrm{N}$ treatment interaction on plant $\mathrm{C}: \mathrm{N}$ ratio $\left(\mathrm{F}_{(2,222)}=2.97, P=0.053\right.$; Fig. 2.6). In general, increasing soil $\mathrm{N}$ treatment availability decreased plant C:N ratio and tetraploids had higher C:N ratios than diploids. Tukey's HSD results showed that diploid and tetraploid C:N ratios were only significantly different at the low $\mathrm{N}$ treatment $(\mathrm{P}<0.05)$. Plant $\mathrm{C}$ : $\mathrm{N}$ ratio was also influenced by genetic line $\left(\mathrm{F}_{(12,22)}=5.39, P<0.0001\right)$.

Diploids and tetraploids differed in their relative proportion of aboveground resources that were allocated to reproductive output $\left(\mathrm{RO}\right.$ shoot $\left._{\mathrm{N}}\right)$, and such differences were dependent on soil $\mathrm{N}$ treatment and whether plants were selfed or outcrossed. For 
example, when flowers were self-pollinated $\left(\mathrm{RO}_{\text {self: }}:\right.$ hoot $\left._{\mathrm{N}}\right)$, tetraploids allocated more resources to reproduction per $\mathrm{mg}$ of shoot-N relative to diploids $\left(\mathrm{F}_{1,68}=9.44, P=0.003\right.$; Fig. 2.7A), and plants allocated more resources to reproduction per mg of shoot-N with decreasing soil $\mathrm{N}$ treatment $\left(\mathrm{F}_{2,68}=3.93, P=0.024\right)$. The $\mathrm{RO}_{\text {self:shoot }}$ ratio was not influenced by an interaction between ploidy and soil $\mathrm{N}$ treatment or genetic line (Table 2.2). We found that ploidy had significant effects on the ratio of reproductive output to total shoot-N in terms of seeds produced in outcrossed pollinations $\left(\mathrm{RO}_{\text {outcross }}: \mathrm{shoot}_{\mathrm{N}}\right)$, but that such effects depended upon soil nitrogen treatment (i.e. there was a significant interaction between soil $\mathrm{N}$ treatment and ploidy; $\mathrm{F}_{2,75}=7.20, P=0.001$; Fig. 2.7B). When soil nitrogen was low, diploids allocated more resources to reproduction per mg of shoot-N compared to tetraploids whereas when soil nitrogen was not low, diploids allocated fewer resources to reproduction per mg of shoot-N compared to tetraploids. The $\mathrm{RO}_{\text {outcross: }}:$ shoot $_{\mathrm{N}}$ ratio was not influenced by genetic line (Table 2.2). 

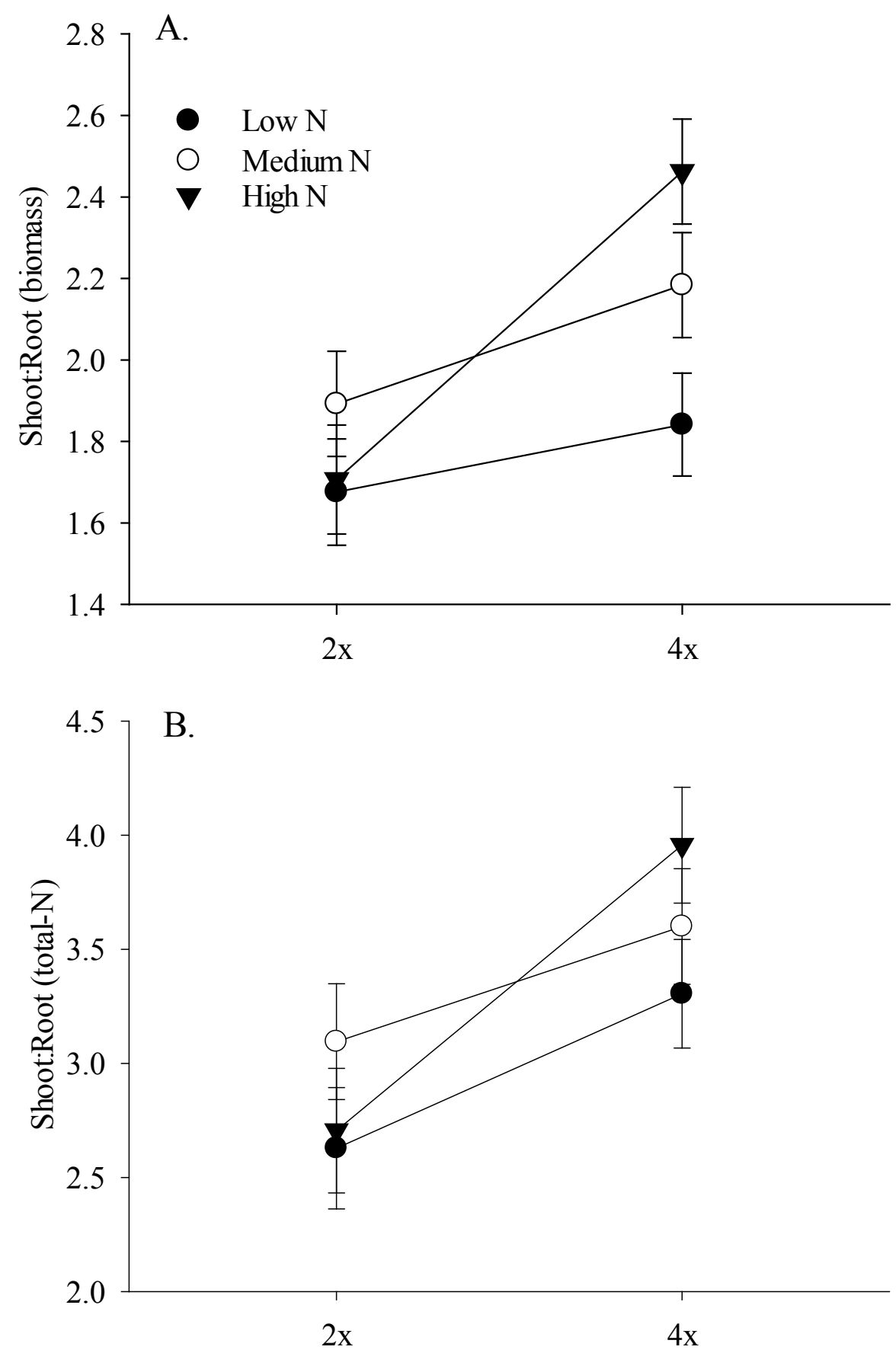

Fig. 2.5: ANOVA results showing the effects of ploidy and soil $N$ treatment on the ratio of shoot biomass to root biomass (A) and the ratio of total shoot-N to total root-N (B). Both ploidy $\left(\mathrm{F}_{1,221}=19.10, P<0.0001\right)$ and soil $\mathrm{N}\left(\mathrm{F}_{2,221}=3.73, P=0.026\right)$ affected the ratio of shoot to root biomass, whereas only ploidy influenced the ratio of total shoot-N to total root-N $\left(\mathrm{F}_{(1,113)}=18.47, P<0.0001\right)$. Error bars represent $\pm 1 \mathrm{SE}$. 
TABLE 2.2: ANOVA results for ploidy and soil $\mathrm{N}$ treatment effects on components of fireweed resource allocation. $\mathrm{P} \times \mathrm{N}$ is a ploidy by soil $\mathrm{N}$ interaction. Genetic line is a fixed effect nested within ploidy.

\begin{tabular}{|c|c|c|c|}
\hline Factor & Source & $\overline{F_{d f}}$ & $P$ \\
\hline \multirow[t]{4}{*}{ Shoot $_{\text {mass }}:$ Root $_{\text {mass }}$} & Ploidy & $19.10_{(1,221)}$ & $<0.001$ \\
\hline & Soil N & $3.73_{(2,221)}$ & 0.026 \\
\hline & $\mathrm{P} \times \mathrm{N}$ & $2.80_{(2,221)}$ & 0.063 \\
\hline & Genetic line & $2.05_{(12,221)}$ & 0.022 \\
\hline \multirow[t]{4}{*}{ Shoot $_{\mathrm{N}}: \operatorname{Root}_{\mathrm{N}}$} & Ploidy & $18.47_{(1,113)}$ & $<0.001$ \\
\hline & Soil N & $0.77_{(2,113)}$ & 0.466 \\
\hline & $\mathrm{P} \times \mathrm{N}$ & $1.78_{(2,113)}$ & 0.174 \\
\hline & Genetic line & $1.49_{(12,113)}$ & 0.139 \\
\hline \multirow[t]{4}{*}{$\mathrm{C}: \mathrm{N}$} & Ploidy & $22.11_{(1,222)}$ & $<0.001$ \\
\hline & Soil N & $189.69_{(2,222)}$ & $<0.001$ \\
\hline & $\mathrm{P} \times \mathrm{N}$ & $2.97_{(2,222)}$ & 0.053 \\
\hline & Genetic line & $5.39_{(12,222)}$ & $<0.001$ \\
\hline \multirow{4}{*}{$\mathrm{RO}_{\text {self: }}$ Shoot-N } & Ploidy & $9.44_{(1,68)}$ & 0.003 \\
\hline & Soil N & $3.94_{(2,68)}$ & 0.024 \\
\hline & $\mathrm{P} \times \mathrm{N}$ & $0.61_{(2,68)}$ & 0.546 \\
\hline & Genetic line & $1.23_{(12,68)}$ & 0.281 \\
\hline \multirow{4}{*}{$\mathrm{RO}_{\text {outcross }}:$ Shoot-N } & Ploidy & $0.01_{(1,75)}$ & 0.934 \\
\hline & Soil N & $9.04_{(2,75)}$ & $<0.001$ \\
\hline & $\mathrm{P} \times \mathrm{N}$ & $7.20_{(2,75)}$ & 0.001 \\
\hline & Genetic line & $0.71_{(12,75)}$ & 0.738 \\
\hline
\end{tabular}

Shoot ${ }_{\text {mass }}:$ Root $_{\text {mass }}$ and Shoot $_{\mathrm{N}}:$ Root $_{\mathrm{N}}$ values were log-transformed. 


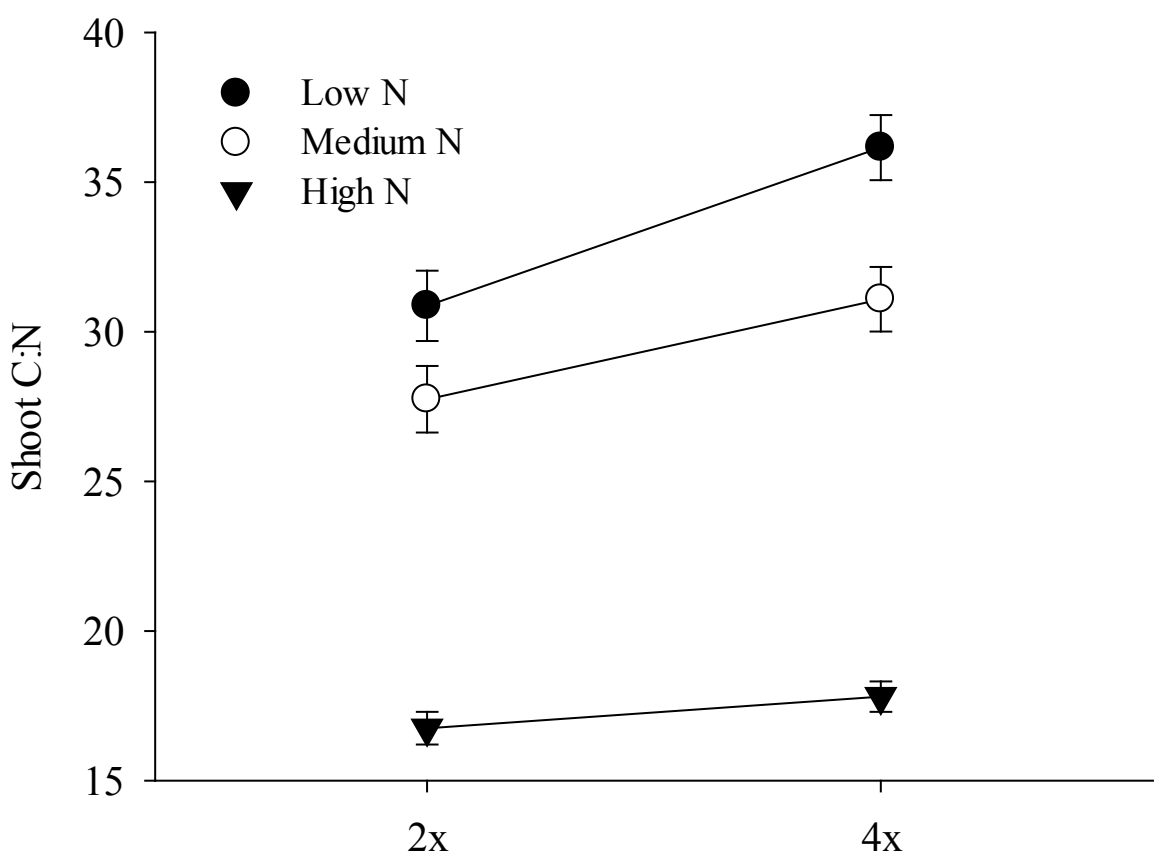

Fig. 2.6: ANOVA results showing the effects of ploidy and soil $\mathrm{N}$ treatment on shoot $\mathrm{C}: \mathrm{N}$ ratio. There was a significant interaction between ploidy and soil $\mathrm{N}$ treatment on $\mathrm{C}: \mathrm{N}$ ratio $\left(\mathrm{F}_{(2,222)}=2.97, P=0.053\right)$. Error bars represent $\pm 1 \mathrm{SE}$. 

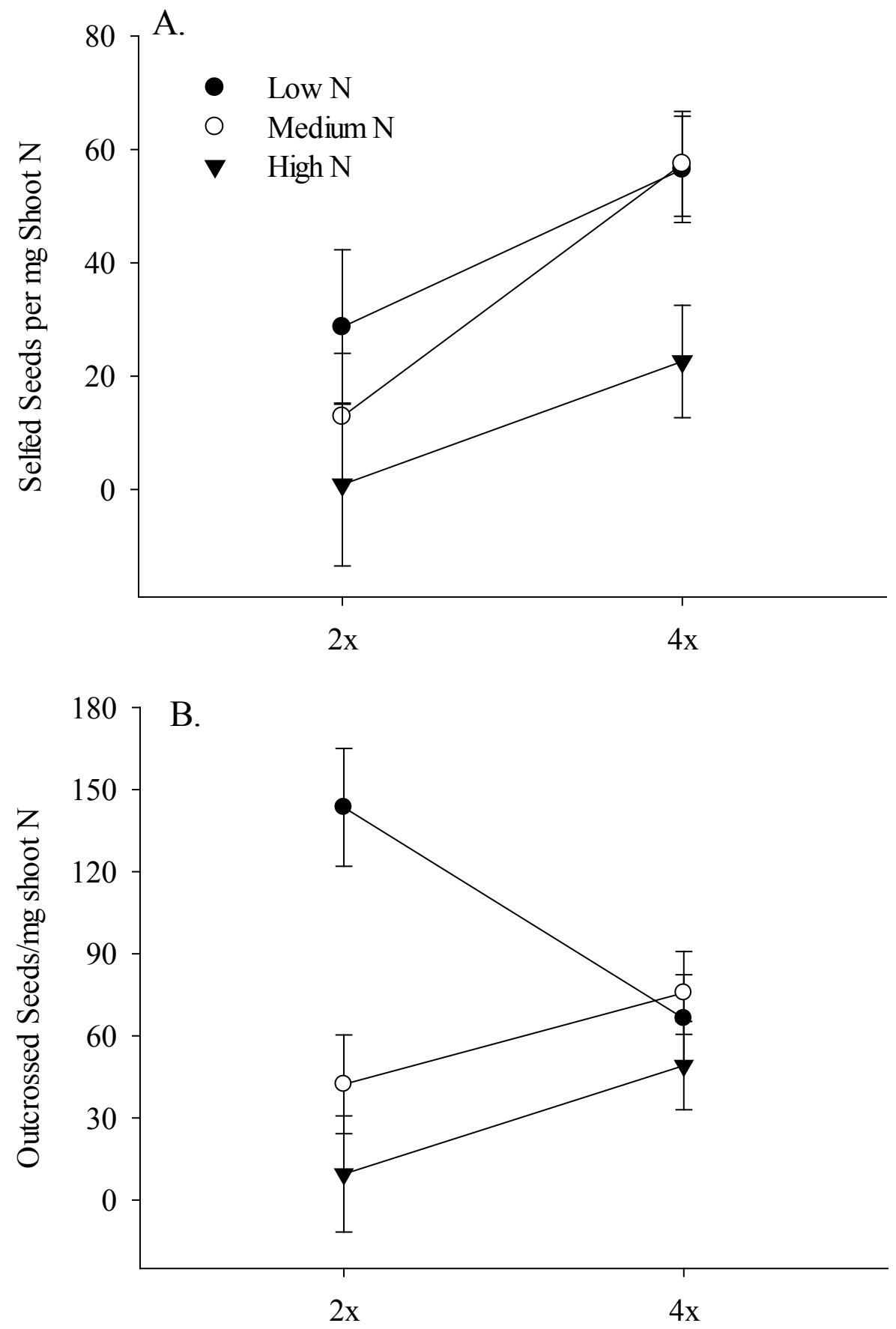

Fig. 2.7: ANOVA results showing the effects of ploidy and soil $\mathrm{N}$ treatment on the $\mathrm{RO}_{\text {self: }}$ :shoot $\mathrm{N}$ ratio (A) and the $\mathrm{RO}_{\text {outcross: }}$ : hhoot $_{\mathrm{N}}$ ratio (B). Both ploidy $\left(\mathrm{F}_{1,68}=9.44, P=\right.$ $0.003)$ and soil $\mathrm{N}\left(\mathrm{F}_{2,68}=3.93, P=0.024\right)$ influenced the $\mathrm{RO}_{\text {self }}$ :shoot $\mathrm{N}_{\mathrm{N}}$ ratio, whereas ploidy and soil $\mathrm{N}$ interacted to influence $\mathrm{RO}_{\text {outcross }}: \operatorname{shoot}_{\mathrm{N}}\left(\mathrm{F}_{2,75}=7.20, P=0.001\right)$. Error bars represent \pm 1 SE. 


\section{Discussion}

Our results suggest that the role of soil $\mathrm{N}$ availability in regulating the relative success of diploid and tetraploid fireweed is complex. We found that polyploidy can alter the resource allocation strategies and reproductive success of fireweed, and that some of these effects may be dependent upon soil $\mathrm{N}$ availability.

Tetraploids have larger shoots but lower $N$ content - We found that tetraploids produced more aboveground biomass relative to diploids (Fig. 2.4A), which has previously been reported in fireweed (Husband and Schemske 1998) and other polyploid species (Eigsti 1957, Evans 1967, Maceira et al. 1993, Liu et al. 2011). However, when we examined whether the percentage of nitrogen in shoot tissues differed between cytotypes, we found that diploids had more nitrogen-rich aboveground tissues than tetraploids. This suggests that diploids have more nitrogen concentrated leaves. Such differences in leaf quality may have important implications for plant-herbivore interactions. For example, insect herbivores are often limited by available nitrogen and several studies have shown that insects prefer more nitrogen-rich plants (Mattson Jr 1980). Furthermore, $\mathrm{C}: \mathrm{N}$ ratios were higher in tetraploids than in diploids (Fig. 2.6), and $\mathrm{C}: \mathrm{N}$ ratio has been positively associated with concentrations of carbon-based secondary compounds that are used in plant defense against herbivory (Bryant et al. 1987, Ibrahim et al. 2011). Whether diploids are, in fact, more susceptible to insect herbivore damage than tetraploids is being tested. However, it should be noted that differences in $\mathrm{CN}$ ratio

are most likely driven by differences in nitrogen concentrations, as the percent carbon in 
shoot tissues did not vary among diploids and tetraploids. Diploids were also more effective at capturing nitrogen in their roots - they had more overall root nitrogen and their root tissues had a higher percentage of nitrogen than tetraploids despite the fact that diploids and tetraploids had similar root mass.

It is unclear why tetraploids have less nitrogen-rich stems and roots than diploids, although such findings may be related to allometric relationships associated with the larger cell sizes of tetraploids (Maherali et al. 2009). Genome duplication in other species has been shown to produce a two-fold increase in cell volume relative to related diploids, but a less than two-fold increase in nitrogen containing cellular structures (e.g. RNA, microtubules, membranes; Molin et al. 1982, Storchová et al. 2006). This allometric difference in cell volume to cellular structure ratio could partially explain tetraploids' lower nitrogen concentrations if their larger cell size does not equip them with a proportionally large quantity of nitrogenous cellular structures. Furthermore, some plants adapted to nitrogen-poor habitats have an ability to acquire and store nitrogen in large vacuolar storage reserves (i.e. luxury consumption; Chapin 1980). It is possible that diploids are better able to store nitrogen in cells relative to tetraploids, possibly because less nitrogen is required for synthesizing diploids' smaller genomes and more soil nitrogen is available for cellular storage. 
Tetraploids invest more into shoots than roots compared to diploids - Compared to diploids, tetraploids invested a larger proportion of their biomass and nitrogen into shoots relative to roots (Fig. 2.5A, B). While tetraploids' shoot ${ }_{\text {mass }}$ :root mass $_{\text {increased with }}$ increasing soil nitrogen availability (Fig. 2.5A), which is a common response of plants in general (Austin and Austin 1980, Austin et al. 1985, Tilman 1986b), diploids did not appear to respond to increasing soil nitrogen with the same level of plasticity. Although the interaction effect was not significant, these results indicate that tetraploids may have greater plasticity in responding to $\mathrm{N}$-rich soils, as they were more capable of reducing their investment in root tissue relative to shoot tissue than diploids. Fireweed is a perennial plant species, and reduced investment in root production may provide tetraploids with a disadvantage in terms of their following year's productivity and/or an ability to re-allocate resources if late season reproduction is threatened (Chapin et al. 1990).

Reproductive output is influenced by cytotype - Greater soil nitrogen availability generally has positive effects on plant productivity and reproductive output. Furthermore, because nitrogen is often a major limiting factor to plant growth and reproduction, it is not surprising that many experiments have found that fertilization often results in increased plant "fitness" (Shaver et al. 1986, Chapin 1991, Shaver et al. 1992, Bret-Harte et al. 2002). Here, we expected that plant fitness measures would increase as soil nitrogen increased and that relative effects between cytotypes would vary. Specifically, we predicted that diploids would have greater reproductive output relative to tetraploids 
in N-poor soils because soil nitrogen limitation would more severely impact tetraploid reproductive capacity because they require more nitrogen to synthesize larger genomes. In agreement with our initial projections, it appears that diploid fireweed may have a greater tolerance for N-poor soils relative to diploids in terms of outcrossed seed production. For example, tetraploids in the low nitrogen treatment produced fewer outcrossed seeds per pod relative to diploids, but more outcrossed seeds relative to diploids in the medium and high nitrogen treatments (Fig. 2.4C).

Surprisingly, we found that soil nitrogen availability had no effect on biomass production, flower production, or the odds of a plant producing flowers. This might indicate that soil nitrogen was not limiting or it was not the only limiting nutrient in terms of biomass and flower production. Noteworthy, we did not vary phosphorous, and it is possible that phosphorous limitation may have also influenced plant productivity and flower production. Although nitrogen did not affect these specific measures of reproductive output, tetraploids, in general, were more productive than diploids. Tetraploids had more biomass, were more likely to flower, and produced more seeds from self-pollinations.

In contrast, diploids produced more pollen grains per anther (Fig. 2.4D), suggesting that diploids may have an advantage over tetraploids in terms of male fitness, although tetraploids were more likely to flower. It is unclear whether cytotypes would have different fitness consequences if both soil phosphorous and nitrogen were augmented. Interestingly, a previous study found that polyploid species responded more positively to phosphorous fertilization relative to diploids, and if phosphorous was 
limiting in our study this may have muted effects of nitrogen treatments. Nonetheless our understanding of the role of polyploidy in regulating nutrient demands and the responses of plants to changing nutrient-availabilities would benefit from studies that consider the co-limitation of nitrogen and phosphorous as well as other important environmental factors such as water limitation.

In areas where soil nitrogen limits plant productivity, plants may have an advantage if they are able to produce more seeds and flowers with fewer resources allocated to shoot growth (i.e. a higher RO:shoot $\mathrm{N}_{\mathrm{N}}$ ratio). Plants that are dominant in Npoor habitats have been shown to allocate a high proportion of their aboveground biomass to reproduction relative to those in higher $\mathrm{N}$-soils (Tilman and Cowan 1989). We expected diploids to be more efficient at producing seeds and flowers per unit of shoot-N relative to tetraploids at the low soil nitrogen level and that such differences among cytotypes might disappear with increasing soil nitrogen. Our data suggest that if all flowers are cross-pollinated, diploids grown in N-poor soils are more efficient at producing seeds per unit of shoot-N relative to tetraploids, while diploids in N-rich soils appear to be less efficient than tetraploids (Fig. 2.7B). If all flowers are self-pollinated, however, tetraploids appear to be more efficient at producing selfed seeds per unit of nitrogen in shoot tissues relative to diploids. However, this effect appears to be more related diploids' lower selfed-seed production relative to tetraploids, likely a result of their higher inbreeding depression (Husband and Schemske 1997). 
Biological significance. - Nitrogen is often scarce in high latitude regions and likely contributes to low levels of primary productivity (Shaver et al. 1986, Chapin 1991, Shaver et al. 1992, Bret-Harte et al. 2002). Despite major anthropogenic inputs of nitrogen to ecosystems worldwide, it is unclear whether any increases in soil nitrogen availability will affect cytotype distributions and the relative success of different cytotypes. Given that polyploidy commonly occurs in plants, information about the effects of changes in nitrogen availability may allow us to better predict how distributions might change in the future. Our results suggest that tetraploids might be better suited for competing against diploids in nitrogen-rich soils. For example, tetraploids had higher seed production and produced more seeds per mg of shoot-N compared to diploids at the high soil nitrogen treatment. Furthermore, they produced less nitrogen rich tissues and shoots with higher $\mathrm{C}: \mathrm{N}$ ratios, which may afford them an advantage relative to diploids in the resistance against herbivores. However, tetraploids also invest more growth into shoots than roots, which may put them at a disadvantage relative to diploids when environmental conditions negatively affect survival and/or threaten reproduction. Diploids may also have an advantage in nitrogen-poor soils in terms of their ability to allocate a large portion of aboveground resources to reproduction with a relatively small proportion of resources allocated to vegetative shoots.

Our understanding of the role of soil nitrogen availability in regulating the relative success of diploid and tetraploid fireweed would benefit from studies in the field that are also able to examine the competitiveness of each cytotype under a variety of environmental conditions. Our greenhouse experiment allowed us to control for 
extraneous variables (i.e. water limitation and herbivory) that commonly occur in field conditions and could interact to influence the results of fertilization experiments.

In summary, our results suggest that increases in soil nitrogen may have significant influences on the relative success of diploids versus polyploids, but that cumulatively, these effects are complex and individualistic (i.e., there was genotypic variation in many of the responses measured). It is unclear whether tetraploid fireweed is replacing diploid fireweed in Alaska, and additional surveys of diploid and tetraploid distributions throughout other areas of Alaska are needed. More studies are also needed to better assess how increased soil nitrogen may influence the relative distribution of polyploid and related diploid plants. 


\section{Appendix 1 - Fireweed sampling in Alaska}

We collected leaves and seeds from four fireweed populations in interior Alaska in August 2013 and 2014 and from an additional four populations throughout southern Alaska in August 2014 (Table 2.3). Leaves and seeds were collected from separate plants that were spaced at a minimum of 15 meters from each other. After collection, leaves were immediately placed into envelopes with desiccant to ensure fast drying of material whereas seed pods were allowed to dry naturally before seeds were collected. We determined ploidy for a total of 684 plants (594 field collected leaf samples and 90 leaf samples from plants grown from different individual field collected seeds).

To determine the ploidy of field collected seeds we grew at least two plants from each of 90 different maternal lines (field collected seeds) in the greenhouse at MTU (Dept. of Biological Science, Houghton, MI). The 2C DNA content of fireweed cells has been shown to be highly correlated and indicative of plant ploidy or chromosome number (Husband and Schemske 1998). Therefore, we used flow cytometry to estimate plant nuclear 2C DNA content of both dried leaf material collected in the field and live leaf material from the greenhouse to serve as a proxy for cytotype determination. For each

plant sampled, we co-chopped a $1-2 \mathrm{~cm}^{2}$ piece of fireweed leaf material with a $1-2 \mathrm{~cm}^{2}$ piece of a Solanum lycospersicum leaf material as an internal standard (Solanum lycospersicum - 2C DNA content $=1.96$, Doležel et al. 2007). Leaves were co-chopped in a modified DeLaat's nuclei isolation buffer with $50 \mu \mathrm{g} \mathrm{ml}^{-1}$ RNase and $50 \mu \mathrm{g} \mathrm{ml}^{-1}$ propidium iodide. Cells were allowed to stain for approximately 40 minutes, and the filtered cell solution was analyzed on an Accuri C6 flow cytometer with CFlow Plus 
Analysis software (Accuri Inc., Ann Arbor, MI, USA). We used the FL2 detector to measure the relative fluorescence of our samples, and we removed uninformative noise in the data by gating scatter plots to only include particles within the fluorescence range of C. angustifolium and S. lycospersicum nuclei. We determined ploidy of fireweed using histogram plots showing the relative FL2 fluorescence of C. angustifolium and $S$. lycospersicum nuclei counts. We estimated the plant nuclear DNA content by dividing the $C$. angustifolium nuclei fluorescence by the $S$. lycospersicum to obtain a sample:standard ratio. We then multiplied the ratio by the nuclear DNA content of $S$. lycospersicum (1.96 pg) to obtain an estimate of C. angustifolium DNA content. The mean nuclear DNA content of diploids, triploids, and tetraploids was $1.48 \pm 0.0033 \mathrm{pg}$, $2.19 \pm 0.015 \mathrm{pg}$, and $2.95 \pm 0.0048 \mathrm{pg}$, respectively.

In general, we found that sites were predominantly dominated by tetraploid cytotypes of fireweed ( 7 of 8 sites, Table 2.3 ) and that triploid cytotypes were rare in all sites. Only the most northern site, Caribou-Poker Creek Basin, was dominated by diploid cytotypes (Table 2.3). For all subsequent experiments we only used seeds collected from Bonanza Creek, Caribou-Poker Creek Basin, and the UAF trail system (three sites that contrasted in the relative frequencies of diploid and tetraploid cytotypes) and all plants that were found to be triploid were discarded. 
TABLE 2.3: GPS coordinates of eight locations throughout interior Alaska and the relative proportion of diploid, triploid, and tetraploid plants identified from each location.

\begin{tabular}{|c|c|c|c|c|c|c|}
\hline \multirow[t]{2}{*}{ Location } & \multirow[t]{2}{*}{ Latitude } & \multirow[t]{2}{*}{ Longitude } & \multirow[t]{2}{*}{$\begin{array}{l}\mathrm{N} \text { plants } \\
\text { sampled }\end{array}$} & \multicolumn{3}{|c|}{$\begin{array}{c}\text { Number of } \\
\text { cytotypes }\end{array}$} \\
\hline & & & & $2 \mathrm{x}$ & $3 x$ & $4 x$ \\
\hline Bonanza Creek & 64.70369 & -148.29862 & 176 & 33 & 6 & 137 \\
\hline Caribou-Poker Creek & 65.15275 & -147.48417 & 184 & 139 & 6 & 39 \\
\hline UAF trail system & 64.86248 & -147.86169 & 171 & 23 & 14 & 134 \\
\hline Dog Musher's Park & 64.89780 & -147.72948 & 14 & 0 & 0 & 14 \\
\hline Anchorage/Cook Inlet & 61.19964 & -149.99950 & 69 & 1 & 0 & 68 \\
\hline Turnagain Arm & 60.98097 & -149.42759 & 15 & 0 & 0 & 15 \\
\hline Kenai & 60.64740 & -149.33475 & 28 & 0 & 0 & 28 \\
\hline Seward & 60.09247 & -149.43826 & 27 & 0 & 0 & 27 \\
\hline
\end{tabular}




\section{Appendix 2 - Soil sampling}

We collected soil samples from 10 locations at the University of Alaska Fairbanks trail system and 10 locations at the Caribou-Poker Creek Research Watershed. Soil samples were collected using a 3 inch diameter soil corer to remove the top six inches of soil. These samples were immediately frozen for 24 hours, thawed, and extracted for inorganic nitrogen using $2 \mathrm{M} \mathrm{KCl}$ at the Forest Soils Lab (University of Alaska Fairbanks, Fairbanks, AK). Ammonium-N and nitrate-N were determined colorimetrically using standard methods (Mulvaney and Sparks 1996) on a Bran-Luebbe AutoAnalyzer 3.

On average, soils at the Caribou-Poker creek site contained $4.79( \pm 1 \mathrm{SE}=0.59)$ $\mu \mathrm{g} \mathrm{N} \cdot \mathrm{g}^{-1}$ soil. Sites at the UAF trail system contained an average of $2.21( \pm 1 \mathrm{SE}=0.52)$ $\mu \mathrm{g} \mathrm{N} \cdot \mathrm{g}^{-1}$ soil. Across both sites, inorganic soil $\mathrm{N}$ averaged $3.30( \pm 1 \mathrm{SE}=0.51) \mu \mathrm{g} \mathrm{N} \cdot \mathrm{g}^{-1}$ soil (Table 2.4). 
TABLE 2.4: Concentration of inorganic nitrogen extracted from soils at 19 locations throughout the Caribou-Poker Creek Watershed and UAF Fairbanks trail system.

\begin{tabular}{crrr}
\hline \hline & \multicolumn{3}{c}{ Parts per million $\left(\mu \mathrm{g} \mathrm{N} \cdot \mathrm{g}^{-1}\right.$ soil $)$} \\
\hline Site & $\mathrm{NH}_{4}-\mathrm{N}$ & $\mathrm{NO}_{2}+\mathrm{NO}_{3}-\mathrm{N}$ & Total inorganic $\mathrm{N}$ \\
\hline & 3.768 & 0.980 & 4.748 \\
Caribou- & 2.633 & 0.151 & 2.784 \\
Poker & 5.531 & 1.376 & 6.907 \\
Creek & 2.745 & 0.224 & 2.969 \\
Research & 3.241 & 0.130 & 3.371 \\
Watershed & 3.490 & 0.999 & 4.489 \\
& 5.359 & 0.618 & 5.977 \\
& 6.578 & 1.234 & 7.812 \\
& 4.049 & 0.008 & 4.057 \\
\hline & 5.515 & 0.199 & 5.714 \\
University & 4.150 & 0.000 & 4.150 \\
of Alaska & 1.122 & 0.000 & 1.122 \\
Fairbanks & 1.230 & 0.020 & 1.250 \\
trail & 1.229 & 0.000 & 1.229 \\
system & 1.757 & 0.000 & 1.757 \\
& 1.366 & 0.000 & 1.366 \\
& 0.943 & 0.039 & 0.982 \\
& 1.315 & 0.000 & 1.315 \\
Mean & 0.662 & 0.000 & 0.662 \\
\hline
\end{tabular}




\section{Citations}

Abrahamson, W. G., and H. Caswell. 1982. On the comparative allocations of biomass, energy, and nutrients in plants. Ecology 63:982-991.

Austin, M., and B. Austin. 1980. Behaviour of experimental plant communities along a nutrient gradient. The Journal of Ecology 68(3):891-918.

Austin, M., R. Groves, L. Fresco, and P. Kaye. 1985. Relative growth of six thistle species along a nutrient gradient with multispecies competition. The Journal of Ecology 73(2):667-684.

Baldwin, S. J., and B. C. Husband. 2013. The association between polyploidy and clonal reproduction in diploid and tetraploid Chamerion angustifolium. Molecular Ecology 22:1806-1819.

Bret-Harte, M. S., G. R. Shaver, and F. S. Chapin. 2002. Primary and secondary stem growth in arctic shrubs: implications for community response to environmental change. Journal of Ecology 90:251-267.

Bryant, J., T. Clausen, P. Reichardt, M. McCarthy, and R. Werner. 1987. Effect of nitrogen fertilization upon the secondary chemistry and nutritional value of quaking aspen (Populus tremuloides michx.) leaves for the large aspen tortrix (Choristoneura conflictana walker). Oecologia 73:513-517.

Cacco, G., G. Ferrari, and G. Lucci. 1976. Uptake efficiency of roots in plants at different ploidy levels. The Journal of Agricultural Science 87:585-589.

Cavalier-Smith, T. 2005. Economy, speed and size matter: evolutionary forces driving nuclear genome miniaturization and expansion. Annals of Botany 95:147-175.

Chapin, F. S. 1980. The mineral nutrition of wild plants. Annual Review of Ecology and Systematics 11:233-260.

Chapin, F. S., III. 1991. Integrated responses of plants to stress. BioScience 41:29-36.

Chapin, F. S., E.-D. Schulze, and H. A. Mooney. 1990. The ecology and economics of storage in plants. Annual Review of Ecology and Systematics 21:423-447.

Christie, E., and J. Moorby. 1975. Physiological responses of semiarid grasses. I. The influence of phosphorus supply on growth and phosphorus absorption. Crop and Pasture Science 26:423-436.

Clein, J. S., and J. P. Schimel. 1995. Nitrogen turnover and availability during succession from alder to poplar in Alaskan taiga forests. Soil Biology and Biochemistry 27:743-752.

Dennis, J. G., and P. L. Johnson. 1970. Shoot and rhizome-root standing crops of tundra vegetation at Barrow, Alaska. Arctic and Alpine Research 2(4):253-266.

Doležel, J., J. Greilhuber, and J. Suda. 2007. Estimation of nuclear DNA content in plants using flow cytometry. Nature Protocols 2:2233-2244.

Eigsti, O. J. 1957. Induced polyploidy. Amercan Journal of Botany 44:272-279.

Evans, P. 1967. Aspects of growth and morphology of seedlings of diploid and tetraploid western wolths ryegrass: Lolium multiflorum lam. var. westerwoldicum. New Zealand Journal of Botany 5:203-210.

Fukuda, I. 1967. The biosystematics of Achlys. Taxon 2:308-316. 
Gordon, A. M., M. Tallas, and K. Van Cleve. 1987. Soil incubations in polyethylene bags: effect of bag thickness and temperature on nitrogen transformations and $\mathrm{CO}_{2}$ permeability. Canadian Journal of Soil Science 67:65-76.

Grime, J., and A. Curtis. 1976. The interaction of drought and mineral nutrient stress in calcareous grassland. The Journal of Ecology 64:975-988.

Hao, G. Y., M. E. Lucero, S. C. Sanderson, E. H. Zacharias, and N. M. Holbrook. 2013. Polyploidy enhances the occupation of heterogeneous environments through hydraulic related trade-offs in Atriplex canescens (Chenopodiaceae). New Phytologist 197:970-978.

Hickman, J. C. 1975. Environmental unpredictability and plastic energy allocation strategies in the annual Polygonum cascadense (Polygonaceae). The Journal of Ecology 63(2):689-701.

Huang, M. L., X. P. Deng, Y. Z. Zhao, S. L. Zhou, S. Inanaga, S. Yamada, and K. Tanaka. 2007. Water and nutrient use efficiency in diploid tetraploid and hexaploid wheats. Journal of Integrative Plant Biology 49:706-715.

Huenneke, L. F., S. P. Hamburg, R. Koide, H. A. Mooney, and P. M. Vitousek. 1990. Effects of soil resources on plant invasion and community structure in Californian serpentine grassland. Ecology 71:478-491.

Husband, B. C., and D. W. Schemske. 1997. The effect of inbreeding in diploid and tetraploid populations of Epilobium angustifolium (Onagraceae): implications for the genetic basis of inbreeding depression. Evolution 51(3):737-746.

Husband, B. C., and D. W. Schemske. 1998. Cytotype distribution at a diploid-tetraploid contact zone in Chamerion (Epilobium) angustifolium (Onagraceae). American Journal of Botany 85:1688-1694.

Ibrahim, M. H., H. Z. E. Jaafar, A. Rahmat, and Z. A. Rahman. 2011. Effects of nitrogen fertilization on synthesis of primary and secondary metabolites in three varieties of Kacip fatimah (labisia, pumila, blume). International Journal of Molecular Sciences 12:5238-5254.

Karn, J. F., A. B. Frank, J. D. Berdahl, and W. W. Poland. 2003. Water, nitrogen and ploidy effects on russian wildrye mineral concentrations. Journal of Range Management 56:534-541.

Kearns, C. A., and D. W. Inouye. 1993. Techniques for pollination biologists. University Press of Colorado, Niwot.

Kennedy, B. F., H. A. Sabara, D. Haydon, and B. C. Husband. 2006. Pollinator-mediated assortative mating in mixed ploidy populations of Chamerion angustifolium (Onagraceae). Oecologia 150:398-408.

Kielland, K., J. McFarland, R. Ruess, and K. Olson. 2007. Rapid cycling of organic nitrogen in taiga forest ecosystems. Ecosystems 10:360-368.

Leitch, I., and M. Bennett. 2004. Genome downsizing in polyploid plants. Biological Journal of the Linnean Society 82:651-663.

Levin, D. A. 2002. The role of chromosomal change in plant evolution. Oxford University Press.

Lewis Jr, W. M. 1985. Nutrient scarcity as an evolutionary cause of haploidy. American Naturalist 125:692-701. 
Liu, S., S. Chen, Y. Chen, Z. Guan, D. Yin, and F. Chen. 2011. In vitro induced tetraploid of Dendranthema nankingense (Nakai) Tzvel. shows an improved level of abiotic stress tolerance. Scientia Horticulturae 127:411-419.

Lumaret, R., J.-L. Guillerm, J. Delay, A. A. L. Loutfi, J. Izco, and M. Jay. 1987. Polyploidy and habitat differentiation in Dactylis glomerata L. from Galicia (Spain). Oecologia 73:436-446.

Maceira, N. O., P. Jacquard, and R. Lumaret. 1993. Competition between diploid and derivative autotetraploid Dactylis glomerata L. from Galicia. Implications for the establishment of novel polyploid populations. New Phytologist 124:321-328.

Maherali, H., E. W. Alison, and B. C. Husband. 2009. Genome duplication and the evolution of physiological responses to water stress. New Phytologist 184:721731.

Matson, P., K. A. Lohse, and S. J. Hall. 2002. The globalization of nitrogen deposition: consequences for terrestrial ecosystems. AMBIO: A Journal of the Human Environment 31:113-119.

Mattson Jr, W. J. 1980. Herbivory in relation to plant nitrogen content. Annual review of ecology and systematics 11:119-161.

Molin, W. T., S. P. Meyers, G. R. Baer, and L. E. Schrader. 1982. Ploidy effects in isogenic populations of alfalfa. II. Photosynthesis, chloroplast number, ribulose1,5-bisphosphate carboxylase, chlorophyll, and dna in protoplasts. Plant Physiology 70:1710-1714.

Mosquin, T., and E. Small. 1971. An example of parallel evolution in Epilobium (Onagraceae). Evolution 25(4):678-682.

Mulvaney, R., and D. Sparks. 1996. Methods of soil analysis. Part 3. Chemical methods. Soil Science Society of America Book Series 1123-1184 pp.

Rabalais, N. N. 2002. Nitrogen in aquatic ecosystems. AMBIO: A Journal of the Human Environment 31:102-112.

Ramsey, J. 2011. Polyploidy and ecological adaptation in wild yarrow. Proceedings of the National Academy of Sciences 108:7096-7101.

Schemske, D. W. 2000. Ecological mechanisms of reproductive isolation between diploid and tetraploid Chamerion angustifolium. Journal of Ecology 88:689-701.

Shaver, G. R., W. D. Billings, F. S. Chapin, A. E. Giblin, K. J. Nadelhoffer, W. C. Oechel, and E. Rastetter. 1992. Global change and the carbon balance of arctic ecosystems. BioScience 42(6):433-441.

Shaver, G. R., and F. S. Chapin. 1980. Response to fertilization by various plant growth forms in an Alaskan tundra: Nutrient accumulation and growth. Ecology 61:662675.

Shaver, G. R., F. C. Iii, and B. L. Gartner. 1986. Factors limiting seasonal growth and peak biomass accumulation in Eriophorum vaginatum in Alaskan tussock tundra. Journal of Ecology 74:257-278.

Šmarda, P., M. Hejcman, A. Březinová, L. Horová, H. Steigerová, F. Zedek, P. Bureš, P. Hejcmanová, and J. Schellberg. 2013. Effect of phosphorus availability on the selection of species with different ploidy levels and genome sizes in a long-term grassland fertilization experiment. New Phytologist 200:911-921. 
Storchová, Z., A. Breneman, J. Cande, J. Dunn, K. Burbank, E. O'Toole, and D. Pellman. 2006. Genome-wide genetic analysis of polyploidy in yeast. Nature 443:541-547.

Strauss, S. Y., J. K. Conner, and S. L. Rush. 1996. Foliar herbivory affects floral characters and plant attractiveness to pollinators: implications for male and female plant fitness. American Naturalist 147(6):1098-1107.

Suding, K. N., S. L. Collins, L. Gough, C. Clark, E. E. Cleland, K. L. Gross, D. G. Milchunas, and S. Pennings. 2005. Functional-and abundance-based mechanisms explain diversity loss due to $\mathrm{N}$ fertilization. Proceedings of the National Academy of Sciences 102:4387-4392.

Sutherland, S., and L. F. Delph. 1984. On the importance of male fitness in plants: patterns of fruit-set. Ecology 65:1093-1104.

Tamm, C. O. 1991. Nitrogen-limited and nitrogen-depleted terrestrial ecosystems: Ecological characteristics. pp 34-49. Nitrogen in terrestrial ecosystems. Springer.

Thompson, K. A., B. C. Husband, and H. Maherali. 2014. Climatic niche differences between diploid and tetraploid cytotypes of Chamerion angustifolium (Onagraceae). American Journal of Botany 101:1868-1875.

Tilman, D. 1982. Resource Competition and Community Structure. Monographs in Population Biology. Princeton University Press Princeton, NJ.

Tilman, D. 1986a. Evolution and differentiation in terrestrial plant communities: the importance of the soil resource: light gradient. Community Ecology. (eds J. Diamond \& T.J. Case), pp. 359-380. Harper and Row, New York.

Tilman, D. 1986b. Nitrogen-limited growth in plants from different successional stages. Ecology 67(2):555-563.

Tilman, D. 1987. Secondary succession and the pattern of plant dominance along experimental nitrogen gradients. Ecological Monographs 57:189-214.

Tilman, D. 1988. Plant strategies and the dynamics and structure of plant communities. Princeton University Press.

Tilman, D., and M. Cowan. 1989. Growth of old field herbs on a nitrogen gradient. Functional Ecology 3:425-438.

Van Cleve, K., R. Barney, and R. Schlentner. 1981. Evidence of temperature control of production and nutrient cycling in two interior Alaska black spruce ecosystems. Canadian Journal of Forest Research 11:259-274.

Van Cleve, K., W. C. Oechel, and J. L. Hom. 1990. Response of black spruce (Picea mariana) ecosystems to soil temperature modification in interior Alaska. Canadian Journal of Forest Research 20:1530-1535.

Vitousek, P. M., J. D. Aber, R. W. Howarth, G. E. Likens, P. A. Matson, D. W. Schindler, W. H. Schlesinger, and D. G. Tilman. 1997. Human alteration of the global nitrogen cycle: sources and consequences. Ecological Applications 7:737750.

Vitousek, P. M., S. Hättenschwiler, L. Olander, and S. Allison. 2002. Nitrogen and nature. AMBIO: A Journal of the Human Environment 31:97-101.

Wang, Z., M. Wang, L. Liu, and F. Meng. 2013. Physiological and proteomic responses of diploid and tetraploid black locust (Robinia pseudoacacia L.) subjected to salt stress. International Journal of Molecular Sciences 14:20299-20325. 


\section{Chapter 3: Effects of polyploidy and soil nitrogen availability on} the resistance and tolerance of Chamerion angustifolium to insect herbivory $^{2}$

\section{Introduction}

Plant-herbivore interactions are ubiquitous in natural populations, and consumption of plants by herbivores can have major impacts on community, landscape, ecosystem, and evolutionary dynamics (Harper 1968, Windle and Franz 1979, Strong et al. 1984, Adler et al. 2001, Poelman et al. 2008). Insect herbivores most often have negative fitness consequences for plants, but they can also have no or even positive fitness consequences (Wise and Abrahamson 2005). For example, insect herbivores often reduce plant fitness directly through the consumption of plant reproductive parts or indirectly through the consumption of leaf tissues and consequent reduction in resources (Kulman 1971, Rockwood 1973, Rausher and Feeny 1980, Marquis 1992). Plants have adapted two primary alternate strategies for reducing fitness losses caused by insect damage - resistance and tolerance. Resistance can be defined as the ability of plants to avoid damage by herbivores. Several traits associated with resistance to herbivory include the production of secondary defense compounds (plant chemicals used in the deterrence of herbivores; Mithöfer and Boland 2012) and structural leaf features (e.g. thorns, trichomes, leaf toughness; Rausher and Feeny 1980, Coley 1983, Karban and Myers

\footnotetext{
${ }^{2}$ The material in this chapter is planned for submission
} 
1989) have been shown to limit damage. In contrast, tolerance is defined as the ability to maintain fitness and growth despite herbivore damage (Simms and Triplett 1994, Tiffin and Rausher 1999). The relative tolerance of plants to herbivore damage can be described by the degree to which plants are able to compensate for damaged tissue. For example, undercompensation occurs when damaged plants experience a reduction in fitness relative to when they are not damaged (i.e. low tolerance), full compensation occurs when plants have equal fitness when damaged, and overcompensation occurs when plants have improved fitness when damaged (i.e. high tolerance). Although a range of tolerance responses has been observed (Stowe et al. 2000, Núñez-Farfán et al. 2007), overcompensation most often occurs following mammal grazing, due to an associated release of apical dominance and subsequent branching (McNaughton 1979, Paige and Whitham 1987, Gronemeyer et al. 1997, Haukioja and Koricheva 2000). Tolerance has been associated with several mechanisms including (1) a plastic photosynthetic rate that is upregulated after damage (Meidner 1970, Detling et al. 1979, Trumble et al. 1993, Strauss and Agrawal 1999), (2) a high proportion of root biomass to shoot biomass that provides large stores of resources for regrowth (Briske et al. 1996, Mabry and Wayne 1997, Strauss and Agrawal 1999), (3) a high relative growth rate (Detling et al. 1979, Oba et al. 2000), (4) and increased branching following removal of apical dominance (Paige and Whitham 1987, Haukioja and Koricheva 2000).

Plant resistance and tolerance to herbivory are alternative strategies for reducing fitness losses caused by herbivore attack, and therefore, it is generally thought that interand intraspecific trade-offs occur between these two strategies (Strauss and Agrawal 
1999, Leimu and Korecheva 2006). For example, the effects of nutrient availability on plant responses to herbivory may differentially favor resistance over tolerance or vice versa (Hamilton et al. 2001, Wise and Abrahamson 2007). Plants that are grown under nitrogen-poor conditions often have high carbon:nitrogen ratios (Chapin 1980), a trait that, in some cases, is positively associated with carbon-based secondary defense compounds and plant resistance to herbivory (Bryant et al. 1987, Ibrahim et al. 2011). In contrast, plants grown in nutrient-poor conditions have inadequate resources for regrowing and maintaining fitness following herbivore attack and can be less tolerant of damage than plants grown in nutrient-rich environments (compensatory continuum hypothesis; Maschinski and Whitham 1989). Additional factors that can affect resistance and tolerance patterns to herbivore damage include a plant's phenological age at the time of attack (Kearsley and Whitham 1989, Boege 2005, Boege and Marquis 2005), the region of plant that is attacked (Mutikainen et al. 1996, Fordyce and Agrawal 2001), water availability (Cox and McEvoy 1983), and genetic variability within and between populations (Fritz and Simms 1992).

Despite an abundance of data describing the resistance (Fritz and Simms 1992, Brodbeck et al. 2001, Behmer et al. 2002, Mithöfer and Boland 2012) and tolerance (Strauss and Agrawal 1999, Stowe et al. 2000, Haukioja and Koricheva 2000, Boege 2005) responses of a variety of different plant groups in different environments, we still do not have a good understanding of how plant-insect interactions are influenced by the polyploidization of plants. Polyploidy is the possession of more than two complete sets of chromosomes. It is common in plants from both natural (estimated 35\% of vascular 
plants; Wood et al. 2009) and agricultural (estimated 65\% of all crop species; Hilu 1993) systems and is thought to have played a major role in the evolution and diversification of plants (estimated $15 \%$ of all flowering plant speciation events accompanied by an increase in ploidy; Wood et al. 2009). Polyploidy occurs predominantly through interspecific hybridization (allopolyploidy) but also occurs through intraspecific genome duplication (autopolyploidy). Polyploid plants often differ in their morphological, physiological, and chemical characteristics relative to closely related diploids (Dhawan and Lavania 1996, Levin 2002, Ramsey and Schemske 2002, Arvanitis et al. 2007), and these phenotypic differences between ploidal races (cytotypes) could influence plantinsect interactions (Thompson et al. 1997, Janz and Thompson 2002, Halverson et al. 2008, Arvanitis et al. 2010, Münzbergová et al. 2015). For example, polyploids often have greater concentrations of secondary defense compounds (reviewed in Dhawan and Lavania 1996), and thus may be more resistant to herbivore damage than diploids. In contrast, polyploids often grow more slowly than related diploids (Noguti et al. 1940, Von Well and Fossey 1998, Otto and Whitton 2000), and this could render them less tolerant of damage (Detling et al. 1979, Oba et al. 2000). Nonetheless, contrasting studies have shown that polyploids can be more, less, or equally resistant and tolerant to damage by insect herbivores (Thompson et al. 1997, Halverson et al. 2008, Boalt et al. 2010, König et al. 2014a). Perhaps some of these contrasting results are influenced by other abiotic or biotic factors that affect responses to damage. For example, polyploids are thought to require greater amounts of soil nutrients in order to synthesize their larger genomes (Lewis Jr 1985, Leitch and Bennett 2004, Cavalier-Smith 2005), and so 
polyploids might be even less tolerant of herbivore damage than diploids in nutrient-poor soils. In order to better understand the role of polyploidy in plant-insect interactions, more studies using a variety of polyploid species and environmental conditions are needed.

In this study, we used Chamerion angustifolium (fireweed), an autopolyploid herbaceous perennial plant species, to examine the effects of genome duplication and soil nitrogen availability on plant resistance and tolerance to insect herbivore damage. By studying an autopolyploid relative to its related diploid, we are able to examine the effects of genome doubling while removing the confounding effects of interspecific genome combinations seen in allopolyploids. Fireweed is distributed throughout much of the northern hemisphere, and it consists mostly of diploid $(2 \mathrm{n}=2 \mathrm{x}=36)$ and tetraploid $(2 n=4 x=72)$ cytotypes, although triploid cytotypes with reduced fertility and viability occur in low proportions (Burton and Husband 2000). Historical census data in North America shows that diploids generally occupy more extreme northern latitudes, tetraploids occupy more southern latitudes, and a broad mixed-ploidy zone occurs in the middle (Fig. 3.1, redrawn from Mosquin and Small 1971). Interestingly, we more recently found that tetraploid fireweed is more common than diploids in interior Alaska (Chapter 2, Fig. 3.1), perhaps suggesting that autotetraploids might be replacing diploid cytotypes. Fireweed is a model system for studying the physiological (i.e. drought tolerance and inbreeding depression; Husband and Schemske 1997, Maherali et al. 2009), and ecological (e.g. pollinator visitation; Husband And and Schemske 2000, Kennedy et al. 2006), consequences of autopolyploidy. Although insects are readily seen on fireweed 
plants in natural populations, and fireweed is known to contain high concentrations ellagitannins (a class of carbon-based secondary metabolites that are effective at curtailing herbivory by insects; Yoshida et al. 2010, Salminen and Karonen 2011), we do not know whether diploids and autotetraploids have similar resistance and tolerance responses to herbivory. Soil nitrogen availability has been shown to influence the relative growth, fitness, and resource allocation strategies of diploid and tetraploid fireweed (Chapter 1) and is also known to influence tolerance and resistance patterns in other species (Bryant et al. 1983, Coley et al. 1985, McNaughton and Chapin 1985, Hawkes and Sullivan 2001), but it is unclear how these factors may interact to regulate the resistance and tolerance responses of fireweed cytotypes. Here, we used several methods to examine whether polyploidy and soil nitrogen availability influence (1) fireweed resistance and tolerance responses to herbivory and (2) traits that are often associated with plant resistance and tolerance to herbivory. 


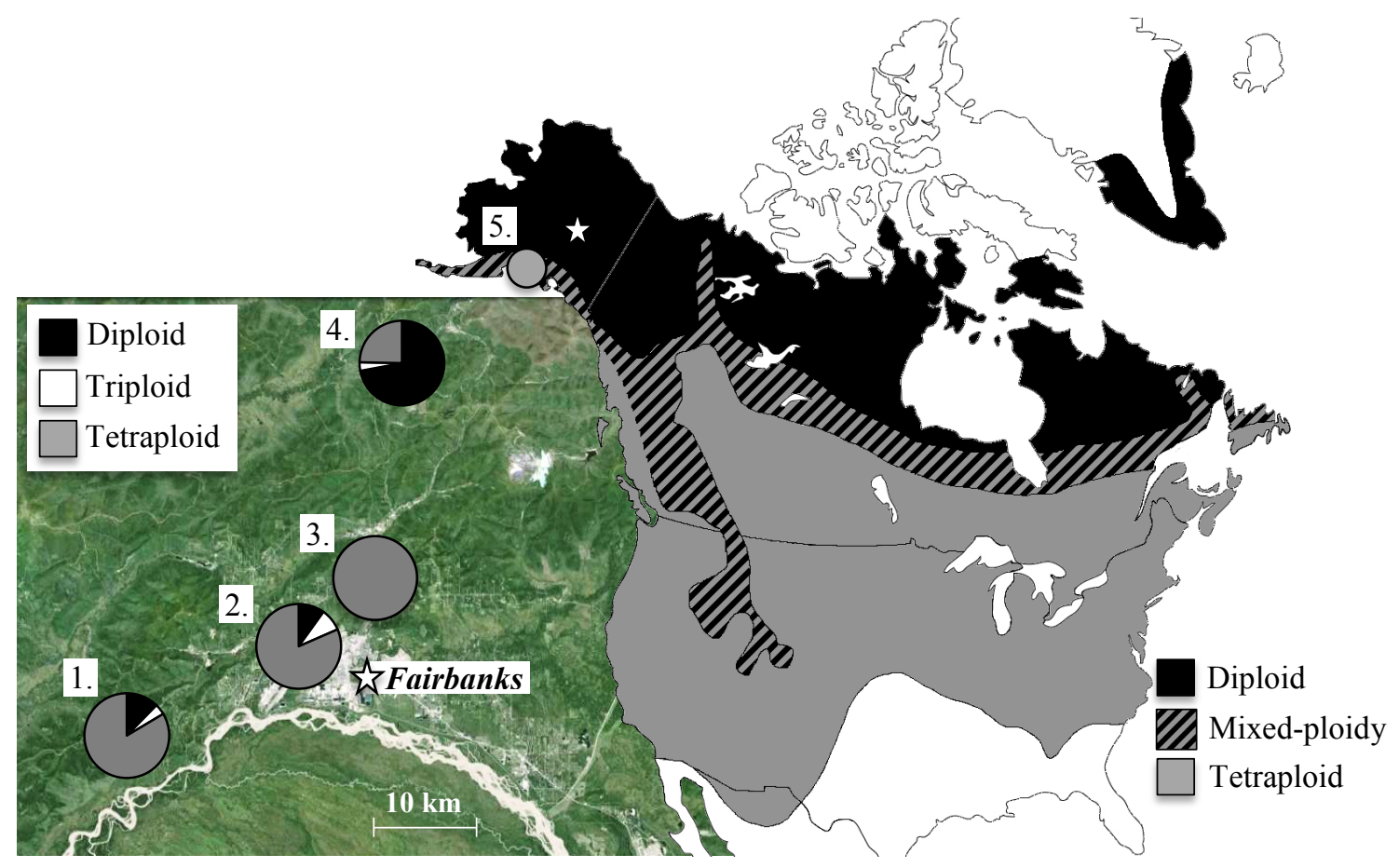

Fig. 3.1: Putative distribution of diploid and tetraploid fireweed throughout North America (right; redrawn from Mosquin and Small 1971). The star is Fairbanks, Alaska and serves as a reference point to the location of fireweed sampling locations (left). Pie charts represent the relative proportion of 684 plants sampled in August 2013 and 2014 (196 diploid, 26 triploid and 462 tetraploid plants). Plants were collected from five general areas: (1) Bonanza Creek Long-term Ecological Research Site, (2) the University of Alaska Fairbanks trail system, (3) Dog Mushers Association Park, (4) the Caribou-Poker Creek Research Watershed, and (5) Southern Alaska, an area spanning Anchorage to Seward AK (see Appendix 1 for location and sampling details). Seeds collected from sites 1,2, and 4 were used to generate plants used in greenhouse experiments. Map data (C2015 Google. 


\section{Methods}

Plant material. - In summer 2013 and 2014, we collected diploid and tetraploid fireweed seeds from mixed-ploidy populations throughout three sites in interior Alaska (Bonanza Creek Experimental Forest, Caribou-Poker Creek Research Watershed, and University of Alaska Fairbanks trail system; Fig. 3.1). In fall 2013 and 2014, we grew plants from field collected seeds in the Michigan Technological University greenhouses (MTU; Dept. of Biological Sciences, Houghton, MI) to create genetic lines of known parentage to be used in greenhouse experiments of resistance and tolerance. We first determined the ploidy level of each plant at the rosette stage of growth using flow cytometry to estimate DNA content (see methods in Baldwin and Husband 2013 and Chapter 1); in fireweed, DNA content is highly correlated with the number of chromosomes per cell and ploidy level (Burton and Husband 2000). Then, once plants began flowering, we hand cross-pollinated plants within each cytotype by applying two anthers worth of pollen to each stigma of several flowers per plant to generate diploid and tetraploid full sibling genetic lines. Growing all parental plants in the same environment for one generation also allowed us to minimize any possible maternal effects imposed by different environmental conditions in the field that could potentially confound our results (Roach and Wulff 1987). We selected 34 of these genetic lines to be used in two different greenhouse studies. In greenhouse study \#l (October 2014 to January 2015), we grew 18 plants from each of 7 diploid and 7 tetraploid genetic lines and divided them evenly into one of three soil $\mathrm{N}$ treatments ( 2 ploidy levels $\times 3$ soil $\mathrm{N}$ treatments $\times 7$ genetic lines $\times 6$ replicates $=252$ plants total). Each plant in study $\# 1$ received a total of 2, 20, or $200 \mathrm{mg}$ 
of $\mathrm{N}$ (low, medium, high soil $\mathrm{N}$ treatments, respectively). In greenhouse study \#2 (March 2015 to July 2015), we grew 12 plants from each of the remaining 10 diploid and 10 tetraploid genetic lines and divided them evenly into one of two soil $\mathrm{N}$ treatments $(2$ ploidy levels $\times 2$ soil $\mathrm{N}$ treatments $\times 10$ genetic lines $\times 6$ replicates $=240$ plants total). Each plant in study $\# 2$ received a total of 1 or $100 \mathrm{mg}$ of $\mathrm{N}$ (low and high soil $\mathrm{N}$ treatments, respectively). For both study $\# 1$ and study $\# 2$, we began administering soil $\mathrm{N}$ treatments approximately three weeks after seeds germinated. We supplied fertilizer once per week for three weeks as a prepared nitrogen-phosphorous-potassium (NPK) solution, wherein plants received $\mathrm{N}$ supplied as ammonium nitrate, plus $2.5 \mathrm{mg}$ of phosphorous and $40 \mathrm{mg}$ of potassium supplied as potassium monophosphate and potassium sulfate. We also supplied micronutrients to each plant as $0.615 \mathrm{~mL}$ Fertilome Chelated Liquid Iron and Other Micronutrients (Voluntary Purchasing Groups, Inc., Bonham, TX).

\subsection{Plant resistance}

Resistance is defined as the ability of plants to defer damage (Fritz and Simms 1992); plants that experience more damage are considered less resistant. We used leaf bioassays and estimates of insect damage to whole plants to examine whether ploidy, soil $\mathrm{N}$ treatment, and/or a ploidy $\times$ soil $\mathrm{N}$ treatment interaction (hereafter referred to as " $\mathrm{P} \times$ $\mathrm{N}$ interaction") affected plant resistance to generalist insects. 
No-choice and choice bioassays. - No-choice bioassays can provide an absolute measure of plant resistance, while choice bioassays can provide a measure of how differences in plant resistance might alter feeding choices of insects (Behmer et al. 2002, Mcguire and Johnson 2006). For all bioassays, we used a generalist leaf-chewing herbivore, Spodoptera exigua (army beet worm), which we reared from eggs at $28.5^{\circ} \mathrm{C}$ in containers with supplied food (eggs and media from Benzon Research, Carlisle PA). In December 2014, we used excised leaves from plants in study $\# 1$ for the no-choice bioassay and the choice bioassay \#1 trials (a total of 252 no-choice and 126 choice bioassays). In May 2015, we used excised leaves from study \#2 plants for the choice bioassay \#2 trials (a total of 120 bioassays). For all trials, we sampled leaves from the upper-third region of each plant (one leaf per bioassay) approximately eight weeks after germination. For the no-choice bioassay, we placed a second instar larva into a $60 \mathrm{~mm}$ petri dish with moistened filter paper and a single leaf. For both choice bioassay \#l and \#2, we placed a single third-instar larva into the center of a $60 \mathrm{~mm}$ petri dish with a moistened filter paper plus a diploid and tetraploid leaf from the same soil $\mathrm{N}$ treatment. We cut each leaf into a four $\mathrm{cm}^{2}$ rectangle to control for differences in leaf size, because tetraploids generally have bigger leaves than diploids (mean length $\times$ width \pm 1 SE equal to $21.89 \pm 0.95 \mathrm{~cm}^{2}$ and $37.00 \pm 1.68 \mathrm{~cm}^{2}$ for diploids' and tetraploids' largest leaf, respectively; unpublished data), and we thought this could influence insect feeding choice. After placing larvae in petri dishes, we sealed the petri dishes with Parafilm and allowed larvae to feed for 40 hours. To estimate the amount of leaf area consumed, we measured leaf area immediately before and after feeding by scanning leaves with a 
computer scanner and estimating leaf area with image processing software (ImageJ version 1.48; Rasband, W.S., US National Institutes of Health, Bethesda, MD, USA). For the no-choice bioassay, we calculated the total leaf area consumed by subtracting the post-feeding leaf area from the pre-feeding leaf area. For the choice bioassays, we calculated the percent leaf area consumed by dividing the post-feeding leaf area by the pre-feeding leaf area. We did not calculate the percent leaf area consumed for the nochoice bioassay because leaf sizes varied between samples, which would inherently influence the calculated percentage value.

To examine damage patterns when insects were not given a choice between leaf material (no-choice bioassay), we used a partially nested ANOVA to examine the effects of ploidy $(2 \mathrm{x}, 4 \mathrm{x})$, soil $\mathrm{N}$ treatment (low, medium, high), $\mathrm{P} \times \mathrm{N}$ interaction, and genetic line (a fixed effect nested within ploidy) on the total leaf area consumed by S. exigua. To assess damage patterns when insects were given a choice between plants to consume (choice-bioassays), we analyzed the results in two ways. First, using the results from our choice bioassay \#1 (3 nitrogen levels), we used a matched-pairs t-test to examine (1) whether differences between diploid and tetraploids in the percent leaf area consumed were significantly different from zero, (2) whether soil $\mathrm{N}$ treatment had an effect on percent leaf area consumed, and (3) whether any observed ploidal differences were dependent on soil $\mathrm{N}$ treatment (i.e. a significant $\mathrm{P} \times \mathrm{N}$ interaction). Second, because we had sampled leaves to examine carbon and nitrogen content at the same time that we collected leaves for the choice bioassay \#2, we were able to directly assess whether leaf nitrogen content influenced insect feeding (rather than nitrogen treatment). To do this we 
used an analysis of covariance (ANCOVA) with ploidy, the percentage of nitrogen in leaves $(\% \mathrm{~N})$, ploidy $\times \% \mathrm{~N}$, and genetic line (fixed effect nested within ploidy) as model effects and the percent leaf area consumed in choice-bioassay \#2 as the response variable.

Resistance to a naturally occurring herbivore. - Interestingly, during study \#1, we observed that plants were being damaged by Frankliniella occidentalis (flower thrip), a common insect invader of greenhouses that feeds on plants by penetrating leaves and/or pollen grains and ingesting cellular contents (Kindt et al. 2003). During the fifteenth week of growth, just before plants began senescing, we estimated resistance to thrip damage by visually scoring each plant for the percentage of total leaf area damaged on an ordinal scale, where $0=0 \% ; 1=1-2 \% ; 2=3-5 \% ; 3=6-10 \% ; 4=11-20 \% ; 5=$ greater than $20 \%$ leaf damage respectively. We used ordinal logistic regression to examine whether ploidy, soil $\mathrm{N}$ treatment, $\mathrm{P} \times \mathrm{N}$ interaction, genetic line (fixed effect nested in ploidy), and the total number of flowers produced influenced the severity of damage by thrips (ordinal metric). Total number of flowers was used as a covariate because thrips feed on pollen grains (Lewis 1997), and thus plants that produced more flowers might be more likely to attract thrips. 
Resistance to caged S. exigua. - Using plants from study \#2, we examined whether ploidy and/or soil N treatment influenced resistance to S. exigua larvae by directly caging insects onto plants (See Fig. 3.2 for general experimental design details). We randomly selected two diploid and two tetraploid plants from all genetic lines in both low and high soil $\mathrm{N}$ treatments (total of 40 diploid and 40 tetraploid plants) and placed two third-instar larvae directly onto nine-week old plants. We wrapped plants in mesh bags to prevent larvae from escaping, allowed larvae to feed for 60 hours, and removed the larvae and bags from the plants. We scored damage by (1) calculating total leaf area consumed by S. exigua larvae per plant and (2) estimating the percentage of leaf area consumed by S. exigua larvae in the upper and the lower half of each plant. To calculate total leaf area consumed, we photographed (with a scale) all damaged leaves on a plant and analyzed photos with ImageJ (Rasband, W.S., US National Institutes of Health, Bethesda, MD, USA). To estimate percent leaf area consumed, we visually divided each plant into an upper and lower half and estimated the percentage of leaf area that was consumed by S. exigua larvae. Because the phenological age of plants has been shown to influence resistance patterns (Kearsley and Whitham 1989, Scheirs et al. 2002), we measured plant phenology at the time of caged-insect trials to be used as a covariate in subsequent analyses. We scored phenology on an ordinal scale of increasing developmental age, where $1=$ rosette; $2=$ elongated stem; $3=$ green flower buds, $4=$ mature flower buds; $5=$ at least one open flower; $6=$ at least one fruit. To examine whether ploidy, leaf nitrogen content, phenology, or genetic line influenced resistance patterns of plants in caged-insect trials, we used partially nested ANCOVA models with 
the effects of ploidy, $\% \mathrm{~N}$, ploidy $\times \% \mathrm{~N}$ interaction, genetic line (fixed effect nested within ploidy), and phenology on (1) the total leaf area consumed (square-root transformed) by S. exigua and (2) the percent leaf area consumed $(\log (y+1)$ transformed) by S. exigua in the upper and the lower portions of plants; transformations were necessary to meet model assumptions.



Fig. 3.2: Experimental design of study $\# 2$ showing in parentheses the number of plants from each ploidy $(2 \mathrm{x}, 4 \mathrm{x})$, soil $\mathrm{N}$ treatment (low, high), damage (damaged, control), and type of damage (artificial, artificial + insect damage) treatment. 


\subsection{Plant resistance traits}

We measured three traits that have all been found to be positively associated with plant resistance to insect damage (ellagitannin content, carbon:nitrogen ratio, and leaf mass per area). We tested whether these traits are related to patterns of resistance in fireweed and whether any observed relationship is dependent upon ploidy and/or soil $\mathrm{N}$ treatment. We also measured trichome density as a forth resistance trait, but found that fireweed plants in our study did not contain any trichomes.

Ellagitannins are a group of carbon-based plant secondary metabolites that occur in high concentrations in fireweed (Yoshida et al. 2010) and are highly effective at limiting damage by insect herbivores (i.e., ellagitannin content is negatively correlated with damage, Salminen and Karonen 2011). Plant carbon to nitrogen ratio (C:N ratio) can be indicative of the total relative carbon-based secondary defense compounds in plants and the nutrients available to insects, as plants with a higher $\mathrm{C}: \mathrm{N}$ ratio are thought to have higher concentrations of carbon-based secondary defense compounds relative to nitrogen (Bryant et al. 1983, Ibrahim et al. 2011). We predicted that plants with higher C:N ratios and higher concentrations of ellagitannins would experience less damage during herbivore feeding trials and that plant $\mathrm{C}: \mathrm{N}$ ratio would be positively correlated with ellagitannin content.

To measure C:N ratio and ellagitannin content, we collected and immediately froze 4-5 leaves in liquid $\mathrm{N}$ from the upper-third region of half of the plants from study \#2 (three plants per genetic line per soil $\mathrm{N}$ treatment per ploidy level) during the choice 
bioassay $\# 2$, freeze-dried them, and ground them to a fine powder with a ball mill. We used an elemental analyzer (ECS 4010, Costech Analytical Technologies Inc., Valencia, CA) to measure plant carbon and nitrogen content at MTU (School of Forest Resources and Environmental Science, Houghton, MI). Ellagitannin content is being measured in the Natural Chemistry Lab at the University of Turku (Dept. of Chemistry, Turku, Finland) following published methods (Salminen et al. 1999). Data on ellagitannins are pending and not included in this thesis.

We estimated leaf toughness, a trait that has been found to be positively associated with resistance to herbivory (Rausher and Feeny 1980, Coley 1983), by estimating leaf mass per area (LMA - grams of leaf per square meter of leaf; Westoby et al. 2002). A higher LMA indicates a tougher leaf, and so we predicted that leaves with higher LMA would experience less damage during herbivore feeding trials than leaves with lower LMA. To measure LMA, we used the remaining portions of leaf material that were used in cutting the $4 \mathrm{~cm}^{2}$ rectangles for choice bioassays $\# 2$ to measure leaf surface area with Image J (Rasband, W.S., US National Institutes of Health, Bethesda, MD, USA), dried and weighed leaves to obtain leaf dry weight and calculated LMA as the grams of leaf material per meter squared.

To examine whether ploidy, soil $\mathrm{N}$ treatment, and/or genotype affected plant C:N ratio and/or leaf toughness (LMA), we used ANOVA models with ploidy, soil N treatment, $\mathrm{P} \times \mathrm{N}$ interaction, and genetic line (fixed effect nested in ploidy) as model effects and C:N ratio and LMA as response variables. To analyze whether C:N ratio and or LMA influenced resistance to herbivore damage, we first tested for multicollinearity 
among variables and found that $\mathrm{C}: \mathrm{N}$ ratio and LMA were not highly correlated $(\mathrm{r}=0.74)$, and thus, we were able to analyze the effects of these variables separately. To examine whether $\mathrm{C}: \mathrm{N}$ ratio and/or LMA affected damage, we only used estimates of damage from the choice bioassay \#2 trial and the upper portion of plants from caged insect trials because these two damage estimates, $\mathrm{C}: \mathrm{N}$ content, and LMA were all estimated from the upper portion of the same plants. Because both $\mathrm{C}: \mathrm{N}$ ratio and LMA are significantly correlated with soil $\mathrm{N}$ treatment $\left(\mathrm{C}: \mathrm{N}-\mathrm{t}_{117}=3.05, P=0.003 ; \mathrm{LMA}-\mathrm{t}_{231}=1.90, P=\right.$ 0.030), we ran models separately for low and high soil $\mathrm{N}$ treatments. To examine whether plants with a higher $\mathrm{C}: \mathrm{N}$ ratio were less likely to be damaged than plants with a lower $\mathrm{C}: \mathrm{N}$ ratios at both low and/or high soil $\mathrm{N}$, we used separate ANOVA models that included plants from either soil $\mathrm{N}$ treatment and contained ploidy, $\mathrm{C}: \mathrm{N}$ ratio, ploidy $\times$ $\mathrm{C}: \mathrm{N}$ ratio interaction, and genetic line (fixed effect nested in ploidy) as model effects and percent leaf area consumed in choice bioassay \#2 (square-root transformed) and percent leaf area consumed in the upper portion of plants during caged insect trials $(\log (y+1)$ transformed the) as response variables. To examine whether plants with tougher leaves (higher LMA) were less likely to be damaged than plants with a lower LMA at both low and/or high soil N, we used separate ANOVA models that included plants from either soil $\mathrm{N}$ treatment and contained ploidy, LMA, ploidy $\times$ LMA interaction, and genetic line (fixed effect nested in ploidy) as model effects and percent leaf area consumed in choice bioassay \#2 (square-root transformed) and percent leaf area consumed in the upper portion of plants during caged insect trials $(\log (y+1)$ transformed the $)$ as response variables. 


\subsection{Plant tolerance}

Plant tolerance is defined as the ability of plants to regrow and/or maintain fitness following damage by herbivores (Marquis 1992, Strauss and Agrawal 1999). We compared the growth and fitness of insect-damaged and undamaged fireweed from the same genetic line to examine whether tolerance to herbivory is influenced by ploidy and/or soil $\mathrm{N}$ availability. We selected 80 plants that we exposed to 60 hours of feeding by two third-instar S. exigua larvae (two plants from each genetic line from both soil N treatments; see resistance to caged S. exigua methods above). After insect feeding, we also artificially damaged these plants (treatment $=$ insect + artificial damage). In addition, we artificially damaged an additional 40 plants (one plant from each genetic line in both soil $\mathrm{N}$ treatments; treatment $=$ artificial damage); both of the insect + artificial damage and the artificial damage treatments represented the damage treatment (see Fig. 3.2 for experimental design). We artificially damaged plants using a six-millimeter diameter hole punch to obtain a total of $35 \%$ foliar removal per plant, and this level of damage represents the average level of herbivory experienced by plants observed at field sites in Alaska in 2013 (Hersch-Green, unpublished data). We avoided damaging the main central leaf vein, which S. exigua does not typically damage (A. Bales, personal observation). We used a combination of insect and artificial damage on plants to standardize the level of insect damage experienced by all damage treatment plants and to examine whether there was a difference in plant responses to insect versus artificial damage. Several studies have shown that insect damage can illicit different plant responses than artificial damage (Capinera and Roltsch 1980, Baldwin 1988, Tiffin and 
Inouye 2000, Karban and Baldwin 2007). Standardizing damage levels also enabled us to measure tolerance without the confounding issues of resistance (van der Meijden et al. 1988). Trade-offs between resistance and tolerance are thought to occur, whereby plants are either highly resistant to damage but have low tolerance, or plants are not resistant to damage but are highly tolerant of damage (van der Meijden et al. 1988); both strategies have comparable fitness. A total of 120 plants received no damage and served as the control group (three plants from each of 10 diploid and 10 tetraploid genetic lines per soil $\mathrm{N}$ treatment, See Fig. 3.2 for experimental design). Plants from the control group were wrapped in mesh bags for 60 hours (similarly to plants exposed to insect feeding) to test for any unintended effects that bagging may have had on tolerance measures.

We measured six components of plant fitness (total seed production, total flower production, viable pollen production, percent pollen viability, root bud production, and aboveground plant dry biomass) on all plants. To estimate seed production, (a proxy for female fitness; Strauss et al. 1996), we outcross-pollinated all flowers produced; crosses were done within the same ploidy, soil N, and damage treatments. We only outcrossed plants because diploid and tetraploid fireweed differ in their relative inbreeding depression (i.e. reduction in fitness when selfed; Husband and Schemske 1997), which could impact estimates of the effects of damage on seed production. For each flower, we applied two anthers worth of pollen evenly onto the four lobes of the stigma, collected fruits as they began to dehisce, and counted the total number of seeds per plant using a Pfueffer Contador 2 seed counter (Pfueffer GmbH, Kitzingen, Bavaria, Germany). We counted the total number of flowers produced per plant over the course of the experiment 
to determine flower production, (a proxy for male fitness; Sutherland and Delph 1984). We estimated percentage pollen viability (proxies for male fitness; Strauss et al. 1996) by collecting one anther near dehiscence from two flowers on each plant, allowing them to dehisce, suspending them in $400 \mu 1$ of lactophenol blue (a stain that only turns pollen grains blue when they are viable; Kearns and Inouye 1993, page 111), and counting the average percentage of viable pollen grains out of total pollen grains in two $10 \mu 1$ subsamples. Plant biomass was estimated by harvesting plants immediately following collection of all fruits (at approximately 16 weeks of growth), separating the above and belowground portions of plants, drying them $65^{\circ} \mathrm{C}$, and weighing each. During plant harvest, we counted the total number of root buds per plant, which are structures capable of generating new independent shoots as a means of clonal reproduction and are visually differentiated from root initials by their elongated vertical structure and leaf primordia (Baldwin and Husband 2013).

To examine tolerance, we first used t-tests to examine whether artificially damaged plants and insect + artificially damaged plants differed in their fitness responses, and found no difference between damage types for any fitness component (all $\mathrm{P}>0.50$ ). Therefore we combined damage treatments for subsequent analysis. We estimated tolerance to herbivore damage using a reaction norm approach, in which tolerance is equal to the least squares slope of the regression of fitness on the level of damage (Simms and Triplett 1994, Strauss and Agrawal 1999, Tiffin and Rausher 1999). We used five fitness measures (biomass, flower production, seed production, viable pollen production, and root bud production) and two levels of damage (damage and 
undamaged) for slope calculations (i.e. measures of tolerance). For each fitness measure, we calculated the mean fitness of plants from each genetic line within each soil $\mathrm{N}$ and damage treatment (mean of three plants per genetic line per soil $\mathrm{N}$ treatment per damage treatment) and calculated tolerance as the slope of the regression of fitness on the level of damage using the following equation,

$$
\text { Tolerance }=T=\frac{\bar{W}(\text { damaged })-\bar{W}(\text { undamaged })}{0.35-0}
$$

where $\bar{W}$ refers to an the average fitness of each genetic line in the damaged and undamaged treatments. The denominator reflects the difference in levels of damage between the damage and control treatments. In total, we calculated 40 slopes (measures of tolerance; 20 genetic lines at each of two soil $\mathrm{N}$ treatments) for the five different fitness measures. We determined whether plants responded to damage with (1) full compensation (FC) for herbivory (i.e. damaged plants have equal fitness to undamaged plants, $T=0=\mathrm{FC}$ ), (2) undercompensation (U) for herbivory (i.e. damaged plants have lower fitness than undamaged plants, $T<0=\mathrm{U}$ ), or overcompensation (O) for herbivory (i.e. damaged plants have higher fitness than undamaged plants, $T>0=0$ ). We used two-way ANOVAs to test whether ploidy, soil $\mathrm{N}$ treatment, and/or an interaction between ploidy and soil $\mathrm{N}$ treatment influenced tolerance responses (biomass, flower production, seed production, viable pollen production, and root bud production). 


\subsection{Plant tolerance traits}

Plant photosynthetic rate and shoot:root ratio are traits thought to be associated with plant tolerance to insect herbivory (Strauss and Agrawal 1999). We measured both of these traits to test (1) whether they are influenced by ploidy and/or soil $\mathrm{N}$ treatments, (2) whether they are correlated with observed patterns of fireweed tolerance, and (3) whether any such correlation with tolerance is influenced by ploidy and/or soil $\mathrm{N}$ treatment.

Plant photosynthetic rate. - In some plants, herbivory has been shown to increase the maximum rate at which leaves are able to fix carbon during photosynthesis $\left(A_{\max }\right)$, which may allow these damaged plants to more effectively replace damaged tissues and better compensate for herbivory (Detling et al. 1979, Trumble et al. 1993, Strauss and Agrawal 1999). We measured the plasticity of $A_{\max }$ by measuring $A_{\max }$ on 80 plants (one plant from each genetic line from both soil $\mathrm{N}$ and damage treatments) using a LI-COR 6400 portable gas exchange system (LI-COR Inc., Lincoln, Nebraska). Leaf temperature was set at $24-25^{\circ} \mathrm{C}$, humidity at $60-65 \%$, and light intensity from the LI-COR system's LED at $1400 \mu \mathrm{mol}$ photons $\cdot \mathrm{m}^{-2} \cdot \mathrm{s}^{-1}$. We took measurements on the most recently fullyexpanded leaf of each plant, and only undamaged portions of leaves from plants in the damage treatment were used. For each measurement, we placed a single leaf into the chamber, waited for the photosynthetic rate to stabilize, and recorded the $\mathrm{A}_{\max }$ value. Plants from the same genetic line, soil $\mathrm{N}$ treatment, but different damage treatment were measured consecutively to control for variation in $\mathrm{A}_{\max }$ caused by the time of day and 
amount of sunlight, which can influence $\mathrm{A}_{\max }$ (A. Bales, personal observation). These measurements were repeated for the same plants at five different temporal intervals (immediately prior to feeding by S. exigua, plus 12 , plus 36 , plus 84 , and plus 132 hours after insects were removed from caged plants).

In order to examine whether ploidy and/or the percentage of $\mathrm{N}$ in leaves influenced the plasticity of $\mathrm{A}_{\max }$ following damage, we first standardized $\mathrm{A}_{\max }$ measurements to account for inherent variation caused by the time of day and the date of measurement. We standardized values by calculating the difference in $\mathrm{A}_{\max }$ between damaged and undamaged plants from the same genetic line and soil $\mathrm{N}$ treatment. Here, a positive value indicates that plants responded to herbivory with an increased $A_{\max }$, while a negative value indicates that plants responded to damage with a reduced $\mathrm{A}_{\max }$. To examine whether ploidy, $\% \mathrm{~N}$ in leaves, and/or the interaction between ploidy and $\% \mathrm{~N}$ influenced plasticity in photosynthetic capacity $\left(\mathrm{A}_{\max }\right)$, we used multivariate analysis of covariance (MANCOVA) for repeated measures with time of measurement (pre-feeding, plus 12 , plus 36 , plus 84 , and plus 132 hours) as the repeated measure. To examine whether a higher initial $\mathrm{A}_{\max }$ (prior to damage) was indicative of higher tolerance, and whether such a relationship is influenced by ploidy and/or $\% \mathrm{~N}$ in leaves, we first averaged $A_{\max }$ values recorded immediately prior to administering insect damage within each genetic line for both soil $\mathrm{N}$ treatments ( 2 plants per genetic line in each soil $\mathrm{N}$ treatment). Next, we tested for factors contributing to measures of plant tolerance (biomass, seed production, flower production, viable pollen production, root bud production) by using backwards step-wise regression analyses with a starting model that 
included $\mathrm{A}_{\max }$, ploidy, $\% \mathrm{~N}, \mathrm{~A}_{\max } \times$ ploidy, $\mathrm{A}_{\max } \times \% \mathrm{~N}$, ploidy $\times \% \mathrm{~N}$, and $\mathrm{A}_{\max } \times$ ploidy $\times$ $\% \mathrm{~N}$. Stepwise removal of these factors was performed using standard approaches until the model only included factors with p-values $<0.15$ (Hosmer Jr and Lemeshow 2004).

Shoot:root ratio. - Plants with a low shoot:root ratio are thought to be more tolerant of herbivory because larger root systems should allow more resources to be shunted from roots into new shoot growth following herbivory (Rausher and Feeny 1980). We measured plant shoot:root ratios to test (1) whether it was influenced by ploidy and/or soil $\mathrm{N}$ treatments and (2) whether a lower shoot:root ratio was indicative of greater tolerance responses. Shoot:root dry biomass was measured as the shoot dry biomass divided by root dry biomass for all 240 plants.

To examine whether ploidy, soil $\mathrm{N}$ treatment, and/or damage influenced the shoot:root ratio, we used a partially nested ANOVA with ploidy, soil $\mathrm{N}$ treatment, damage, all possible interactions between these three variables, and genetic line (fixed effect nested within ploidy) as effects and the shoot:root ratio (log-transformed) as a response variable. To examine whether a lower shoot:root ratio is indicative of greater tolerance responses, we first averaged the shoot:root ratios of the three plants from each genetic line in the undamaged treatment from both low and high soil $\mathrm{N}$ treatments. We examined shoot:root ratios of only those plants that were not damaged because damage itself could influence shoot:root ratios. Then, to examine which factors were influencing tolerance responses (biomass, seed production, flower production, viable pollen production, root bud production), we used backwards stepwise regression analyses with a 
starting model that included mean-shoot:root, ploidy, soil $\mathrm{N}$ treatment, mean-shoot:root $\times$ ploidy, mean-shoot:root $\times$ soil N, ploidy $\times$ soil $\mathrm{N}$ treatment, and mean-shoot:root $\times$ ploidy $\times$ soil $\mathrm{N}$ treatment. For each tolerance measure, we entered all effects into the model and performed stepwise removal of each until the model only contained effects with a p-value $<0.15$ (Hosmer Jr and Lemeshow 2004). 


\section{Results}

Do ploidy, soil N, and/or an interaction affect plant resistance? - Overall, plant resistance patterns varied markedly between diploid and tetraploid fireweed. For example, in choice bioassay $\# 1$, diploids experienced significantly more damage by $S$. exigua compared to tetraploids ( $\mathrm{t}_{125}=4.43, P<0.0001$; Fig. 3.3); S. exigua consumed an average of $21.5 \%$ of diploid leaves $(\mathrm{SE}=0.098$ ) but only $10.57 \%$ of tetraploid leaves (SE $=0.098)$. Percent leaf area consumed in choice bioassay $\# 1$ was not influenced by soil $\mathrm{N}$ treatment $\left(\mathrm{F}_{2,124}=1.33, P=0.269\right)$ or an interaction between ploidy and soil $\mathrm{N}$ treatment $\left(\mathrm{F}_{2,124}=0.49, P=0.613\right)$. In contrast, the percent leaf area consumed in choice bioassay $\# 2$ was not influenced by ploidy $\left(\mathrm{F}_{1,97}=0.58, P=0.449\right)$ but was influenced by the percentage of $\mathrm{N}$ in leaves $\left(\mathrm{F}_{1,97}=9.18, P=0.003\right.$; Fig. 3.4); S. exigua consumed more from plants with higher nitrogen content. The ploidy $\times \% \mathrm{~N}$ interaction effect was not significant $\left(\mathrm{F}_{1,97}=0.38, P=0.978\right)$. Lastly, in the no-choice bioassay, plant genotype (genetic line) appeared to influence the total leaf area consumed $\left(\mathrm{F}_{12,222}=1.763, P=\right.$ 0.055), and no other factors significantly affected the amount of damage to plants (ploidy $-\mathrm{F}_{1,222}=1.08, P=0.301 ;$ soil $\mathrm{N}-\mathrm{F}_{1,222}=0.06, P=0.941 ; \mathrm{P} \times \mathrm{N}$ interaction $-\mathrm{F}_{1,222}=$ $0.44, P=0.645)$.

The relative severity of thrip damage to diploid and tetraploid plants depended upon soil $\mathrm{N}$ treatments (i.e. significant interaction effect; $\chi_{(2, \mathrm{~N}=240)}^{2}=10.53, P=0.005$; Fig. 3.5), where diploids and tetraploids at the low soil $\mathrm{N}$ treatment both received relatively low levels of thrip damage, but tetraploids at the medium and high $\mathrm{N}$ 
treatments experienced more severe thrip damage than diploids. There was also genetic variation for thrip damage (genetic line; $\chi_{(12, \mathrm{~N}=240)}^{2}=25.65, P=0.012$ ), and thrip damage was not significantly influenced by plant flower production $\left(\chi_{(1, \mathrm{~N}=240)}^{2}=0.68, P\right.$ $=0.410)$.

In caged-insect trials, only the percentage of $\mathrm{N}$ in leaves significantly affected the total leaf area consumed by $S$. exigua $\left(\mathrm{F}_{1,52}=9.31, P=0.004\right.$; Fig. 3.6); insects consumed more from plants with higher $\mathrm{N}$ content in leaves. No other factors significantly affected total leaf area consumed by S. exigua (Table 3.1). Plants received different amounts of damage on their upper and lower halves, and in general, plants were more damaged on their lower half. On both the upper and lower halves of plants, the percentage of leaf area damaged by $S$. exigua decreased as plants developed from the rosette to early flower bud stage and then increased as plants began producing flowers and fruits (phenological age; $\mathrm{F}_{5,53}=2.31, P=0.056$, Fig. 3.7, Table 3.1). No other factors or interaction among factors significantly influenced the leaf area consumed on the lower portion of plants during caged-insect trials (Table 3.1). In contrast, on the upper half of plants, $S$. exigua consumed a higher percentage of diploid plants' leaf area $(2.18 \%$ $\pm \mathrm{SE}=0.37)$ than tetraploid plants' leaf area $\left(1.75 \% \pm \mathrm{SE}=0.25 ; \mathrm{F}_{1,54}=3.77, P=0.057\right.$

Fig. 3.8A, Table 3.1). S. exigua also consumed a significantly higher percentage of plants with higher $\mathrm{N}$ content in the upper half of plants $\left(\mathrm{F}_{1,53}=5.40, P=0.024\right.$; Fig. 3.8B). 


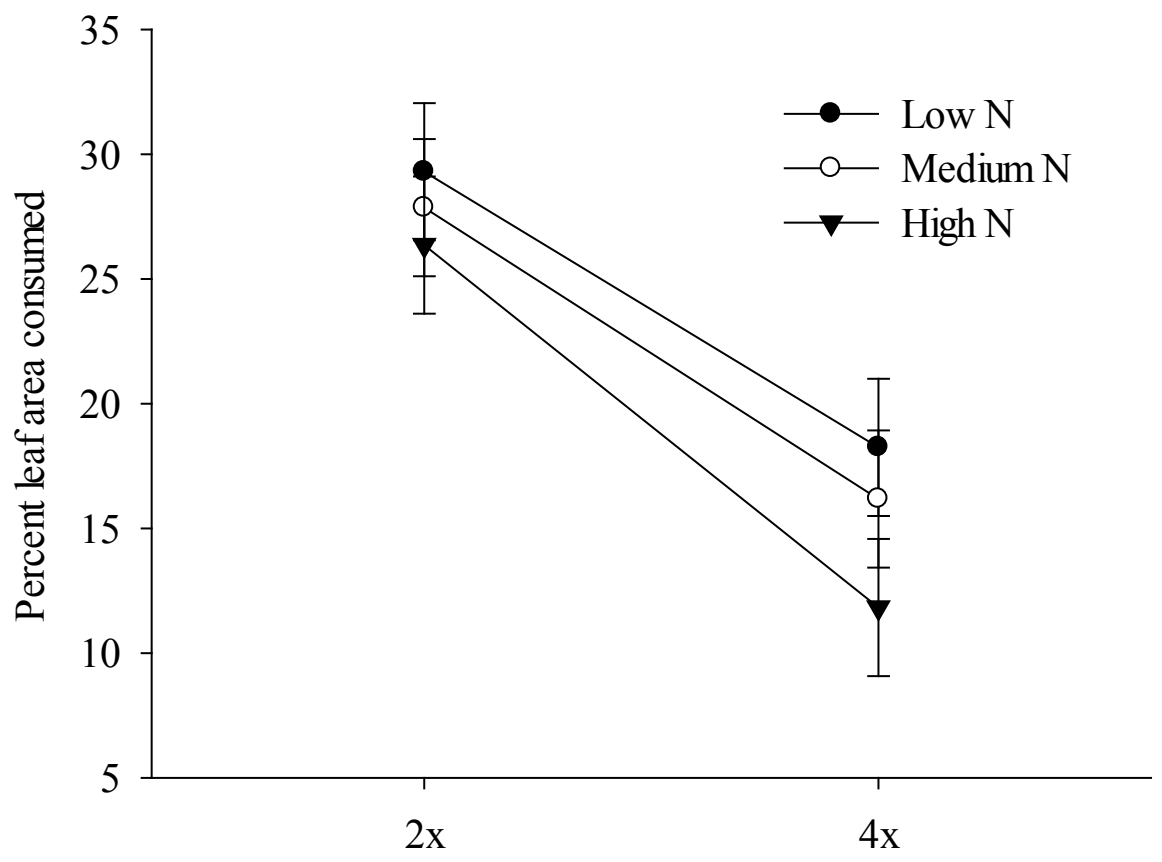

Fig. 3.3: Effects of ploidy and soil $\mathrm{N}$ treatment on the percent leaf area consumed by S. exigua in choice bioassay $\# 1$. Only ploidy significantly affected the percentage of leaf area consumed $\left(\mathrm{t}_{125}=4.43, P<0.0001\right)$. Error bars represent $\pm 1 \mathrm{SE}$. 


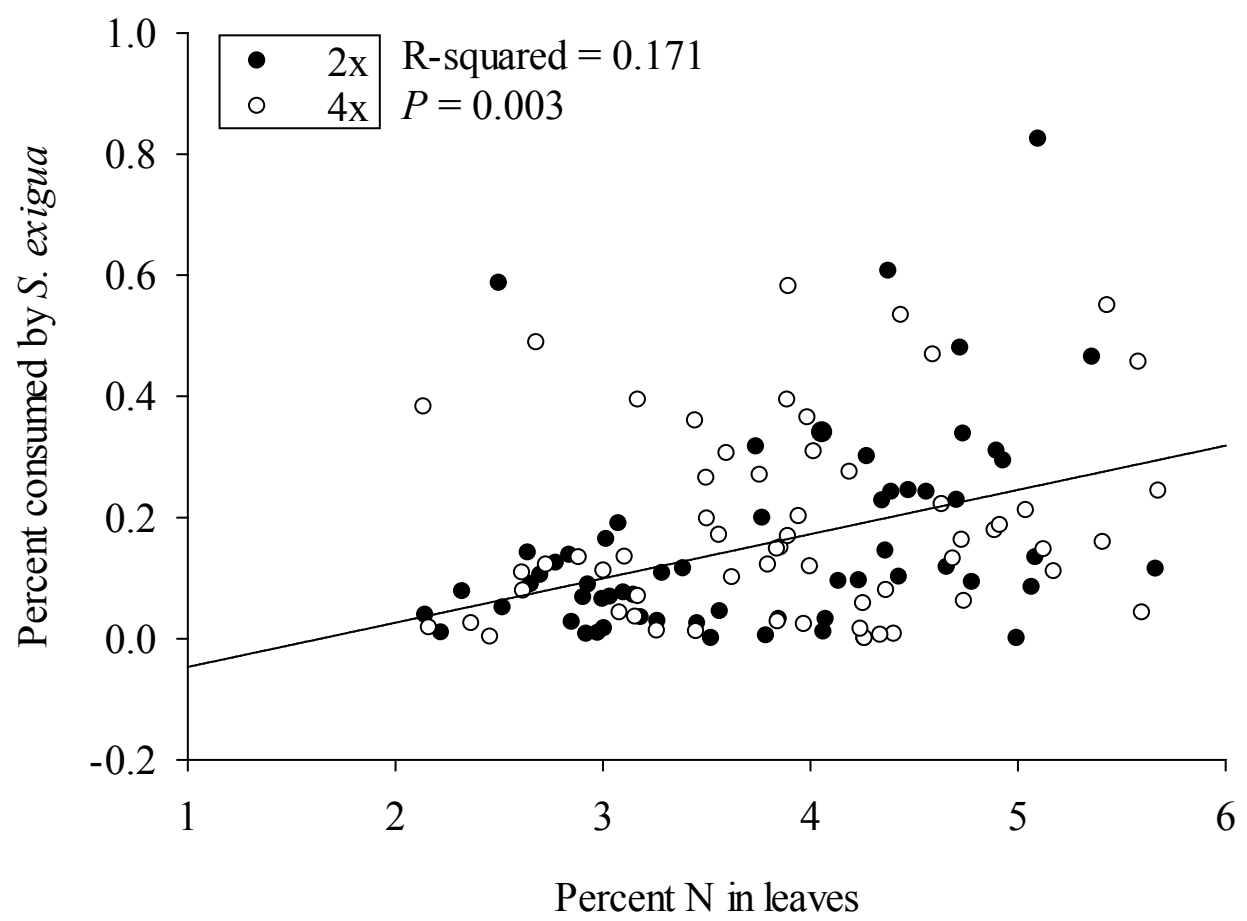

Fig. 3.4: ANCOVA results showing effects of plant nitrogen content on the percent leaf area consumed in choice bioassay $\# 2$. 

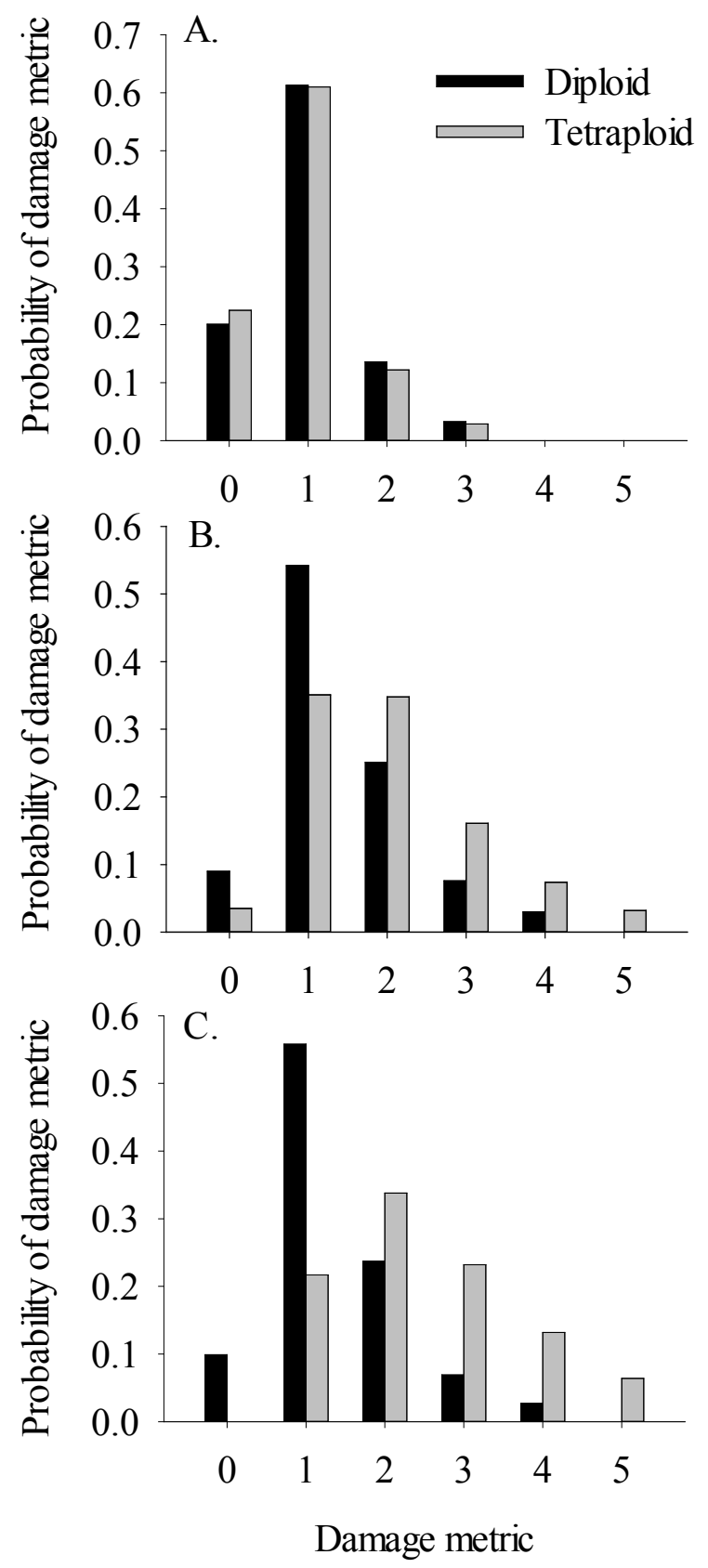

Fig. 3.5: Results of ordinal logistic regression showing the effects of ploidy on the probability of receiving each of six damage metrics $(0=0 \%$ leaf area damaged; $1=1-2 \%$ leaf area damaged; $2=3-5 \%$ leaf area damaged; $3=6-10 \%$ leaf area damaged; $4=10$ $20 \%$ leaf area damaged; $5=$ greater than $20 \%$ leaf area damaged) at low (A), medium (B), and high (C) soil $\mathrm{N}$ treatments. Damage by thrips was influenced by a significant interaction between ploidy and soil $\mathrm{N}$ treatment $\left(\chi_{(2, \mathrm{~N}=240)}^{2}=10.53, P=0.005\right)$. 


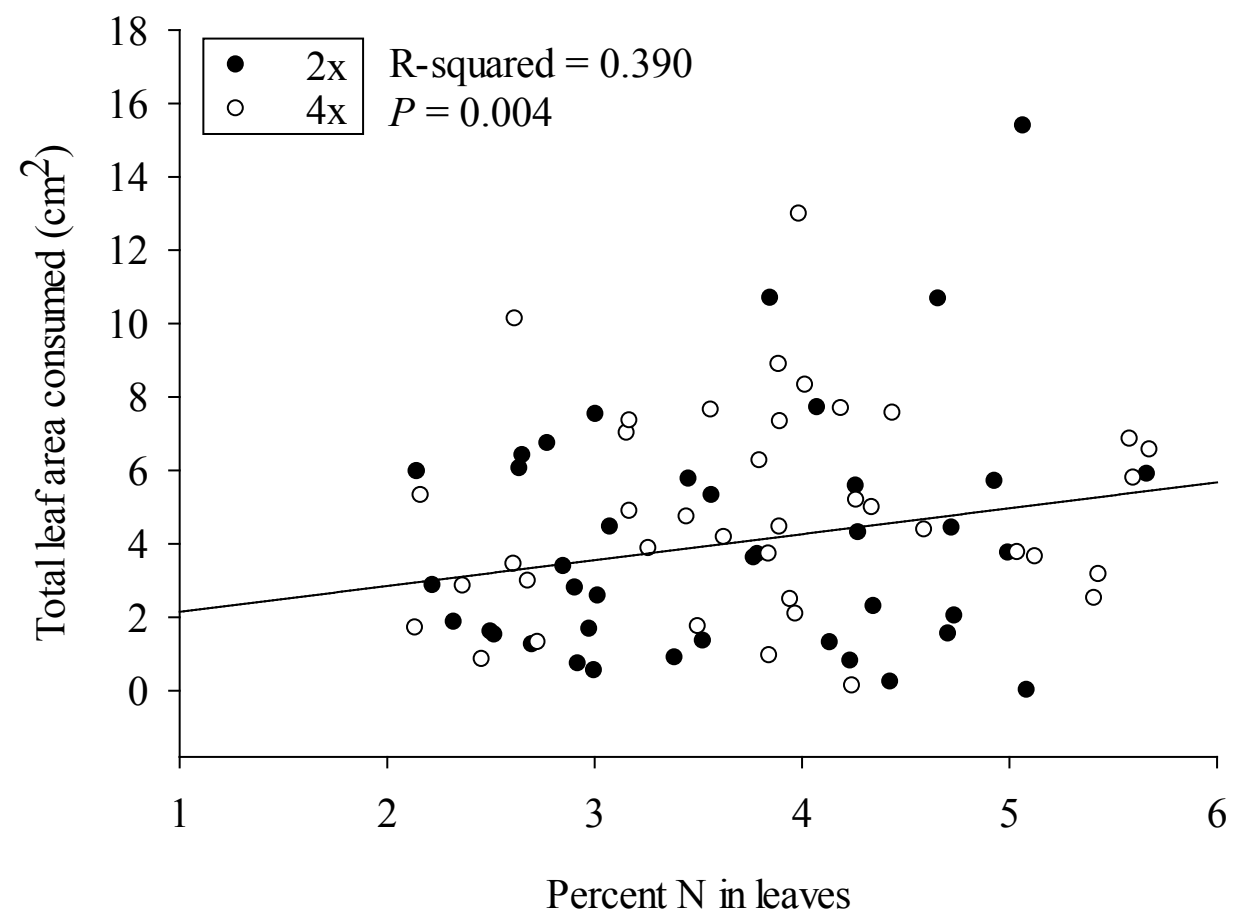

Fig. 3.6: ANCOVA results showing effects of plant nitrogen content on the total leaf area consumed by $S$. exigua during caged-insect trials. 
TABLE 3.1: ANCOVA results for effects of ploidy, percent $N$ in leaves, genetic line, and phenology on three measures of insect damage in caged-insect trials.

\begin{tabular}{lllc}
\hline \hline Factor & Source & $F_{\mathrm{df}}$ & $P$ \\
\hline Total leaf area consumed & Ploidy & $0.05_{(1,52)}$ & 0.821 \\
& $\% \mathrm{~N}$ & $9^{.31_{(1,52)}}$ & 0.004 \\
& Ploidy $\times$ \%N & $1.09_{(1,52)}$ & 0.301 \\
& Genetic line & $1.40_{(18,52)}$ & 0.173 \\
& Phenology & $1.65_{(5,52)}$ & 0.164 \\
Percent leaf area consumed & Ploidy & $0.95_{(1,53)}$ & 0.335 \\
(Lower plant) & $\% \mathrm{~N}$ & $1.25_{(1,53)}$ & 0.268 \\
& Ploidy $\times$ \%N & $2.64_{(1,53)}$ & 0.110 \\
& Genetic line & $1.19_{(18,53)}$ & 0.305 \\
Percent leaf area consumed & Phenology & $2.31_{(5,53)}$ & 0.056 \\
(Upper plant) & Ploidy & $4.77_{(1,53)}$ & 0.034 \\
& \%N & $5.40_{(1,53)}$ & 0.024 \\
& Ploidy $\times$ \% & $1.76_{(1,53)}$ & 0.191 \\
& Genetic line & $0.88_{(8,53)}$ & 0.601 \\
& Phenology & $3.43_{(5,53)}$ & 0.009 \\
\hline
\end{tabular}

Total leaf area consumed was square-root-transformed, percent leaf area consumed (lower and upper) were $\log (y+1)$ transformed. 


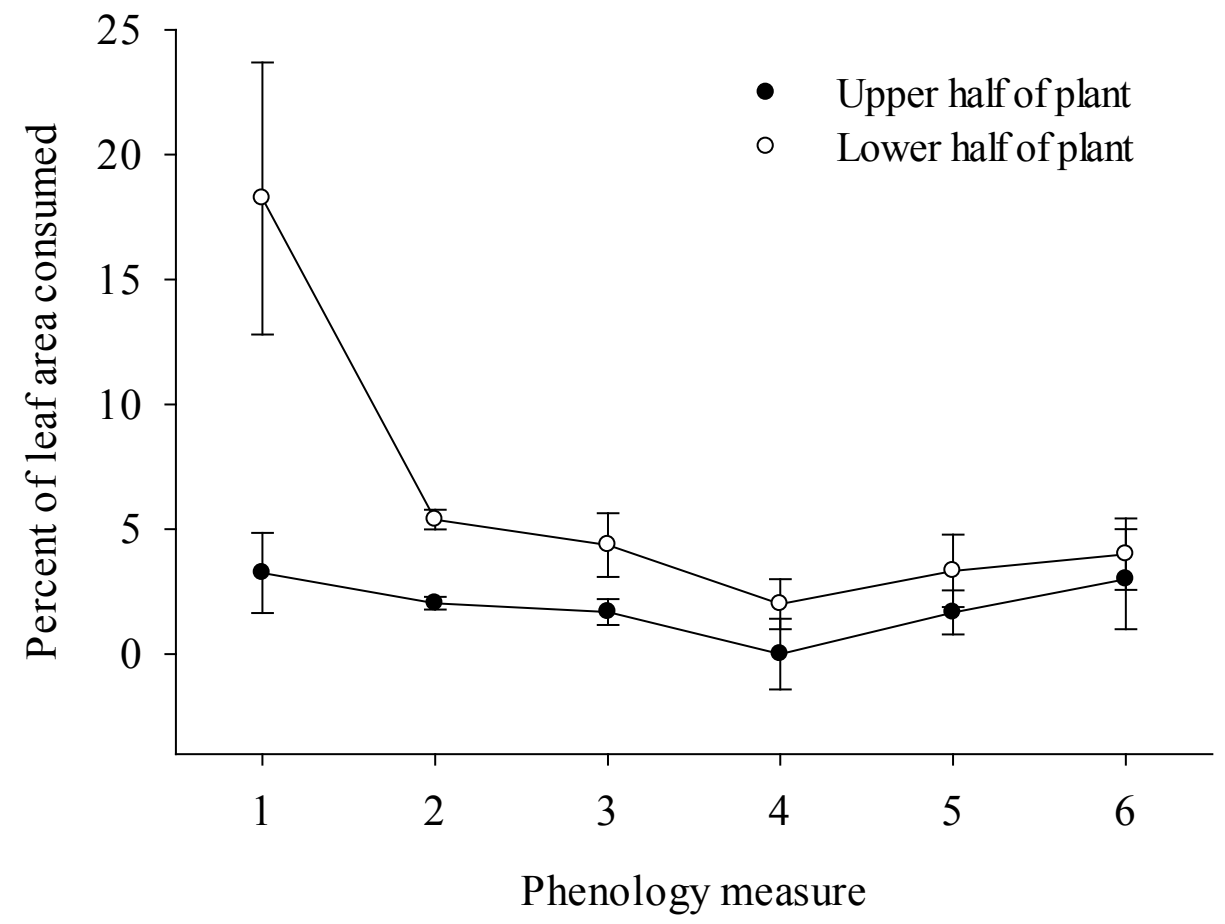

Fig. 3.7: The percent leaf area consumed from the upper and lower halves of plants during caged insect trials by phenological stage of plant development $(1=$ rosette; $2=$ elongated stem; $3=$ green flower buds, $4=$ mature flower buds; $5=$ at least one open flower; $6=$ at least one fruit). Phenological age significantly influenced the percentage of leaf area consumed from the upper $\left(\mathrm{F}_{5,53}=3.43, P=0.009\right)$ and lower $\left(\mathrm{F}_{5,53}=2.31, P=\right.$ 0.056 ) halves of plants. Error bars represent $\pm 1 \mathrm{SE}$. 

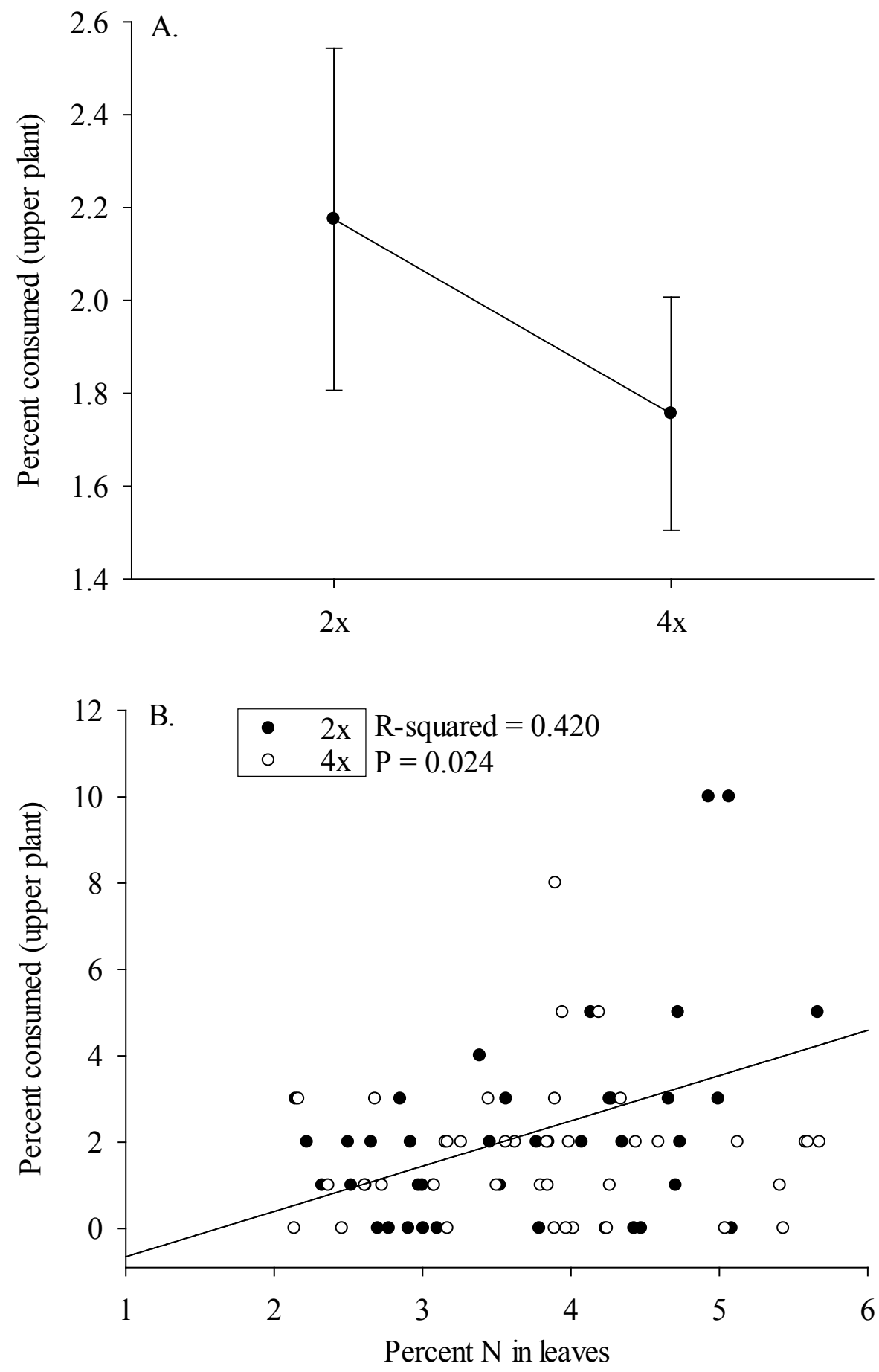

Fig. 3.8: ANCOVA results showing the effects of ploidy $\left(\mathrm{A} ; \mathrm{F}_{1,54}=3.77, P=0.057\right)$ and plant nitrogen content $(\mathrm{B})$ on the percent leaf area consumed on the upper half of plants during caged-inset trials. Error bars represent $\pm 1 \mathrm{SE}$. 


\section{Do ploidy, soil N, and/or an interaction affect plant resistance traits, and do}

plant resistance traits affect damage? - Both the C:N ratio and LMA (resistance traits) were influenced by ploidy and soil $\mathrm{N}$ treatments. C:N ratio was affected by ploidy and soil $\mathrm{N}\left(\mathrm{P} \times \mathrm{N}\right.$ interaction, $\mathrm{F}_{1,97}=3.87, P=0.052 ;$ Fig. 3.9$)$, wherein tetraploids at the low $\mathrm{N}$ treatment had a lower $\mathrm{C}: \mathrm{N}$ ratio $(9.65 \pm 0.46)$ than diploids at the low $\mathrm{N}$ treatment (12.09 \pm 0.45$)$, but a similar C: $\mathrm{N}$ ratio to diploids at the high $\mathrm{N}$ treatment $(4 \mathrm{x}=12.11 \pm$ $0.46 ; 2 \mathrm{x}=12.10 \pm 0.45)$. There was also genetic variation for the $\mathrm{C}: \mathrm{N}$ ratio $\left(\mathrm{F}_{18,97}=2.85\right.$, $P<0.001)$. Plant $\mathrm{C}: \mathrm{N}$ ratio was negatively correlated with the percent leaf area consumed during choice bioassay $\# 2$, but only for plants in the high soil $\mathrm{N}$ treatment $\left(\mathrm{F}_{(1,37)}=5.55\right.$, $P=0.024$; Fig. 3.10). For plants in the low soil $\mathrm{N}$ treatment, C:N ratio was not correlated with the percent leaf area consumed in choice bioassay \#2, and the interaction between ploidy and C:N ratio was not significant (Table 3.2). The percent leaf area consumed in the upper portion plants during caged-insect trials was not influenced by $\mathrm{C}: \mathrm{N}$ ratio, ploidy, or an interaction between $\mathrm{C}: \mathrm{N}$ ratio and ploidy at either soil $\mathrm{N}$ treatment (Table $3.2)$.

LMA was significantly influenced by ploidy $\left(\mathrm{F}_{1,217}=58.98, P<0.0001\right)$; diploid leaves had an average LMA of $24.16 \mathrm{~g} \cdot \mathrm{m}^{-2}(\mathrm{SE}=0.31)$ while tetraploid leaves had an average LMA of only $20.79 \mathrm{~g} \cdot \mathrm{m}^{-2}(\mathrm{SE}=0.31)$. LMA was also significantly influenced by $\mathrm{N}$ treatment $\left(\mathrm{F}_{1,217}=5.17, P=0.024\right)$; plants in the low $\mathrm{N}$ treatment had an average LMA of $21.97 \mathrm{~g} \cdot \mathrm{m}^{-2}(\mathrm{SE}=0.31)$ while those from the high $\mathrm{N}$ treatment had an average LMA of $22.97 \mathrm{~g} \cdot \mathrm{m}^{-2}(\mathrm{SE}=0.31)$. LMA was significantly affected by genetic line $\left(\mathrm{F}_{18,217}=748.96\right.$, $P<0.0001)$ and was not influenced by an interaction between ploidy and soil $\mathrm{N}$ 
treatment $\left(\mathrm{F}_{1,217}=0.87 . P=0.353\right)$. LMA was not correlated with the percent leaf area consumed in choice bioassay \#2 or caged-insect trials (upper region); neither LMA nor the interaction between ploidy and LMA had significant effects on damage (Table 3.3).

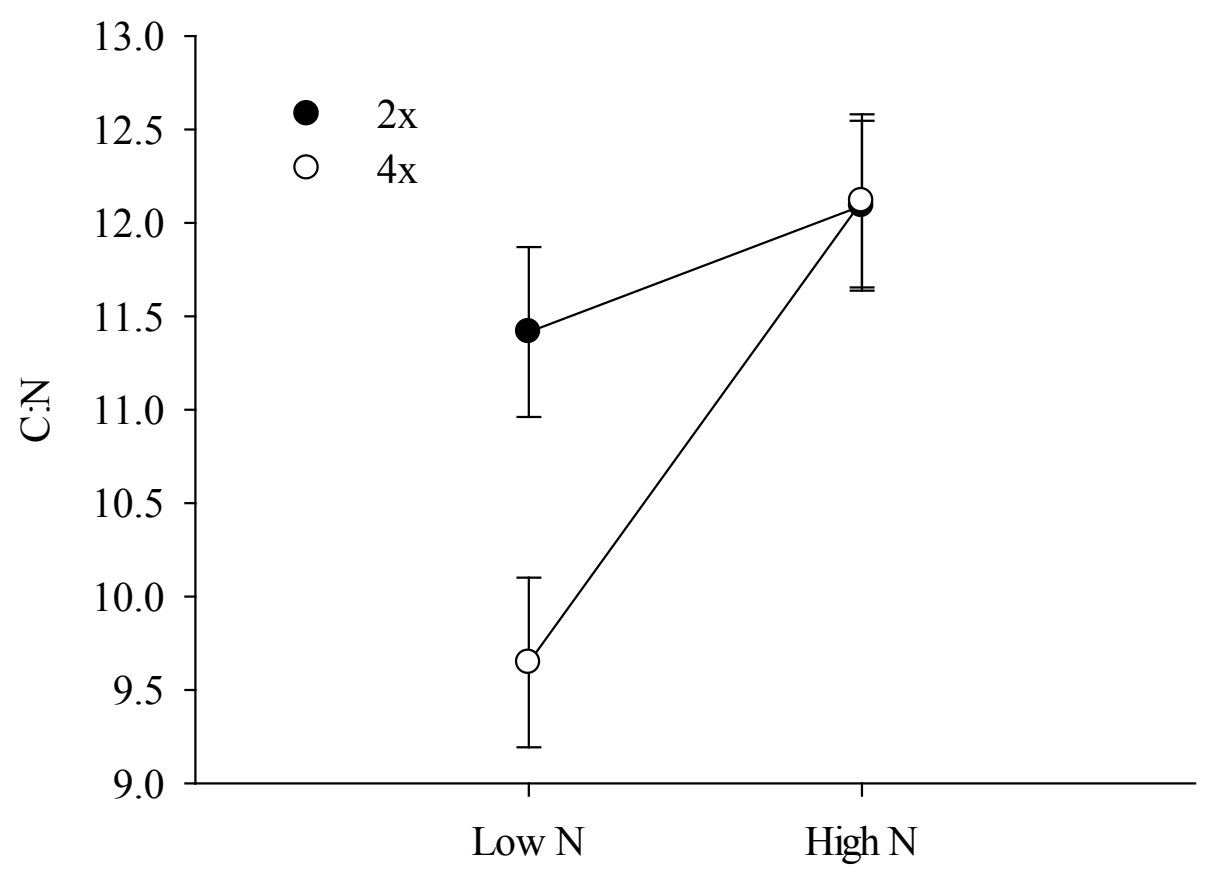

Fig. 3.9: Two-way ANOVA results showing the effects of soil $N$ treatment and ploidy on plant $\mathrm{C}: \mathrm{N}$ ratio. Error bars represent $\pm 1 \mathrm{SE}$. Ploidy and soil $\mathrm{N}$ treatment interacted to influence plant $\mathrm{C}: \mathrm{N}$ ratio $\left(\mathrm{F}_{1,97}=3.87, P=0.052\right)$. 


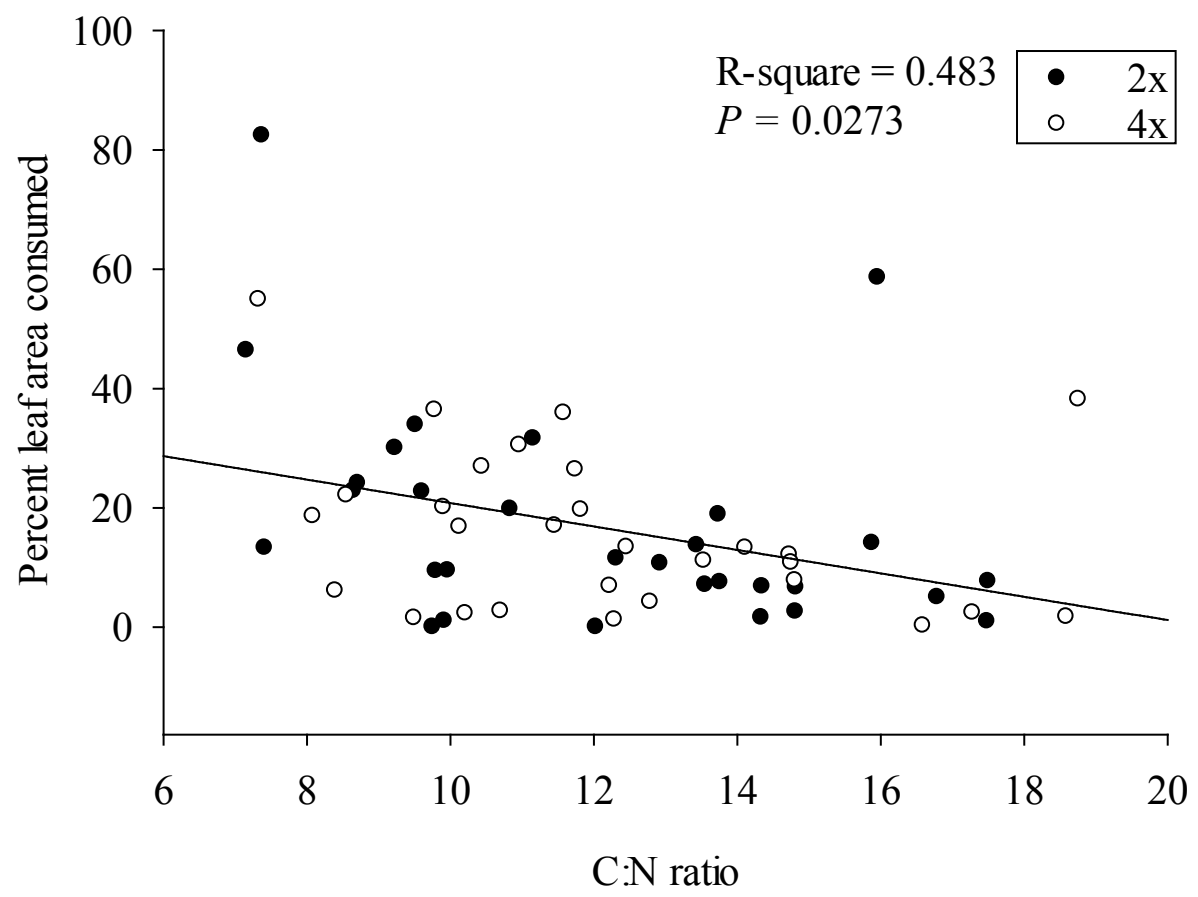

Fig. 3.10: The effects of C:N ratio on the percent leaf area consumed on plants from the high soil $\mathrm{N}$ treatment by S. exigua during choice bioassay $\# 2$. 
TABLE 3.2: ANOVA results showing effects of ploidy, $\mathrm{C}: \mathrm{N}$ ratio, $\mathrm{P} \times \mathrm{C}: \mathrm{N}$ ratio interaction, and genetic line (nested in ploidy) on the percent leaf area consumed in choice bioassay \#2 and the upper half of plants in caged-insect trials. ANOVAs were run separately for each soil $\mathrm{N}$ treatment (see methods).

\begin{tabular}{|c|c|c|c|c|}
\hline Factor and source & \multicolumn{2}{|c|}{ Low $\mathrm{N}$ treatment } & \multicolumn{2}{|c|}{ High $\mathrm{N}$ treatment } \\
\hline Choice bioassay \#2 & $F_{\mathrm{df}}$ & $P$ & $F_{\mathrm{df}}$ & $P$ \\
\hline Ploidy & $1.30_{(1,38)}$ & 0.262 & $0.01_{(1,38)}$ & 0.915 \\
\hline $\mathrm{C}: \mathrm{N}$ ratio & $0.43_{(1.38)}$ & 0.515 & $5.55_{(1.38)}$ & 0.024 \\
\hline Ploidy $\times \mathrm{C}: \mathrm{N}$ ratio & $0.0001_{(1.38)}$ & 0.980 & $0.01_{(1.38)}$ & 0.905 \\
\hline Genetic line & $0.67_{(18,38)}$ & 0.818 & $1.34_{(18,38)}$ & 0.222 \\
\hline \multicolumn{5}{|c|}{ Caged-insects (upper plants) } \\
\hline Ploidy & $0.68_{(1,19)}$ & 0.420 & $0.49_{(1,19)}$ & 0.493 \\
\hline $\mathrm{C}: \mathrm{N}$ ratio & $0.55_{(1,19)}$ & 0.468 & $0.55_{(1.19)}$ & 0.493 \\
\hline Ploidy $\times \mathrm{C}: \mathrm{N}$ ratio & $0.04_{(1,19)}$ & 0.842 & $0.11_{(1.19)}$ & 0.748 \\
\hline Genetic line & $1.06_{(18,19)}$ & 0.449 & $1.07_{(18,19)}$ & 0.447 \\
\hline
\end{tabular}

Percent consumed in choice bioassay \#2 was square-root transformed and in cagedinsect trials was $\log (\mathrm{y}+1)$-transformed. 
TABLE 3.3: ANOVA results showing effects of ploidy, LMA, $P \times$ LMA interaction, and genetic line (nested in ploidy) on the percent leaf area consumed in choice bioassay \#2 and the upper half of plants in caged-insect trials. ANOVAs were run separately for each soil $\mathrm{N}$ treatment (see methods).

\begin{tabular}{|c|c|c|c|c|}
\hline Factor and source & \multicolumn{2}{|c|}{ Low $\mathrm{N}$ treatment } & \multicolumn{2}{|c|}{ High $\mathrm{N}$ treatment } \\
\hline Choice bioassay \#2 & $F_{\mathrm{df}}$ & $P$ & $F_{\mathrm{df}}$ & $P$ \\
\hline Ploidy & $6.21_{(1,98)}$ & 0.014 & $0.15_{(1,98)}$ & 0.700 \\
\hline LMA & $0.18_{(1,98)}$ & 0.670 & $0.20_{(1.98)}$ & 0.652 \\
\hline Ploidy $\times$ LMA & $2.48_{(1,98)}$ & 0.119 & $1.89_{(1.98)}$ & 0.172 \\
\hline Genetic line & $0.99_{(18,98)}$ & 0.480 & $1.06_{(18,98)}$ & 0.310 \\
\hline \multicolumn{5}{|c|}{ Caged-insects (upper plants) } \\
\hline Ploidy & $1.37_{(1,19)}$ & 0.256 & $0.71_{(1,19)}$ & 0.411 \\
\hline LMA & $2.19_{(1,19)}$ & 0.156 & $3.63_{(1.19)}$ & 0.074 \\
\hline Ploidy $\times$ LMA & $0.02_{(1,19)}$ & 0.884 & $1.38_{(1.19)}$ & 0.256 \\
\hline Genetic line & $1.28_{(18,19)}$ & 0.297 & $1.07_{(18,19)}$ & 0.442 \\
\hline
\end{tabular}

Percent consumed in choice bioassay \#2 was square-root transformed and in cagedinsect trials was $\log (\mathrm{y}+1)$ transformed. 


\section{Do ploidy, soil N, and/or an interaction affect plant tolerance and/or tolerance}

traits, and do plant tolerance traits affect compensation? - On average, all plants tended to compensate $($ slope $=0$ ) or undercompensate $($ slope $<0$ ) for damage, and we did not see any evidence of overcompensation (slope $>0$; Table 3.4). We found no significant effects of ploidy or soil $\mathrm{N}$ treatment on fireweed tolerance to herbivory with respect to any of the five fitness measures (Table 3.5).

We examined the effects of ploidy and soil $\mathrm{N}$ treatment on the plasticity of plants in terms of their change in maximum photosynthetic capacity $\left(\mathrm{A}_{\max }\right)$ following herbivory. $\mathrm{A}_{\max }$ increased following herbivory for both diploids and tetraploids, but the relative increase was significantly greater for tetraploids than for diploids $\left(\mathrm{F}_{1,34}=6.07, P=\right.$ 0.019; Fig. 3.11); neither $\% \mathrm{~N}\left(\mathrm{~F}_{1,34}=0.01, P=0.622\right)$ nor the $\mathrm{P} \times \% \mathrm{~N}$ interaction effect $\left(\mathrm{F}_{1,34}=0.0001, P=0.962\right)$ were significant for the increase in $\mathrm{A}_{\max }$ following herbivory. We tested whether a higher $\mathrm{A}_{\max }$ prior to damage, ploidy, $\% \mathrm{~N}$, and/or any possible interactions between these three variables were correlated with any of the five tolerance responses (biomass, flower production, seed production, viable pollen production, and root bud production) using backwards stepwise regression analyses. No factors were significant below the $\mathrm{p}$-value threshold $(P<0.15)$ for tolerance with respect to biomass, flower production, seed production, or viable pollen production. Tolerance with respect to root bud production was influenced by an interaction between ploidy and $\% \mathrm{~N}$, wherein diploid plants with higher nitrogen content in leaves had lower tolerance in terms of root bud production, while tetraploids' nitrogen content was not correlated with tolerance in 
terms of root bud production (Fig. 3.12). $A_{\max }$ prior to damage was not significantly correlated with any tolerance measure ( $P>0.15$ for all tolerance measures).

We measured plant shoot:root ratio to determine whether it was influenced by ploidy, soil $\mathrm{N}$ treatment, damage, all possible interactions between these three variables, and/or genetic line. Genetic line significantly influenced the shoot:root ratio of plants $\left(\mathrm{F}_{18,212}=2.48, P=0.001\right)$, and no other factor or interaction among factors significantly affected shoot:root ratio (Table 3.6). We also calculated the average shoot:root ratio of undamaged plants within genetic lines and soil $\mathrm{N}$ treatments to examine whether shoot:root ratio is correlated with the five tolerance measures. Model effects were selected using backwards stepwise regression analyses and are shown in Table 3.7 for each tolerance measure. We found that shoot:root ratio was negatively correlated with tolerance in terms of biomass compensation $\left(\mathrm{F}_{1,36}=4.10, P=0.050\right)$. Interestingly, flower and seed compensation was also negatively correlated with diploid shoot:root ratios, but positively correlated with the shoot:root ratios of tetraploids (i.e. significant interaction effect; Table 3.7, Fig. 3.13). No other factors or interactions between factors significantly influenced tolerance measures (Table 3.7). 
TABLE 3.4: Effects of ploidy and soil $\mathrm{N}$ treatment on the mean tolerance measures estimated using the least squares slope of the regression of each fitness measure on the level of damage. Letters to the right of each value indicate whether mean tolerance $\pm 1 \mathrm{SE}$ represents undercompensation $(\mathrm{U} ; \mathrm{T}<0)$ or full compensation (FC; $\mathrm{T}=0)$.

\begin{tabular}{|c|c|c|c|c|}
\hline \multirow{2}{*}{ Tolerance measure } & \multicolumn{4}{|c|}{ Ploidy (LS Mean \pm 1 SE) } \\
\hline & \multicolumn{2}{|l|}{$2 \mathrm{x}$} & \multicolumn{2}{|l|}{$4 \mathrm{x}$} \\
\hline Shoot Biomass & $-0.455 \pm 0.299$ & $\mathrm{U}$ & $-0.537 \pm 0.299$ & $\mathrm{U}$ \\
\hline Flower Production & $-1.000 \pm 4.520$ & $\mathrm{FC}$ & $-4.667 \pm 4.520$ & U \\
\hline Seed Production & $-505.667 \pm 569.737$ & $\mathrm{FC}$ & $-552.714 \pm 569.737$ & FC \\
\hline Viable Pollen Production & $-136.616 \pm 71.954$ & $\mathrm{U}$ & $-134.107 \pm 62.175$ & $\mathrm{U}$ \\
\hline \multirow[t]{2}{*}{ Root Bud Production } & $-2.548 \pm 1.683$ & $\mathrm{U}$ & $0.524 \pm 1.683$ & FC \\
\hline & \multicolumn{2}{|l|}{ Low $\mathrm{N}$ treatment } & \multicolumn{2}{|l|}{ High $\mathrm{N}$ treatment } \\
\hline Shoot Biomass & $-0.545 \pm 0.299$ & $\mathrm{U}$ & $-0.447 \pm 0.299$ & U \\
\hline Flower Production & $2.571 \pm 4.520$ & $\mathrm{FC}$ & $-8.238 \pm 4.520$ & $\mathrm{U}$ \\
\hline Seed Production & $20.714 \pm 569.737$ & $\mathrm{FC}$ & $-1079.095 \pm 569.737$ & $\mathrm{U}$ \\
\hline Viable Pollen Production & $-68.167 \pm 65.947$ & $\mathrm{U}$ & $-202.556 \pm 68.514$ & $\mathrm{U}$ \\
\hline Root Bud Production & $-1.333 \pm 1.683$ & $\mathrm{FC}$ & $-0.690 \pm 1.683$ & FC \\
\hline
\end{tabular}


TABLE 3.5: Two-way ANOVA results for ploidy and soil $\mathrm{N}$ treatment effects on five measures of tolerance to insect herbivory.

\begin{tabular}{lllc}
\hline \hline Tolerance factor & Source & $F_{\mathrm{df}}$ & $P$ \\
\hline Biomass production & Ploidy & $0.040_{(1,36)}$ & 0.843 \\
& Soil N & $0.057_{(1,36)}$ & 0.812 \\
& Ploidy $\times \mathrm{N}$ & $0.295_{(1,36)}$ & 0.590 \\
Flower production & Ploidy & $0.329_{(1,36)}$ & 0.570 \\
& Soil N & $2.859_{(1,36)}$ & 0.100 \\
& Ploidy $\times \mathrm{N}$ & $0.103_{(1,36)}$ & 0.751 \\
Seed production & Ploidy & $0.003_{(1,36)}$ & 0.954 \\
& Soil N & $1.863_{(1,36)}$ & 0.181 \\
& Ploidy $\times \mathrm{N}$ & $0.062_{(1,36)}$ & 0.805 \\
Viable pollen production & Ploidy & $0.001_{(1,36)}$ & 0.979 \\
& Soil N & $1.997_{(1,36)}$ & 0.168 \\
& Ploidy $\times \mathrm{N}$ & $3.496_{(1,36)}$ & 0.168 \\
Root bud production & Ploidy & $1_{\left(.666_{(1,36)}\right.}$ & 0.205 \\
& Soil N & $0.073_{(1,36)}$ & 0.789 \\
& Ploidy $\times \mathrm{N}$ & $0.152_{(1,36)}$ & 0.699 \\
\hline
\end{tabular}




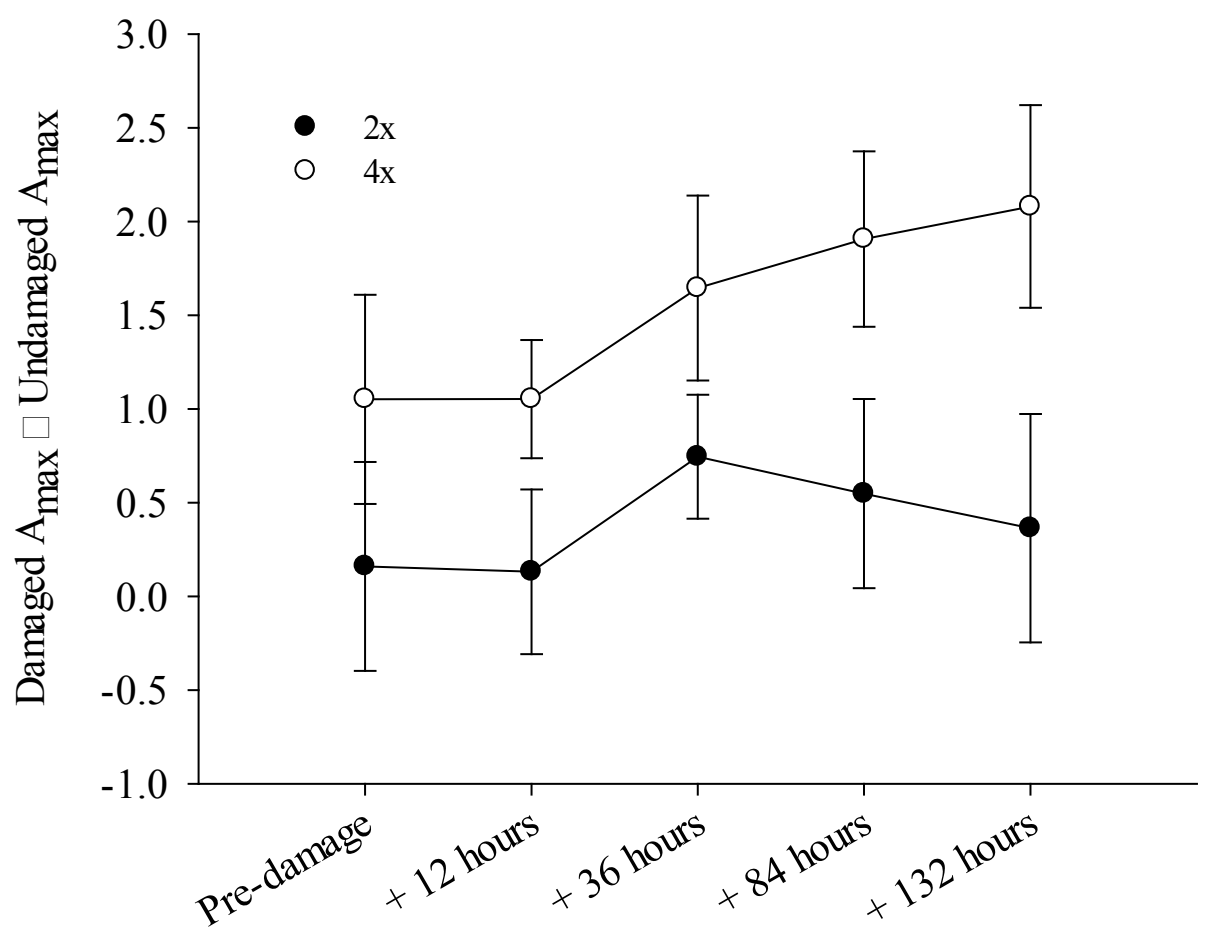

Fig. 3.11: Repeated measures MANOVA results showing the difference in $A_{\max }$ between damaged and undamaged plants by ploidy level across five temporal measurements (immediately prior to damage, plus 12, plus 36, plus 84, and plus 132 hours after caged insects were completed and artificial damage was inflicted. Tetraploids upregulated their $A_{\max }$ significantly more than diploids following herbivory $\left(\mathrm{F}_{1,34}=6.07, P=0.019\right)$. Error bars represent $\pm 1 \mathrm{SE}$. 


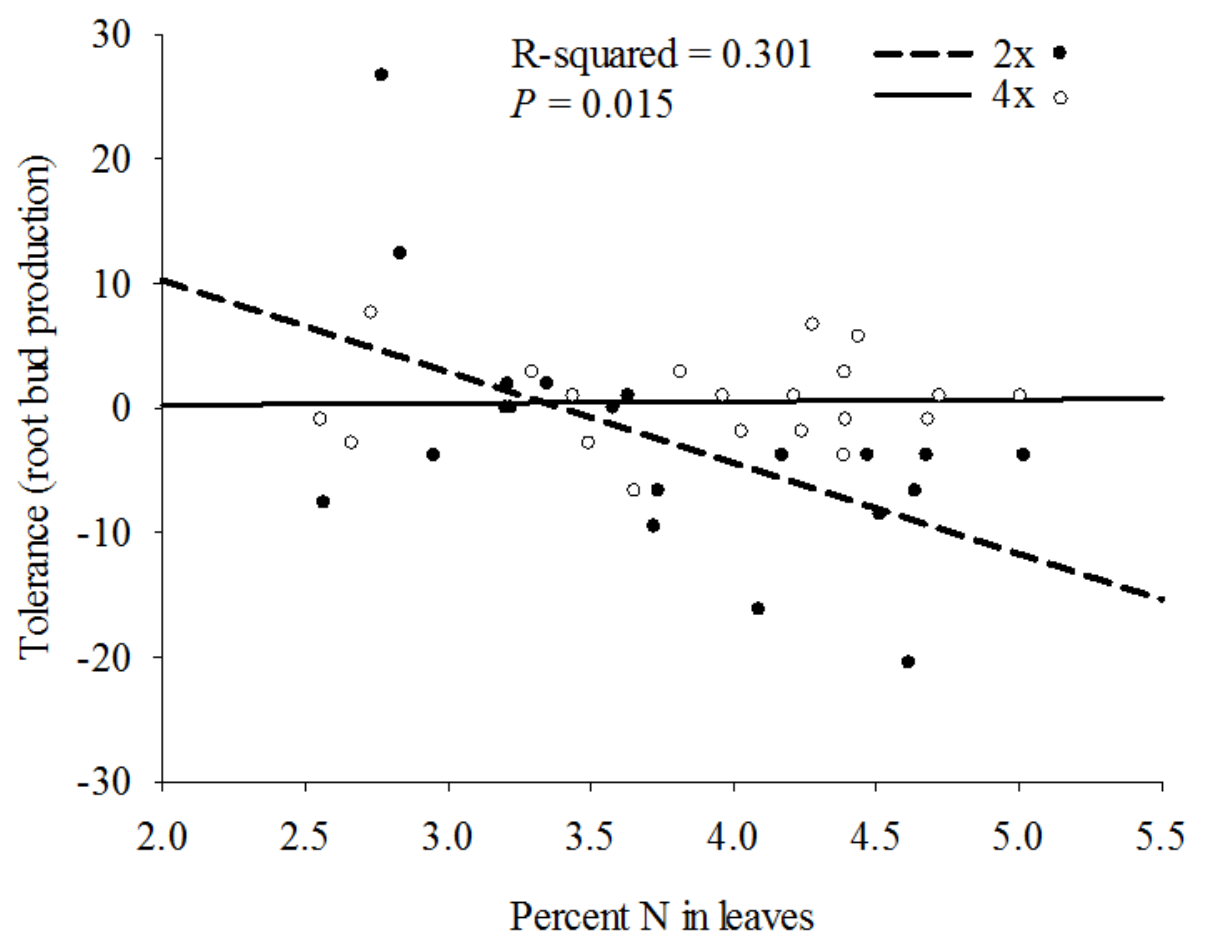

Fig. 3.12: Regression showing the interaction of ploidy and percent nitrogen in leaves on the tolerance of fireweed in terms of root bud production. 
TABLE 3.6: ANOVA results for the effects of ploidy, soil $\mathrm{N}$ treatment, damage, all possible interactions between these three variables, and genetic line on the shoot:root ratio.

\begin{tabular}{lll}
\hline \hline Source & $F_{\mathrm{df}}$ & $P$ \\
\hline Ploidy & $1.90_{(1,212)}$ & 0.170 \\
Soil N & $1.39_{(1,212)}$ & 0.239 \\
Ploidy $\times \mathrm{N}$ & $1.30_{(1,212)}$ & 0.255 \\
Damage & $1.44_{(1,212)}$ & 0.234 \\
Ploidy $\times$ Damage & $0.26_{(1,212)}$ & 0.612 \\
Damage $\times \mathrm{N}$ & $0.60_{(1,212)}$ & 0.438 \\
Ploidy $\times \mathrm{N} \times$ Damage & $1.97_{(1,212)}$ & 0.161 \\
Genetic line & $2.48_{(18,212)}$ & 0.001 \\
\hline
\end{tabular}

Shoot:root values log-transformed. 
TABLE 3.7: Results of backwards stepwise regression analyses showing model effects selected for each of five tolerance measures (biomass production, flower production, seed production, viable pollen production, and root bud production).

\begin{tabular}{lrcc}
\hline \hline Parameter & $\beta$ coefficient & $F_{\mathrm{df}}$ & $P$ \\
\hline Biomass production $\left(\mathrm{r}^{2}=0.097\right)$ & -0.91 & $4.10_{(1,36)}$ & 0.050 \\
$\quad$ Shoot:root & & & \\
Flower production $\left(\mathrm{r}^{2}=0.179\right)$ & -0.09 & $0.13_{(1,36)}$ & 0.716 \\
$\quad$ Ploidy & -28.51 & $4.03_{(1,36)}$ & 0.053 \\
$\quad$ Shoot:root & -38.40 & $7.31_{(1,36)}$ & 0.011 \\
$\quad$ Ploidy $\times$ shoot:root & & & \\
Seed production $\left(\mathrm{r}^{2}=0.116\right)$ & -307.53 & $1.02_{(1,36)}$ & 0.319 \\
$\quad$ Ploidy & -3878.84 & $4.47_{(1,36)}$ & 0.042 \\
$\quad$ Shoot:root ratio & -4737.31 & $6.67_{(1,36)}$ & 0.014 \\
$\quad$ Ploidy $\times$ shoot:root & & & \\
Viable pollen production $\left(\mathrm{r}^{2}=0.171\right)$ & -1.25 & $0.00_{(1,36)}$ & 0.979 \\
$\quad$ Ploidy & 67.19 & $2.00_{(1,36)}$ & 0.168 \\
$\quad$ Soil N & -88.91 & $3.50_{(1,36)}$ & 0.071 \\
$\quad$ Ploidy $\times$ soil N & & & \\
Root bud production $\left(\mathrm{r}^{2}=0.117\right)$ & -1.54 & $1.60_{(1,36)}$ & 0.215 \\
$\quad$ Ploidy & -7.02 & $0.92_{(1,36)}$ & 0.345 \\
$\quad$ Shoot:root ratio & -11.72 & $2.56_{(1,36)}$ & 0.119 \\
$\quad$ Ploidy $\times$ shoot:root & & & \\
\hline Models were constructed using a p-value threshold of $\mathrm{p}<0.15$. &
\end{tabular}



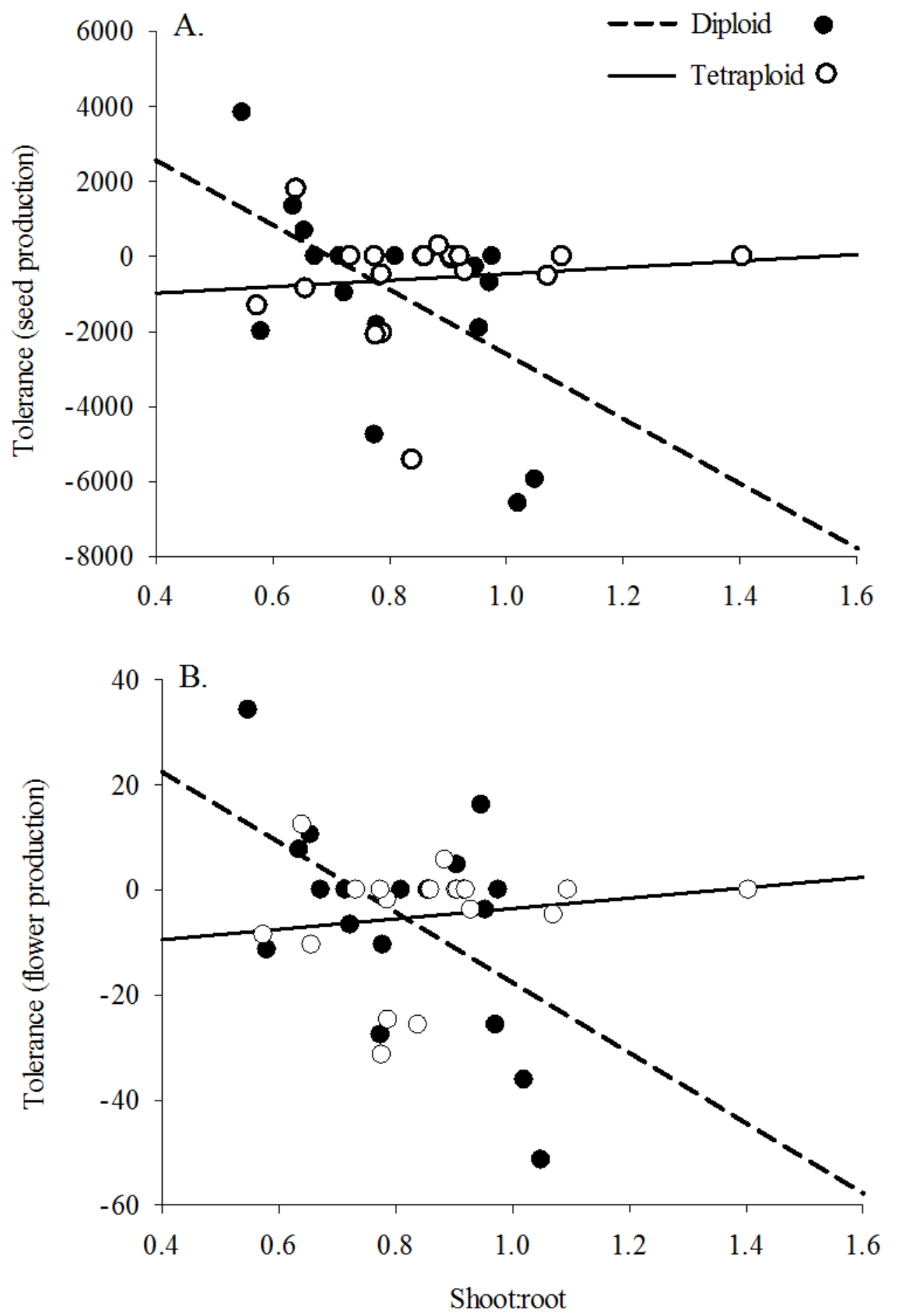

Fig. 3.13: Regressions showing the interaction between ploidy and shoot:root ratio on tolerance to herbivory in terms of seed production $\left(\mathrm{A} ; \mathrm{F}_{1,36}=6.67, P=0.014\right)$ and flower production $\left(\mathrm{B} ; \mathrm{F}_{1,36}=7.31, P=0.011\right)$. 


\section{Discussion}

Our results suggest that, for fireweed, polyploidy influences plant resistance but not tolerance to damage by insect herbivores. Interestingly, observed patterns of resistance were dependent on the type of insect herbivory; diploids were less resistant to damage by caterpillars but more resistant to damage by thrips. Nitrogen availability also both directly and perhaps indirectly (through changes in phenology, plant C:N ratio, and/or LMA) impacted plant resistance patterns. Although tolerance did not differ between cytotypes, damage resulted in declines or no changes in plant fitness. Soil nitrogen availability did not directly affect tolerance patterns, but variation in photosynthesis and shoot:root biomass influenced some tolerance patterns. In summation, polyploidy and nitrogen availability can have complex effects on plant-herbivore interactions, and such interactions may have implications for the relative success of cytotypes in changing environments.

Polyploidy and soil nitrogen influence patterns of plant resistance. - We expected diploid and tetraploid fireweed to differ in their relative resistance to herbivory, possibly due to physiological differences in cytotypes' relative C:N ratio, leaf toughness (LMA), and/or secondary chemistry. In a study that examined how nitrogen availability influences fireweed cytotype fitness and nitrogen content (see Chapter 1), tetraploids were found to have a higher $\mathrm{C}: \mathrm{N}$ ratio than diploids. A higher $\mathrm{C}: \mathrm{N}$ ratio is generally associated with greater resistance to herbivory (Feeny 1970, Bryant et al. 1987, Ibrahim 
et al. 2011), and so we predicted that tetraploid fireweed would be more resistant to herbivory than diploids. Here, we found that tetraploids were more resistant to damage by S. exigua than diploids (e.g., choice bioassay \#1; Fig. 3.3), but they were less resistant to damage by thrips than diploids (Fig. 3.5). We do not know why resistance patterns differed between cytotypes and insects. For instance, we did not find that $\mathrm{C}: \mathrm{N}$ ratios differed significantly between cytotypes at the time of the insect feeding trials (measured for upper leaves in study \#2), and in fact, there was a trend for diploids to have higher $\mathrm{C}: \mathrm{N}$ ratios than tetraploids at this time. Interestingly, when we measured $\mathrm{C}$ and $\mathrm{N}$ content a second time (immediately before plants began senescing), we found that tetraploids had significantly higher $\mathrm{C}: \mathrm{N}$ ratios than diploids.

In general, as soil $\mathrm{N}$ increased, insects damaged a greater proportion of the plants. Preferential feeding of diploids by S. exigua was not observed in all trials, and this could be due to differences in genotypes (genetic lines) used in experiments, different parts of the plant exposed to herbivores (upper or lower leaves), or differences in the phenological age of plants. For example, we used different genetic lines in study $\# 1$ and study $\# 2$, and genetic variation for resistance is known to exist (Fritz and Simms 1992). Additionally, $S$. exigua larvae appeared to feed preferentially on leaves from the lower halves of plants during caged-insect trials. The nutrient content and distribution of plant secondary defense compounds is known to vary throughout different regions of plants (Wiermann 2013), and so it is difficult to make any correlations between damage and C:N ratio or ellagitannins on the lower halves of plants because leaves were sampled from the upper halves. Insects also appeared to consume a higher percentage of plants in the flowering 
stage, and more diploids than tetraploids were flowering during the time of caged-insect trials (Fig.3.7).

We did not measure the $\mathrm{C}: \mathrm{N}$ ratio of plants from choice bioassay $\# 1$, and so it is unclear whether the different nitrogen treatments used in bioassay $\# 1$ and $\# 2$ contributed to contrasting results from the two choice bioassays. Surprisingly, during choice bioassay \#2 and caged-insect trials, tetraploid plants in the low nitrogen treatment had a lower C:N ratio relative to diploids (Fig. 3.9), which would suggest that tetraploids are less resistant. However, ploidy did not have significant effects during choice bioassay \#2 and cagedinsect trials, despite $S$. exigua consuming more from plants with higher nitrogen content (lower C:N ratio; Fig. 3.4, 3.6). We measured the $\mathrm{C}: \mathrm{N}$ ratio of plants used in choice bioassay \#2 and caged-insect trials a second time (seven weeks after the first measurement) and found tetraploids to have a significantly higher $\mathrm{C}: \mathrm{N}$ ratio than diploids $\left(4 \mathrm{x}=43.02 \pm 0.77,2 \mathrm{x}=34.90 \pm 0.77 ; \mathrm{F}_{1,73}=78.64, P<0.0001\right)$, which is in agreement with observations from previous experiments (see Chapter 1). These findings suggest that the $\mathrm{C}: \mathrm{N}$ ratio of tetraploid fireweed is higher than that of diploids in plants' later stages of development but not in plants' earlier stages of development, which would suggest that tetraploids become increasingly resistant throughout their ontogeny. This hypothesis is in contrast to our observed patterns of thrip resistance, wherein tetraploids appeared to be less resistant to thrip damage in their later stages of development despite having a higher $\mathrm{C}: \mathrm{N}$ ratio than diploids (thrips invaded the greenhouse when plants were mature, and population sizes increased until plant harvest). Thrip damage patterns did not appear be related to tetraploids' greater number of flowers, which can attract pollen-feeding thrips 
(Lewis 1997). It is possible that observed thrip resistance patterns were influenced by the feeding strategy of thrips and differences in diploid and tetraploid cell size. For instance, thrips feed by penetrating leaf and pollen cells and ingesting the cellular contents, and they may be attracted to tetraploid fireweed's larger cells. Increasing soil N availability also resulted in both cytotypes experiencing more damage (Fig. 3.5), and these results support previous studies showing thrips preferring plants from high soil nitrogen conditions (Schuch et al. 1998, Brodbeck et al. 2001).

Pending data from analyses of leaf ellagitannin content will allow us to ascertain whether carbon-based secondary defense compounds are in fact correlated with a higher $\mathrm{C}: \mathrm{N}$ ratio and greater resistance to herbivory in our study. These results also may provide insight as to why $S$. exigua consumed a higher percentage of the upper half of diploid leaves compared to the upper half of tetraploid leaves (Fig. 3.8A). It would be interesting to know how these leaf traits differ between the upper and lower halves of fireweed plants and whether these differences are influenced by ploidy and/or soil nitrogen.

Neither ploidy nor soil $N$ influence fireweed tolerance to herbivory. - We measured the tolerance of diploid and tetraploid fireweed to insect herbivory at two levels of soil nitrogen availability using five fitness responses as tolerance measures (biomass, flower production, seed production, viable pollen production, and root bud production). Cytotypes did not differ in their relative tolerance to herbivory (Table 3.5), and all plants either fully compensated $(T=0)$ or undercompensated $(T<0)$ for damage (Table 3.4). 
Despite plants only receiving a one-time $35 \%$ foliar removal in caged-insect trials and artificially induced damage, many plants experienced fitness losses. This is interesting because fireweed plants in natural populations can receive much higher levels of damage (Hersch-Green, unpublished data) and are likely to experience damage over the duration of their phenology, and so herbivory in natural populations is likely to have large negative impacts on fireweed fitness. We did not find any evidence of overcompensation $(T<0)$, which is not commonly observed following foliar herbivory. Overcompensation is more frequently observed following mammal grazing and/or damage by gall-forming insects, which result in removal of the apical meristem, subsequent branching, and greater flower and seed production (McNaughton 1979, Paige and Whitham 1987, Gronemeyer et al. 1997, Haukioja and Koricheva 2000). During caged-insect feeding trials, we did observe apical meristem damage by S. exigua on one plant that resulted in multiple flowering branches and apparent overcompensation. A variety of mammals, such as moose (Axelsson and Stenberg 2014), and gall-forming insects (Hersch-Green, personal observation) are known to damage fireweed in natural populations, but the relative tolerance of diploid and tetraploid fireweed to this type of damage is not known. Other studies have tested for ploidal differences in tolerance to insect herbivory and showed no effects of ploidy on tolerance (König et al. 2014a) and a positive association of ploidy level with tolerance in terms of clonal reproduction (Boalt et al. 2010).

Tolerance to herbivory did not differ for plants in the low and high soil nitrogen treatments. These results differ from what would be expected under the compensatory continuum hypothesis (Maschinski and Whitham 1989), wherein plant tolerance should 
be higher in resource-rich conditions (i.e. high nitrogen treatment) because regrowth is not limited by such resources. The results also differ from what would be expected under the growth rate model hypothesis (GRM; Hilbert et al. 1981), wherein plant tolerance should be lower in resource-rich conditions because plants are operating at nearmaximum growth and do not have the physiological ability to upregulate and compensate for herbivore damage. It is possible that plants in both soil nitrogen treatments were limited by phosphorous. If this is true, the similar tolerance of plants across nitrogen treatments could be explained by the limiting resource model (Wise and Abrahamson 2005). In accordance with this model, higher nitrogen may not have provided plants with a superior tolerance response if plants from both soil nitrogen treatments were limited by phosphorous. Future investigations into the role of polyploidy and nutrient availability in regulating plant tolerance to herbivory would benefit from considering nitrogenphosphorous co-limitation, especially considering that the relative productivity of diploid and polyploid plants has been shown to be influenced by phosphorous availability (Šmarda et al. 2013).

Plants with a higher proportion of biomass invested in roots appeared to better compensate for biomass losses following herbivory (Table 3.7). This effect of plant shoot:root ratio has previously been reported (Rausher and Feeny 1980, Welter and Steggall 1993) and is thought to be the result of greater root biomass providing plants with larger stores of resources to use for shoot regrowth (Strauss and Agrawal 1999). A similar correlation between shoot:root ratio and tolerance was observed in terms of plant compensation for flower and seed production. However, this correlation was only 
apparent for diploid plants (Fig. 3.13A, B). One study has shown that increasing ploidy level is associated with superior ion uptake efficiency by roots (Cacco et al. 1976), and it seems possible that tetraploid fireweed were more effective than diploids at upregulating their ion uptake efficiency in order to acquire nutrients and compensate for damaged tissues, and diploids relied more on their root biomass for compensation.

Fireweed cytotypes differed in their relative ability to respond to damage with increased photosynthetic capacity $\left(\mathrm{A}_{\max }\right.$; Fig. 3.11). Tetraploids responded to herbivory with larger increases in their maximum photosynthetic capacity $\left(\mathrm{A}_{\max }\right)$ compared to diploids, suggesting that tetraploids have greater ability to upregulate their $\mathrm{A}_{\max }$. However, diploids had a $20.0 \%$ higher $\mathrm{A}_{\max }$ than tetraploids prior to insect damage but only a $0.10 \%$ higher $\mathrm{A}_{\max }$ relative to tetraploids 132 hours (5 1/2 days) after caged-insect trials were completed. On a per unit leaf area basis, polyploid plants generally have lower photosynthetic rates relative to closely related diploids (Levin 2002), but these results show that tetraploid fireweed is capable of upregulating its photosynthetic capacity following herbivory to a rate equal to that of diploid fireweed. The pre-herbivory photosynthetic rate of fireweed was not a good predictor of tolerance with respect to the five tolerance measures. However, plant tolerance in terms of root bud production was influenced by an interaction between ploidy and nitrogen content in leaves (Fig. 3.12). Higher leaf nitrogen content was negatively correlated with root bud compensation in diploid fireweed. A possible explanation for this is that diploid plants shunted more of their nitrogen resources into shoot growth and had fewer resources remaining for root 
growth and clonal reproduction. Leaf nitrogen content in tetraploids did not appear to be correlated with root bud compensation.

Biological significance. - Polyploid plants are initially produced within populations of their diploid progenitors. It is assumed that, in order for polyploids to establish within diploid populations, they must have some kind of competitive advantage that allows them to overcome the hurdle of receiving pollen primarily from neighboring diploid plants and producing inviable triploid seed (i.e. minority cytotype exclusion; Levin 1975). We have evidence that tetraploid fireweed may be shifting its range northward into what has historically been considered exclusively diploid populations in Alaska. In high latitude regions like Alaska, soil nitrogen availability is thought to be increasing as a result of anthropogenic inputs and global warming (Nadelhoffer et al. 1992, Shaver et al. 1992, Vitousek et al. 2002). The pronounced warming throughout high latitude regions is also expected to create northward shifts in species ranges (Chen et al. 2011), which could interact with other changes in abiotic (i.e. nitrogen availability) and biotic (i.e. plant-plant interactions and plant-herbivore interactions) conditions. Plantherbivore interactions are known to play an important role in low productivity, nutrientpoor regions, where herbivores can further limit the productivity of primary producers (Oksanen et al. 1981).

It is uncertain how such changes in abiotic and biotic conditions will influence the relative success of diploid and tetraploid fireweed throughout mixed-ploidy populations 
in Alaska. Despite observed differences in diploid and tetraploid tolerance traits, cytotypes did not differ in their overall tolerance to insect herbivory. Polyploidy does appear to influence plant resistance to herbivory, although resistance patterns were dependent on several factors including leaf nitrogen content, the type of insect, the developmental stage of plants, and plant genotype. In these experiments, greenhouse conditions allowed for us to control for extraneous factors such as competition and water stress, which can influence resistance and tolerance in natural populations (Cox and McEvoy 1983, Hakes and Cronin 2012). Additionally, plants in our tolerance experiment were only subjected to herbivory once during their growth, while plants in natural populations are likely to be subjected to herbivory early, late, and/or continuously in their development. The timing and duration of herbivory has been shown to influence tolerance in fireweed (Michaud 1991), but the influence of these factors on the relative tolerance of diploid and tetraploid cytotypes in different nutrient conditions is unknown. Our understanding of the role of polyploidy and nutrient availability in regulating the resistance and tolerance of plant species would benefit from studies conducted in natural mixed-ploidy populations. 


\section{Citations.}

Adler, P. B., D. A. Raff, and W. K. Lauenroth. 2001. The effect of grazing on the spatial heterogeneity of vegetation. Oecologia 128:465-479.

Arvanitis, L., C. Wiklund, and J. Ehrlén. 2007. Butterfly seed predation: effects of landscape characteristics, plant ploidy level and population structure. Oecologia 152:275-285.

Arvanitis, L., C. Wiklund, Z. Munzbergova, J. P. Dahlgren, and J. Ehrlen. 2010. Novel antagonistic interactions associated with plant polyploidization influence trait selection and habitat preference. Ecology Letters 13:330-337.

Axelsson, E., and J. Stenberg. 2014. Associational resistance mediates interacting effects of herbivores and competitors on fireweed performance. Basic and Applied Ecology 15:10-17.

Baldwin, I. T. 1988. The alkaloidal responses of wild tobacco to real and simulated herbivory. Oecologia 77:378-381.

Baldwin, S. J., and B. C. Husband. 2013. The association between polyploidy and clonal reproduction in diploid and tetraploid Chamerion angustifolium. Molecular Ecology 22:1806-1819.

Bale, J. S., G. J. Masters, I. D. Hodkinson, C. Awmack, T. M. Bezemer, V. K. Brown, J. Butterfield, A. Buse, J. C. Coulson, and J. Farrar. 2002. Herbivory in global climate change research: direct effects of rising temperature on insect herbivores. Global Change Biology 8:1-16.

Behmer, S. T., S. J. Simpson, and D. Raubenheimer. 2002. Herbivore foraging in chemically heterogeneous environments: nutrients and secondary metabolites. Ecology 83:2489-2501.

Boalt, E., L. Arvanitis, K. Lehtilä, and J. Ehrlén. 2010. The association among herbivory tolerance, ploidy level, and herbivory pressure in Cardamine pratensis.

Evolutionary Ecology 24:1101-1113.

Boege, K. 2005. Influence of plant ontogeny on compensation to leaf damage. American Journal of Botany 92:1632-1640.

Boege, K., and R. J. Marquis. 2005. Facing herbivory as you grow up: the ontogeny of resistance in plants. Trends in Ecology \& Evolution 20:441-448.

Briske, D., T. Boutton, and Z. Wang. 1996. Contribution of flexible allocation priorities to herbivory tolerance in $\mathrm{C} 4$ perennial grasses: an evaluation with $13 \mathrm{C}$ labeling. Oecologia 105:151-159.

Brodbeck, B. V., J. Stavisky, J. E. Funderburk, P. C. Andersen, and S. M. Olson. 2001. Flower nitrogen status and populations of Frankliniella occidentalis feeding on Lycopersicon esculentum. Entomologia Experimentalis et Applicata 99:165-172.

Bryant, J., T. Clausen, P. Reichardt, M. McCarthy, and R. Werner. 1987. Effect of nitrogen fertilization upon the secondary chemistry and nutritional value of quaking aspen (Populus tremuloides michx.) leaves for the large aspen tortrix (Choristoneura conflictana walker). Oecologia 73:513-517. 
Bryant, J. P., F. S. Chapin, III, and D. R. Klein. 1983. Carbon/nutrient balance of boreal plants in relation to vertebrate herbivory. Oikos 40:357-368.

Burton, T. L., and B. Husband. 2000. Fitness differences among diploids, tetraploids, and their triploid progeny in Chamerion angustifolium: mechanisms of inviability and implications for polyploid evolution. Evolution 54:1182-1191.

Cacco, G., G. Ferrari, and G. Lucci. 1976. Uptake efficiency of roots in plants at different ploidy levels. The Journal of Agricultural Science 87:585-589.

Capinera, J. L., and W. J. Roltsch. 1980. Response of wheat seedlings to actual and simulated migratory grasshopper defoliation. Journal of Economic Entomology 73:258-261.

Cavalier-Smith, T. 2005. Economy, speed and size matter: evolutionary forces driving nuclear genome miniaturization and expansion. Annals of Botany 95:147-175.

Chapin, F. S. 1980. The mineral nutrition of wild plants. Annual Review of Ecology and Systematics 11:233-260.

Chen, I.-C., J. K. Hill, R. Ohlemüller, D. B. Roy, and C. D. Thomas. 2011. Rapid range shifts of species associated with high levels of climate warming. Science 333:1024-1026.

Coley, P. D. 1983. Herbivory and defensive characteristics of tree species in a lowland tropical forest. Ecological Monographs 53:209-234.

Coley, P. D., J. P. Bryant, and F. S. Chapin. 1985. Resource availability and plant antiherbivore defense. Science 230:895-899.

Cox, C. S., and P. B. McEvoy. 1983. Effect of summer moisture stress on the capacity of tansy ragwort (Senecio jacobaea) to compensate for defoliation by cinnabar moth (Tyria jacobaeae). Journal of Applied Ecology 20:225-234.

DeLucia, E. H., P. D. Nabity, J. A. Zavala, and M. R. Berenbaum. 2012. Climate change: resetting plant-insect interactions. Plant Physiology 160:1677-1685.

Detling, J., M. Dyer, and D. Winn. 1979. Net photosynthesis, root respiration, and regrowth of Bouteloua gracilis following simulated grazing. Oecologia 41:127134.

Dhawan, O. P., and U. C. Lavania. 1996. Enhancing the productivity of secondary metabolites via induced polyploidy: A review. Euphytica 87:81-89.

Feeny, P. 1970. Seasonal changes in oak leaf tannins and nutrients as a cause of spring feeding by winter moth caterpillars. Ecology 51:565-581.

Fordyce, J. A., and A. A. Agrawal. 2001. The role of plant trichomes and caterpillar group size on growth and defence of the pipevine swallowtail Battus philenor. Journal of Animal Ecology 70:997-1005.

Fritz, R. S., and E. L. Simms. 1992. Plant resistance to herbivores and pathogens: ecology, evolution, and genetics. University of Chicago Press.

Gronemeyer, P. A., B. J. Dilger, J. L. Bouzat, and K. N. Paige. 1997. The effects of herbivory on paternal fitness in scarlet gilia: better moms also make better pops. The American Naturalist 150:592-602.

Hakes, A. S., and J. T. Cronin. 2012. Successional changes in plant resistance and tolerance to herbivory. Ecology 93:1059-1070. 
Halverson, K., S. B. Heard, J. D. Nason, and J. O. Stireman III. 2008. Differential attack on diploid, tetraploid, and hexaploid Solidago altissima L. by five insect gallmakers. Oecologia 154:755-761.

Hamilton, J., A. Zangerl, E. DeLucia, and M. Berenbaum. 2001. The carbon-nutrient balance hypothesis: its rise and fall. Ecology Letters 4:86-95.

Harper, J. L. 1968. The role of predation in vegetational diversity. Pages 48-62 in Brookhaven Symposia in Biology.

Haukioja, E., and J. Koricheva. 2000. Tolerance to herbivory in woody vs. herbaceous plants. Evolutionary Ecology 14:551-562.

Hawkes, C. V., and J. J. Sullivan. 2001. The impact of herbivory on plants in different resource conditions: a meta-analysis. Ecology 82:2045-2058.

Hilbert, D., D. Swift, J. Detling, and M. Dyer. 1981. Relative growth rates and the grazing optimization hypothesis. Oecologia 51:14-18.

Hilu, K. 1993. Polyploidy and the evolution of domesticated plants. American Journal of Botany 80:1494-1499.

Hosmer Jr, D. W., and S. Lemeshow. 2004. Applied logistic regression. John Wiley \& Sons.

Houghton, J.T., Ding, Y., Griggs, D.J., Noguer, M., van der Linden, P.J., Dai, X., Maskell, K. \& Johnson, C.A. (eds.) 2001. Climate change 2001: The scientific basis. Contribution of Working Group I to the Third Assessment Report of the Intergovernmental Panel on Climate Change. Cambridge University Press, Cambridge, UK.

Husband And, B. C., and D. W. Schemske. 2000. Ecological mechanisms of reproductive isolation between diploid and tetraploid Chamerion angustifolium. Journal of Ecology 88:689-701.

Husband, B. C., and D. W. Schemske. 1997. The effect of inbreeding in diploid and tetraploid populations of Epilobium angustifolium (Onagraceae): implications for the genetic basis of inbreeding depression. Evolution 51(3):737-746.

Ibrahim, M. H., H. Z. E. Jaafar, A. Rahmat, and Z. A. Rahman. 2011. Effects of nitrogen fertilization on synthesis of primary and secondary metabolites in three varieties of Kacip fatimah (labisia, pumila, blume). International Journal of Molecular Sciences 12:5238-5254.

Janz, N., and J. Thompson. 2002. Plant polyploidy and host expansion in an insect herbivore. Oecologia 130:570-575.

Karban, R., and I. T. Baldwin. 2007. Induced responses to herbivory. University of Chicago Press.

Karban, R., and J. H. Myers. 1989. Induced plant responses to herbivory. Annual review of ecology and systematics 20:331-348.

Kearns, C. A., and D. W. Inouye. 1993. Techniques for pollination biologists. University Press of Colorado.

Kearsley, M. J., and T. G. Whitham. 1989. Developmental changes in resistance to herbivory: implications for individuals and populations. Ecology 70(2):422-434. 
Kennedy, B. F., H. A. Sabara, D. Haydon, and B. C. Husband. 2006. Pollinator-mediated assortative mating in mixed ploidy populations of Chamerion angustifolium (Onagraceae). Oecologia 150:398-408.

Kindt, F., N. Joosten, D. Peters, and W. Tjallingii. 2003. Characterisation of the feeding behaviour of western flower thrips in terms of electrical penetration graph (EPG) waveforms. Journal of Insect Physiology 49:183-191.

König, M. A., K. Lehtilä, C. Wiklund, and J. Ehrlén. 2014. Among-population variation in tolerance to larval herbivory by Anthocharis cardamines in the polyploid herb Cardamine pratensis. PLoS One 9:e99333.

Kulman, H. 1971. Effects of insect defoliation on growth and mortality of trees. Annual Review Of Entomology 16:289-324.

Leimu, R., and J. Koricheva. 2006. A meta-analysis of tradeoffs between plant tolerance and resistance to herbivores: combining the evidence from ecological and agricultural studies. Oikos 112:1-9.

Leitch, I., and M. Bennett. 2004. Genome downsizing in polyploid plants. Biological Journal of the Linnean Society 82:651-663.

Levin, D. A. 1975. Minority cytotype exclusion in local plant populations. Taxon 24:3543.

Levin, D. A. 2002. The role of chromosomal change in plant evolution. Oxford University Press.

Lewis Jr, W. M. 1985. Nutrient scarcity as an evolutionary cause of haploidy. American Naturalist 125:692-701.

Lewis, T. 1997. Thrips as crop pests. Cab International.

Mabry, C. M., and P. W. Wayne. 1997. Defoliation of the annual herb Abutilon theophrasti: mechanisms underlying reproductive compensation. Oecologia 111:225-232.

Maherali, H., E. W. Alison, and B. C. Husband. 2009. Genome duplication and the evolution of physiological responses to water stress. New Phytologist 184:721731.

Marquis, R. 1992. Selective impact of herbivores. Pages 301-325 in RS Fritz and EL Simms, editors. Plant resistance to herbivores and pathogens: ecology, evolution, and genetics. University of Chicago Press, Chicago, Illinois, USA.

Maschinski, J., and T. G. Whitham. 1989. The continuum of plant responses to herbivory: the influence of plant association, nutrient availability, and timing. American Naturalist 134(1):1-19.

Mcguire, R. J., and M. T. Johnson. 2006. Plant genotype and induced responses affect resistance to herbivores on evening primrose (Oenothera biennis). Ecological Entomology 31:20-31.

McNaughton, S. 1979. Grazing as an optimization process: grass-ungulate relationships in the Serengeti. American Naturalist 113:691-703.

McNaughton, S., and F. S. Chapin. 1985. Effects of phosphorus nutrition and defoliation on C4 graminoids from the Serengeti Plains. Ecology 66(5):1617-1629.

Meidner, H. 1970. Effects of photoperiodic induction and debudding in Xanthium pennsylvanicum and of partial defoliation in Phaseolus vulgaris on rates of net 
photosynthesis and stomatal conductances. Journal of Experimental Botany 21:164-169.

Michaud, J. 1991. Biomass allocation in fireweed Epilobium angustifolium L.(Onagraceae) in response to simulated defoliation. Botanical Gazette 152(2):208-213.

Mithöfer, A., and W. Boland. 2012. Plant defense against herbivores: chemical aspects. Annual Review of Plant Biology 63:431-450.

Mosquin, T., and E. Small. 1971. An example of parallel evolution in Epilobium (Onagraceae). Evolution 25(4):678-682.

Münzbergová, Z., J. Skuhrovec, and P. Maršík. 2015. Large differences in the composition of herbivore communities and seed damage in diploid and autotetraploid plant species. Biological Journal of the Linnean Society 115(2):270-287.

Mutikainen, P., M. Walls, and J. Ovaska. 1996. Herbivore-induced resistance in Betula pendula: the role of plant vascular architecture. Oecologia 108:723-727.

Nadelhoffer, K . J., A. E. Giblin, G. R. Shaver, and A. E. Linkins. 1992. Microbial processes and plant nutrient availability in arctic soils. Pages 281-300 in E S. Chapin III, R. L. Jefferies, J. F Reynolds, G. R. Shaver, and J. Svoboda, editors. Arctic ecosystems in a changing climate: an ecophysiological perspective. Academic Press, San Diego, California, USA.

Noguti, Y., H. Oka, and T. Ôtuka. 1940. Studies on the polyploidy in Nicotiana induced by the treatment with colchicine. II. Growth rate and chemical analysis of diploid and its autotetraploid in Nicotiana rustica and N. Tabacum. Japanese Journal of Botany 10:343-364.

Núñez-Farfán, J., J. Fornoni, and P. L. Valverde. 2007. The evolution of resistance and tolerance to herbivores. Annual Review of Ecology, Evolution, and Systematics 38:541-566.

Oba, G., Z. Mengistu, and N. C. Stenseth. 2000. Compensatory growth of the African dwarf shrub Indigofera spinosa following simulated herbivory. Ecological Applications 10:1133-1146.

Oksanen, L., S. D. Fretwell, J. Arruda, and P. Niemela. 1981. Exploitation ecosystems in gradients of primary productivity. American Naturalist 118(2):240-261.

Otto, S. P., and J. Whitton. 2000. Polyploid incidence and evolution. Annual review of genetics 34:401-437.

Paige, K. N., and T. G. Whitham. 1987. Overcompensation in response to mammalian herbivory: the advantage of being eaten. American Naturalist 129:407-416.

Poelman, E. H., J. J. van Loon, and M. Dicke. 2008. Consequences of variation in plant defense for biodiversity at higher trophic levels. Trends in plant science 13:534541.

Ramsey, J., and D. W. Schemske. 2002. Neopolyploidy in flowering plants. Annual review of ecology and systematics 33:589-639.

Rausher, M. D., and P. Feeny. 1980. Herbivory, plant density, and plant reproductive success: the effect of Battus philenor on Aristolochia reticulata. Ecology 61(4):905-917. 
Roach, D. A., and R. D. Wulff. 1987. Maternal effects in plants. Annual Review of Ecology and Systematics 18:209-235.

Rockwood, L. L. 1973. The effect of defoliation on seed production of six Costa Rican tree species. Ecology 54(6):1363-1369.

Salminen, J.-P., V. Ossipov, J. Loponen, E. Haukioja, and K. Pihlaja. 1999. Characterisation of hydrolysable tannins from leaves of Betula pubescens by high-performance liquid chromatography-mass spectrometry. Journal of Chromatography A 864:283-291.

Salminen, J. P., and M. Karonen. 2011. Chemical ecology of tannins and other phenolics: we need a change in approach. Functional Ecology 25:325-338.

Scheirs, J., L. D. Bruyn, and R. Verhagen. 2002. Seasonal changes in leaf nutritional quality influence grass miner performance. Ecological Entomology 27:84-93.

Schuch, U. K., R. A. Redak, and J. A. Bethke. 1998. Cultivar, fertilizer, and irrigation affect vegetative growth and susceptibility of chrysanthemum to western flower thrips. Journal of the American Society for Horticultural Science 123:727-733.

Shaver, G. R., W. D. Billings, F. S. Chapin, A. E. Giblin, K. J. Nadelhoffer, W. C. Oechel, and E. Rastetter. 1992. Global change and the carbon balance of arctic ecosystems. BioScience 42(6):433-441.

Simms, E. L., and J. Triplett. 1994. Costs and benefits of plant responses to disease: resistance and tolerance. Evolution 48(6):1973-1985.

Šmarda, P., M. Hejcman, A. Březinová, L. Horová, H. Steigerová, F. Zedek, P. Bureš, P. Hejcmanová, and J. Schellberg. 2013. Effect of phosphorus availability on the selection of species with different ploidy levels and genome sizes in a long-term grassland fertilization experiment. New Phytologist 200:911-921.

Stowe, K. A., R. J. Marquis, C. G. Hochwender, and E. L. Simms. 2000. The evolutionary ecology of tolerance to consumer damage. Annual Review of Ecology and Systematics 31:565-595.

Strauss, S. Y., and A. A. Agrawal. 1999. The ecology and evolution of plant tolerance to herbivory. Trends in Ecology \& Evolution 14:179-185.

Strauss, S. Y., J. K. Conner, and S. L. Rush. 1996. Foliar herbivory affects floral characters and plant attractiveness to pollinators: implications for male and female plant fitness. American Naturalist 147(6):1098-1107.

Strong, D. R., J. H. Lawton, and S. R. Southwood. 1984. Insects on plants. Community patterns and mechanisms. Blackwell Scientific Publicatons.

Sutherland, S., and L. F. Delph. 1984. On the importance of male fitness in plants: patterns of fruit-set. Ecology 65:1093-1104.

Thompson, J. N., K. A. Segraves, B. M. Cunningham, D. M. Althoff, and D. Wagner. 1997. Plant polyploidy and insect/plant interactions. The American Naturalist 150:730-743.

Tiffin, P., and B. D. Inouye. 2000. Measuring tolerance to herbivory: Accuracy and precision of estimates made using natural versus imposed damage. Evolution 54:1024-1029. 
Tiffin, P., and M. D. Rausher. 1999. Genetic constraints and selection acting on tolerance to herbivory in the common morning glory Ipomoea purpurea. The American Naturalist 154:700-716.

Trumble, J., D. Kolodny-Hirsch, and I. Ting. 1993. Plant compensation for arthropod herbivory. Annual review of entomology 38:93-119.

van der Meijden, E., M. Wijn, and H. J. Verkaar. 1988. Defence and regrowth, alternative plant strategies in the struggle against herbivores. Oikos :355-363.

Vitousek, P. M., S. Hättenschwiler, L. Olander, and S. Allison. 2002. Nitrogen and nature. AMBIO: A Journal of the Human Environment 31:97-101.

Von Well, E., and A. Fossey. 1998. A comparative investigation of seed germination, metabolism and seedling growth between two polyploid Triticum species. Euphytica 101:83-89.

Walther, G.-R., E. Post, P. Convey, A. Menzel, C. Parmesan, T. J. Beebee, J.-M. Fromentin, O. Hoegh-Guldberg, and F. Bairlein. 2002. Ecological responses to recent climate change. Nature 416:389-395.

Welter, S. C., and J. W. Steggall. 1993. Contrasting the tolerance of wild and domesticated tomatoes to herbivory: agroecological implications. Ecological applications 3(2):271-278.

Westoby, M., D. S. Falster, A. T. Moles, P. A. Vesk, and I. J. Wright. 2002. Plant ecological strategies: some leading dimensions of variation between species. Annual review of ecology and systematics 33:125-159.

Wiermann, R. 2013. Secondary Plant Products. Secondary Plant Products: A Comprehensive Treatise 7:85.

Windle, P. N., and E. H. Franz. 1979. The effects of insect parasitism on plant competition: greenbugs and barley. Ecology 60(3):521-529.

Wise, M. J., and W. G. Abrahamson. 2005. Beyond the compensatory continuum: environmental resource levels and plant tolerance of herbivory. Oikos 109:417428.

Wise, M. J., and W. G. Abrahamson. 2007. Effects of resource availability on tolerance of herbivory: a review and assessment of three opposing models. The American Naturalist 169:443-454.

Wood, T. E., N. Takebayashi, M. S. Barker, I. Mayrose, P. B. Greenspoon, and L. H. Rieseberg. 2009. The frequency of polyploid speciation in vascular plants. Proc Natl Acad Sci 106:13875-13879.

Yoshida, T., Y. Amakura, and M. Yoshimura. 2010. Structural features and biological properties of ellagitannins in some plant families of the order Myrtales. International journal of molecular sciences 11:79-106. 